\title{
Redox-Based Transcriptional Regulation in Prokaryotes: Revisiting Model Mechanisms
}

\author{
Emma Sevilla, ${ }^{1-3}$ María Teresa Bes, ${ }^{1-3}$ Andrés González, ${ }^{2-4}$ María Luisa Peleato, ${ }^{1-3}$ and María F. Fillat ${ }^{1-3}$
}

\begin{abstract}
Significance: The successful adaptation of microorganisms to ever-changing environments depends, to a great extent, on their ability to maintain redox homeostasis. To effectively maintain the redox balance, cells have developed a variety of strategies mainly coordinated by a battery of transcriptional regulators through diverse mechanisms.

Recent Advances: This comprehensive review focuses on the main mechanisms used by major redoxresponsive regulators in prokaryotes and their relationship with the different redox signals received by the cell. An overview of the corresponding regulons is also provided.

Critical Issues: Some regulators are difficult to classify since they may contain several sensing domains and respond to more than one signal. We propose a classification of redox-sensing regulators into three major groups. The first group contains one-component or direct regulators, whose sensing and regulatory domains are in the same protein. The second group comprises the classical two-component systems involving a sensor kinase that transduces the redox signal to its DNA-binding partner. The third group encompasses a heterogeneous group of flavin-based photosensors whose mechanisms are not always fully understood and are often involved in more complex regulatory networks.

Future Directions: Redox-responsive transcriptional regulation is an intricate process as identical signals may be sensed and transduced by different transcription factors, which often interplay with other DNA-binding proteins with or without regulatory activity. Although there is much information about some key regulators, many others remain to be fully characterized due to the instability of their clusters under oxygen. Understanding the mechanisms and the regulatory networks operated by these regulators is essential for the development of future applications in biotechnology and medicine. Antioxid. Redox Signal. 30, 1651-1696.
\end{abstract}

Keywords: redox sensing, transcriptional regulation, two-component systems, photosensors

\section{Table of Contents}

I. Introduction

II. Direct Redox Sensing and Regulation

A. Regulation involving oxidant-sensitive iron-sulfur clusters 1653

$\begin{array}{ll}\text { 1. SoxR } & 1653\end{array}$

2. IscR 1658

3. NsrR 1659

4. RsrR 1660

5. FNR 1660

6. WhiB/Wbl 1661

Reviewing Editors: Haike Antelmann, Francesca Cutruzzolà, Jaekwon Lee, Brandan Pedre, and Dana Reichmann

\footnotetext{
${ }^{1}$ Departamento de Bioquímica y Biología Molecular y Celular, Universidad de Zaragoza, Zaragoza, Spain.

${ }^{2}$ Instituto de Biocomputación y Física de Sistemas Complejos (BIFI), Universidad de Zaragoza, Zaragoza, Spain.

${ }^{3}$ Grupo de Bioquímica, Biofísica y Biología Computacional (BIFI, UNIZAR), Unidad Asociada al CSIC, Zaragoza, Spain.

${ }^{4}$ Instituto de Investigación Sanitaria Aragón (IIS Aragón), Zaragoza, Spain.
} 
B. Redox sensing by thiol-based targets

1. Sensors involving cysteine-zinc clusters

a. DksA

b. TraR

1662

c. RsrA

1663

1663

2. Nonmetallated thiol-based switches 1664

a. OxyR

1664

b. PpsR/CrtJ

1666

c. OhrR

1667

d. NemR

1669

e. FurA

1669

$\begin{array}{ll}\text { C. Regulation by metal-catalyzed oxidation: PerR } & 1669 \\ \text { D. Methionine oxidation-based transcriptional regulation: HypT } & 1670\end{array}$

E. Redox sensing by heme-based sensor proteins 1670

\begin{tabular}{ll} 
1. CooA & 1670 \\
\hline
\end{tabular}

2. RcoM 1671

3. Heme sensing by thiol-based switch sensors 1671

F. Sensors of the NAD ${ }^{+} / \mathrm{NADH}$ balance: Rex 1672

III. Two-Component Systems: Redox Control of Sensor Kinase Regulation 1673

A. Indirect redox sensing based on PAS-GAF domains 1674

1. Redox control of sensor kinase regulation involving metal clusters 1674

a. PAS domain heme: FixL-FixJ two-component system 1674

b. GAF domain heme: DosS-DosR two-component system 1675

c. PAS domain Fe-S cluster: NreB-NreC two-component system 1675

d. GAF domain Fe-S cluster: AirS-AirR two-component system 1676

2. Sensing by NAD-binding PAS domains: KinA-KinE-Spo0A system 1676

3. Flavin-binding PAS-based HK sensors: MmoS-MmoQ two-component system 1677

4. Signal modulation by disulfide bond formation: ArcB-ArcA two-component system 1677

5. Atypical signal transduction PAS-GAF-based mechanisms: NifL-NifA system 1678

B. Non-PAS domain redox sensing based on disulfide bond formation 1679

1. RegB-RegA two-component system 1679

2. PrrB-PrrA two-component system 1680

IV. Redox Photosensors Based on Flavins 1680

A. LOV domains, a special class of PAS domains 1680

1. LOV/helix-turn-helix DNA-binding proteins 1681

2. Short LOV proteins 1681

3. Phototropins: YtvA (PfyP) and stress response 1681

B. Non-PAS domain photosensors 1681

$\begin{array}{ll}\text { 1. BLUF domains } & 1681\end{array}$

2. Cryptochromes 1682

V. Concluding Remarks 1682

\section{Introduction}

A EROBIC METABOLISM PROVIDES significant advantages in energy production, detoxification of xenobiotics, and virulence of bacterial cells. However, reactive intermediates produced in the reduction of oxygen by electron transfer systems can damage all cellular components. In addition to these reactive oxygen species (ROS), other by-products of metabolism including reactive nitrogen species (RNS) and xenobiotics challenge cellular redox homeostasis. Among the main targets of ROS during oxidative stress are ironcontaining proteins, which become severely damaged due to the ability of $\mathrm{H}_{2} \mathrm{O}_{2}$ and $\mathrm{O}_{2}{ }^{-}$to oxidize the iron present in exposed iron-sulfur clusters and other cofactors $(164,170)$. Furthermore, the release of $\mathrm{Fe}^{2+}$ from these centers promotes the Fenton reaction, which produces even more reactive hydroxyl radicals with deleterious consequences for cells (394).

As a response to this scenario, bacteria have developed a set of redox-responsive proteins that trigger the appropriate in- ducible response according to the level of stress. Redox sensing by the cell is a complex process that integrates diverse stimuli such as $\mathrm{O}_{2}$ tension, nutrient availability, light intensity, RNS, and ROS, among other parameters. Transduction of these redox signals is frequently carried out by transcriptional regulatory proteins through a variety of mechanisms $(237,334$, 364). Owing to the tight relationship between iron metabolism and redox homeostasis, the activity of many major regulators relies on iron, either as an ion cofactor assembled in iron-sulfur clusters or as heme-based sensors $(80,121,134,274,288,291)$.

Other essential metal ions such as zinc or manganese also play important roles in re-establishing the redox balance (71, 234) and act as cofactors in transcriptional regulation (101, 200, 297, 325). Besides their role in zinc metalloregulation, zinc ions often prevent the oxidation of redox-sensitive cysteines that work as thiol-based redox switches in numerous transcriptional regulators $(149,200)$.

As will be highlighted in further sections, multiple transcriptional regulatory mechanisms as response to oxidants 
are widespread strategies in most prokaryotes. Another interesting issue is the diversity of mechanisms developed by the cell to detect and detoxify the same signal. Thus, in Escherichia coli, nitrosative stress is sensed by several transcription factors, such as NorR, FNR (fumarate nitrate reductase regulator), Fur (ferric uptake regulator), MetR, and, to a lesser extent, SoxR and OxyR $(84,351)$. In cyanobacteria, in addition to Fur and PerR, a prominent role for histidine kinases (HKs) in the perception and signal transduction of $\mathrm{H}_{2} \mathrm{O}_{2}$ has been reported in Synechocystis sp. PCC 6803 (32, 181). In Salmonella spp., peroxide is sensed by OxyR, SoxR, and the zinc finger motif DksA (68, 97). Therefore, as a strategy for a more efficient adaptation, the same redox signal may induce different transduction mechanisms, allowing a finer tuning of the cell response.

To better understand redox regulation beyond the identification of the antioxidant defensive genes, numerous mechanistic studies of the diverse regulators that convert redox signals into regulatory outputs have been carried out in recent decades. In this comprehensive review, we revisit the main groups of redox-responsive transcriptional regulators with a particular emphasis on recent findings concerning the structural and mechanistic basis of their regulatory functions.

\section{Direct Redox Sensing and Regulation}

Most of the major direct redox sensors monitorize the redox state of the cell through oxidant-sensitive metal-sulfur clusters or nonmetallated thiol-based switches. Other relevant mechanisms include those used by heme-based sensor proteins. A summary of the direct redox sensors discussed in this section can be found in Tables 1 and 2 .

\section{A. Regulation involving oxidant-sensitive iron-sulfur clusters}

Iron-sulfur clusters function as cofactors of a wide range of transcriptional regulators that exploit the redox and coordination properties of these clusters to act as sensors of environmental conditions.

1. SoxR. SoxR is a conserved regulator in Enterobacteriaceae that belongs to the MerR family of transcriptional regulators. MerR homologues share similar N-terminal winged helix-turn-helix (wHTH) DNA binding regions, whereas Cterminal effector binding regions appear specific to the effector recognized (37). Most members of the family respond to stress signals, such as oxidative stress, heavy metals, or antibiotics. SoxR was initially identified as an $\mathrm{O}_{2}{ }^{-}$stress sensor $(221,370)$, although further studies showed the activation of SoxR by nitric oxide and a variety of endogenous and xenobiotic redoxcycling agents $(267,412)$. In addition, SoxR becomes activated through DNA-mediated oxidation by guanine radicals that are produced in the early stages of oxidative stress (217).

In E. coli, the SoxRS response involves around 100 genes whose transcription is modulated by SoxR through activation of its SoxS partner, an AraC-type regulator (135). Most genes composing this extensive regulon are involved in minimizing oxidative damage caused by free radicals, including destruction of superoxide $(\operatorname{sod} A)$, reduction of iron-sulfur clusters $(f p r)$, DNA repair ( $n f o$ ), and NADPH production (zwf), among others. Induction of the SoxR regulon also confers resistance to a variety of antibiotics due to the re- duction in OmpF and S6A levels $(78,135)$. Conversely, since nonenteric bacteria lack SoxS, SoxR directly controls a small regulon of key genes involved not only in the detoxification of redox-active compounds but also in antibiotic resistance and quorum sensing, which in many cases are essential for full virulence of mammalian pathogens $(248,260,279)$.

The mechanism of action of SoxR in enteric bacteria has been extensively investigated. In solution, SoxR is a homodimer that exhibits one $[2 \mathrm{Fe}-2 \mathrm{~S}]$ cluster per monomer coordinated by the four cysteines in the conserved sequence $\left(\mathrm{Cys}_{2} \mathrm{Cys}_{\mathrm{XC}} \mathrm{Cy}_{5} \mathrm{Cys}\right)$ near the carboxyl terminus. In the absence of oxidative stress, SoxR with the reduced [2Fe-2S] cluster may bind to DNA but it is inactive for transcription initiation (Fig. 1A).

As a MerR-like regulator, SoxR controls the expression of genes whose promoters contain suboptimal 19-bp spacers between their -35 and -10 elements, which are not recognized by the sigma factor of RNA polymerase (RNAP) (37). SoxR activates transcription of its counterpart soxS through the change in the oxidation state of the $[2 \mathrm{Fe}-2 \mathrm{~S}]$ cluster from $[2 \mathrm{Fe}-2 \mathrm{~S}]^{+1}$ to the $[2 \mathrm{Fe}-2 \mathrm{~S}]^{+2}$ form. Upon oxidation, untwisting the soxS promoter allows remodelling of -35 and -10 elements enabling its recognition by RNAP and, in turn, the soxS transcription, which increases around 100-fold (147).

Notably, SoxR is the only regulator able to modulate its transcriptional activity undergoing a single change in the cluster redox state (64). The large conformational change of SoxR and the target promoter triggered just by cluster oxidation could be elicited by the remarkable asymmetric environment of the $[2 \mathrm{Fe}-2 \mathrm{~S}]$ cluster observed in the structural analysis of E. coli SoxR bound to DNA (390). Moreover, the [2Fe-2S] cluster is completely solvent exposed enabling fast electron transfer to several redox partners, as well as direct modification through nitrosylation. The completely conserved Arg55 and Trp91 interacting cysteine residues are important for SoxR activity. Direct interaction of the cluster-binding domain with the DNA-binding domain occurs through the highly conserved residues Arg55' and Trp91' (390) (Fig. 1B).

Previous electrochemical studies suggested that upon binding to DNA targets, the reduction potential of SoxR [2Fe-2S] has undergone a shift from $-285 \mathrm{mV}$ (free regulator) to $+200 \mathrm{mV}$ (complexed to DNA) (80). Those results suggested that only strong oxidants would be able to oxidize the cluster to the +2 state and were not in good agreement with the ability of SoxR to react with some redox-cycling drugs and other weak oxidants. However, a recent study using DNA-modified electrodes concluded that DNA binding causes a moderate shift in the reduction potential of SoxR, namely $-320 \mathrm{mV}$ of the SoxR bound to DNA versus $-293 \mathrm{mV}$ of the free protein versus normal hydrogen electrode, in better concordance with the cognate E. coli SoxR signals (193).

The absence of SoxS in Pseudomonas aeruginosa and Streptomyces coelicolor, as well as their lower SoxR sensitivity to superoxide, one order of magnitude smaller than that of the E. coli homologue, raised the question of SoxR functionality in non-Enterobacteriaceae $(194,279,284,343)$. In $P$. aeruginosa and $S$. coelicolor, unlike in E. coli, SoxR is not oxidized by redox-cycling agents and superoxide, but rather is activated by endogenous redox-active pigments, namely pyocyanin and actinorhodin, to directly regulate a set of targets encoding enzymes likely to be involved in the modification and transport of small molecules, such as antibiotics $(79,338)$. 


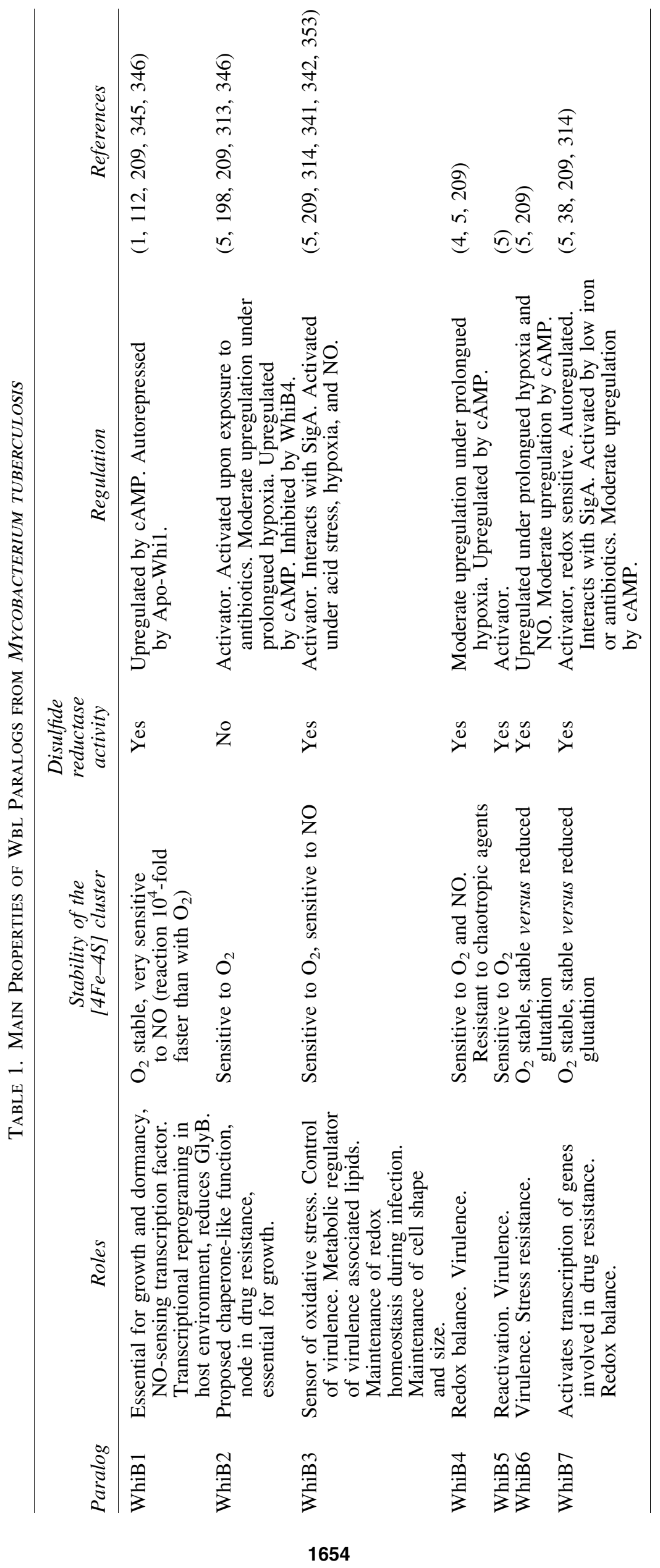




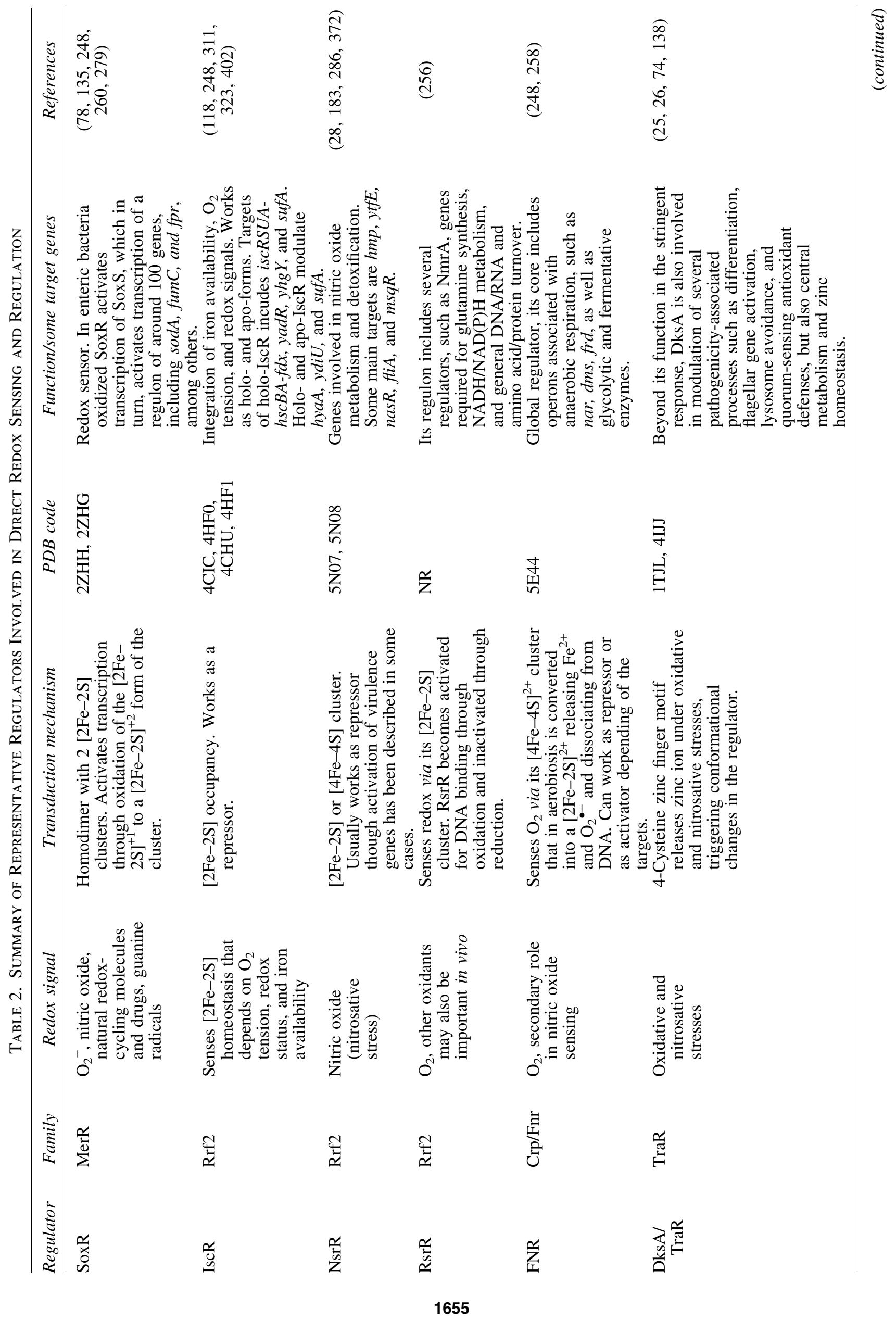




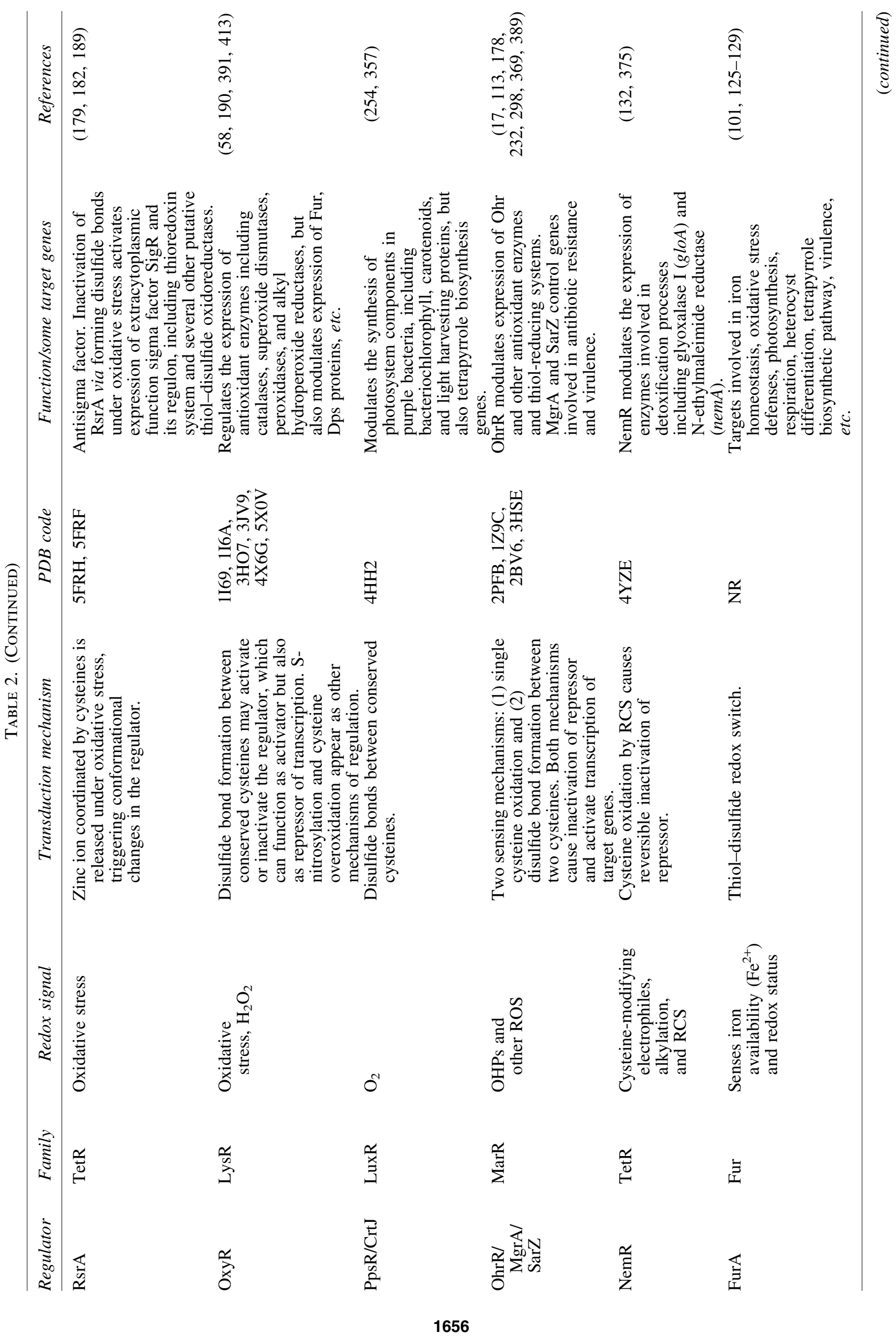




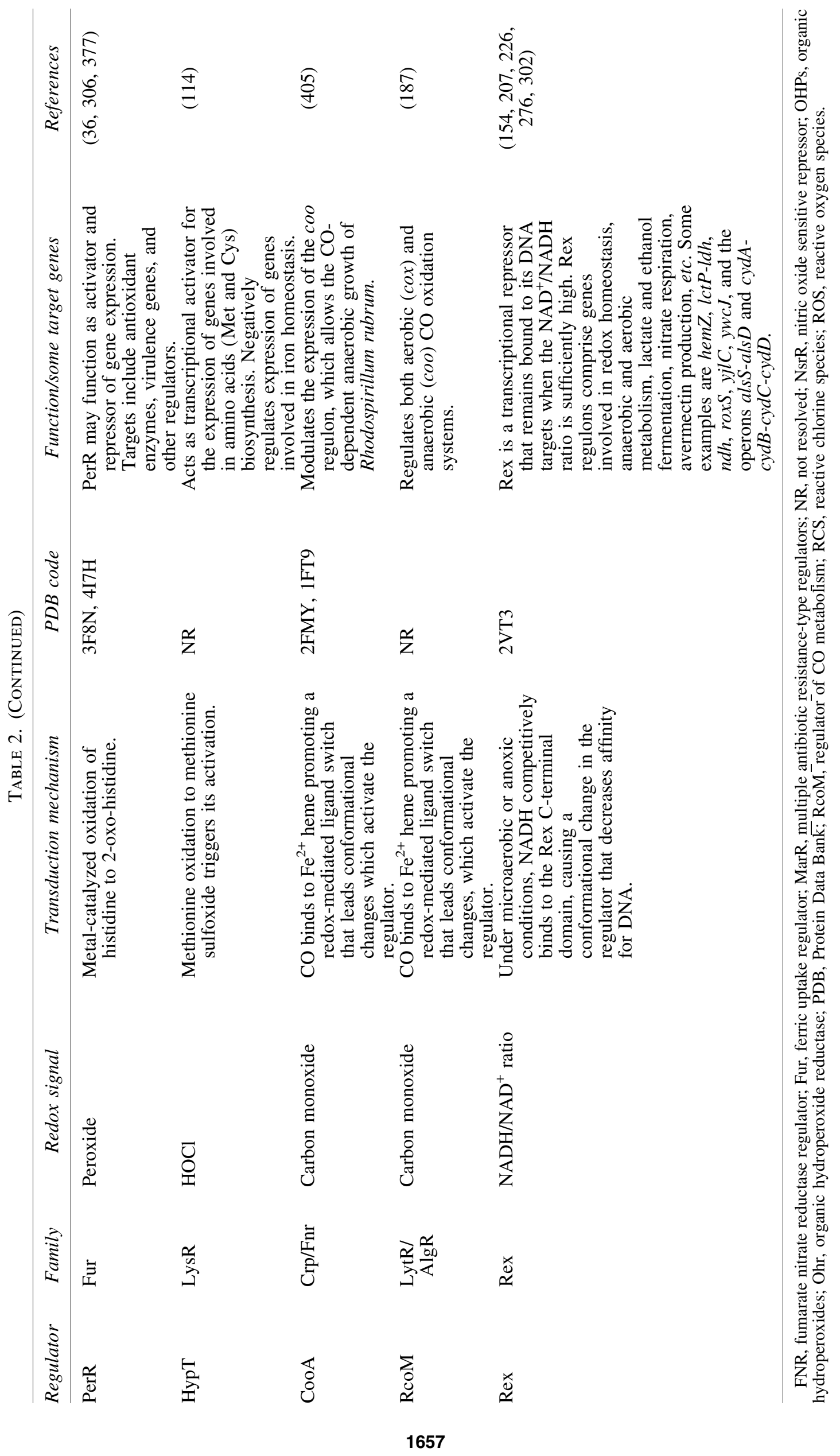


A
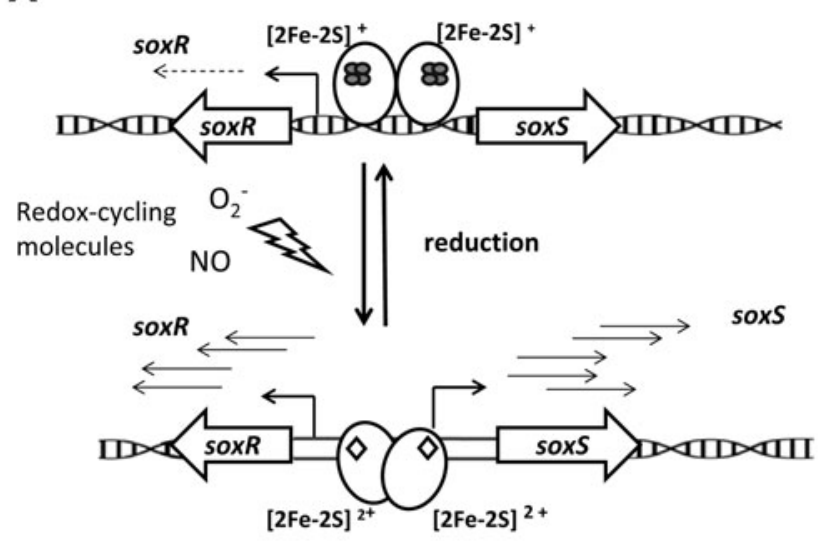

Active SoxR

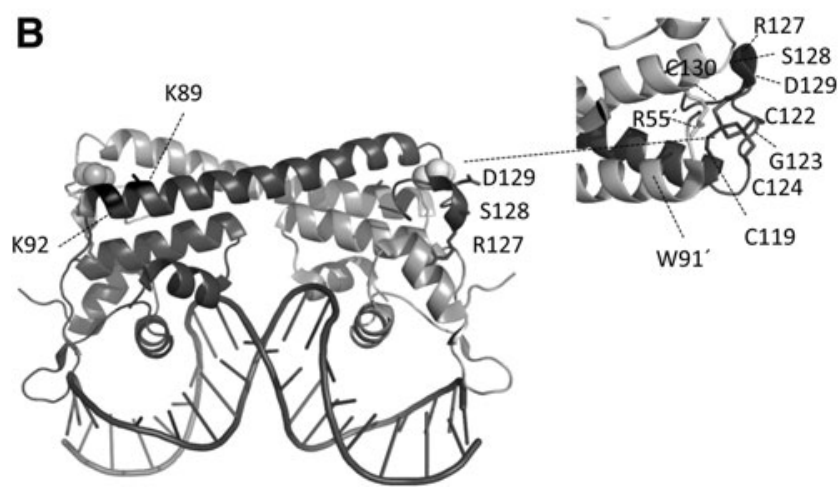

FIG. 1. Scheme of the SoxR-sensing mechanism. (A) Oxidative challenge results in SoxR activation through reversible oxidation of the sulfoferric cluster and untwisting of the soxS promoter allowing its transcription. (B) Structure of the SoxR-soxS promoter complex showing relevant amino acids for the SoxR redox-sensing mechanism. The figure is based on the structure from PDB with code 2ZHG and was produced with PyMol. PDB, Protein Data Bank.

Another interesting issue is the different selectivity against redox-cycling drugs of SoxR regulators from diverse species. Mutational studies demonstrated that small alterations in the SoxR structure can lead to the evolution of proteins with distinct specificities for redox-active small molecules (335). In addition, a series of physicochemical and mutational studies evidenced the importance of two lysine residues in the vicinity of the [2Fe-2S] cluster, namely Lys 89 and Lys 92 in E. coli SoxR crystal structure (Fig. 1B), which are substituted by alanine in nonenteric bacteria (108). Furthermore, the presence of the three-residue hydrophilic motif (Arg127Ser128Asp129) near the [2Fe-2S] cluster in E. coli SoxR, which is not conserved in nonenteric bacteria, also contributed to SoxR sensitivity to redox-active molecules (108). All these results gave valuable information about the molecular basis of functional differences between SoxR proteins and provide new insights into how species-specific residues could tune SoxR sensitivity to different oxidants.

2. IscR. IscR belongs to the Rrf2 family of wHTH transcription factors. Members of the Rrf2 superfamily are widespread in bacteria and respond to different signals, such as nitric oxide (nitric oxide sensitive repressor [NsrR]), iron

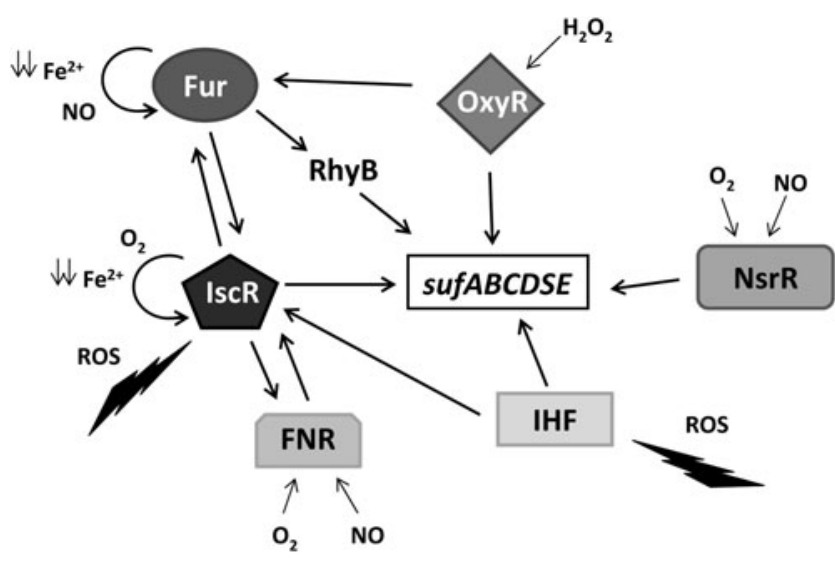

FIG. 2. Factors influencing the regulation and DNAbinding activity of IscR in Escherichia coli and their relationship with the suf operon. FNR, fumarate nitrate reductase regulator; Fur, ferric uptake regulator; NsrR, nitric oxide sensitive repressor; ROS, reactive oxygen species.

limitation (RirA), cysteine availability (CymR), or $\mathrm{O}_{2}(\mathrm{RsrR})$ $(93,146,167,256)$. IscR senses the iron-sulfur cluster status in the cell and it is an outstanding example of the integration of redox, sulfur, and iron availability signals.

IscR was first identified in $E$. coli and isolated in anaerobiosis as a $[2 \mathrm{Fe}-2 \mathrm{~S}]^{1+}$ repressor of the iscRSUA-hscBA-fdx operon involved in $\mathrm{Fe}-\mathrm{S}$ cluster assembly (323). In a feedback loop, IscR senses iron-sulfur homeostasis through the occupancy level of its own [2Fe-2S] cluster $(118,316)$. When iron-sulfur clusters are scarce, apo-IscR dissociates from DNA, derepressing transcription of the cluster biogenesis pathway. Under conditions of low iron, oxidative stress or disruption of the sulfur metabolism, apo-IscR activates transcription of the suf operon involved in iron-sulfur biogenesis $(118,402)$. Therefore, IscR can be active in both holo and apo forms, whose ratio is determined by iron availability, redox status, and $\mathrm{O}_{2}$ tension. Consequently, IscR regulation and activity are directly or indirectly influenced by other master transcriptional regulators, such as FNR, integration host factor, OxyR, or Fur (Fig. 2). An excellent review describing the roles, regulation, and structural details of Isc proteins is available (316).

Owing to the prominent role of $[\mathrm{Fe}-\mathrm{S}]$ clusters in metabolism, IscR is considered a master regulator that controls $>40$ genes of 20 predicted operons in the $E$. coli genome (118). IscR can recognize two different binding motifs. Type I promoters such as those in $i s c R, y a d R$, and $y h g Y$ genes are targets for holo-IscR, whereas type II binding motifs deduced from hyaA, ydiU, and sufA promoter regions exhibit a different consensus and may recruit holo- and apo-IscR (118, 262). This dual activity enables IscR to control two different regulons and, in turn, coordinately regulate iron-sulfur cluster homeostasis.

IscR also plays a critical function in $P$. aeruginosa, which lacks the sulfur mobilization machinery. $P$. aeruginosa IscR controls the isc operon, and contributes to iron homeostasis and resistance to oxidants $(311,347)$. Furthermore, IscR controls the ferredoxin-NADP ${ }^{+}$reductase $f p r B$ that in $P$. aeruginosa is involved in $[4 \mathrm{Fe}-4 \mathrm{~S}]$ cluster biogenesis and tolerance to several stresses (312). The relationship between FprB and IscR suggests that Pseudomonas IscR activity 
could contribute to the modulation of the $\mathrm{NADP}^{+} / \mathrm{NADPH}$ ratio through $\operatorname{frp} B$ regulation. Since IscR is essential in the multiple stress response and pathogenesis of several organisms (248), it has been proposed as a potential therapeutic target for novel drugs.

Although some aspects of the molecular mechanism of IscR remain unknown, significant advances in the understanding of IscR-ligand interaction have been made through the characterization of the IscR $[2 \mathrm{Fe}-2 \mathrm{~S}]$ cluster from $E$. coli (103), and with the resolution of free and DNA-bound structures of apo-IscR from E. coli and Thermincola potens (299, 315). Mössbauer spectroscopy analysis showed that, in vivo, the $[2 \mathrm{Fe}-2 \mathrm{~S}]$ cluster was predominantly reduced. Interestingly, the affinity of IscR for its binding site was not affected by partial cluster oxidation upon anaerobic isolation of the regulator, suggesting that the cluster oxidation state is not important for the regulation of DNA binding (103).

Coordination of the $[2 \mathrm{Fe}-2 \mathrm{~S}]$ cluster takes place through three conserved cysteine residues at the C-terminus (Cys92, Cys98, and Cys104 in the E. coli regulator) and the highly conserved His 107 residue. An exception to this 3Cys-1His coordination is the IscR protein from the facultative phototrophic bacterium Rhodobacter sphaeroides whose singleCys residue is not involved in cluster coordination (304).

The three-dimensional structure of apo-IscR proteins exhibits an overall architecture similar to Rrf2 regulators harboring a wHTH DNA-binding motif and a dimerization domain mainly composed of helix $\alpha 5$ in monomer 1 and helix $\alpha 6$ in the adjacent unit that stabilizes dimer formation mainly by hydrophobic interactions. Analysis of the apo-IscA-DNA interface (Protein Data Bank [PDB] ID: 4CHU), together with sequence alignments of the DNA-binding domains, led to the identification of relevant residues for specific DNA recognition and highlights the role of Glu43 as a selectivity filter in apo-IscR to discriminate against type-1 binding motifs (316). Moreover, the characterization of IscR orthologs from different organisms suggests a high conservation of this unique mechanism of sequence discrimination, unveiling a similar regulation of $[2 \mathrm{Fe}-2 \mathrm{~S}]$ cluster biogenesis to maintain a perfect balance between favorable and adverse conditions (316).

3. NsrR. NsrR is the master regulator of nitrosative stress response in most $\beta$ and $\gamma$ Proteobacteria, with the exceptions of Pseudomonales, Pasteurellaceae, and Vibrio cholerae (309). Under NO stress imposed by macrophages or as a by-product of denitrification, NsrR derepresses the transcription of genes involved in NO detoxification. The most conserved member of the NsrR regulon is the flavohemoglobin gene $h m p$. The main activity of this enzyme consists of the oxidation of $\mathrm{NO}$ to nitrate $(66,372)$.

NsrR is a member of the Rrf2 family that can harbor either a $[2 \mathrm{Fe}-2 \mathrm{~S}]$ or a $[4 \mathrm{Fe}-4 \mathrm{~S}]$ cluster, depending on the organism and the purification conditions $(167,371,407)$. In E. coli, NsrR mediates the adaptive response to NO together with NorR $(28,156)$ and controls a regulon with $>60$ genes including targets involved in iron-sulfur cluster repair, motility, and biofilm development (28). Usually, NsrR works as a transcriptional repressor, recognizing and binding as a dimer to a conserved A/T-rich 11-3-11-bp inverted repeat sequence. Upon nitrosylation of the sulfo-ferric cluster, NsrR releases from DNA. However, it has been reported that NsrR can
A Class I promoter

Class II promoter
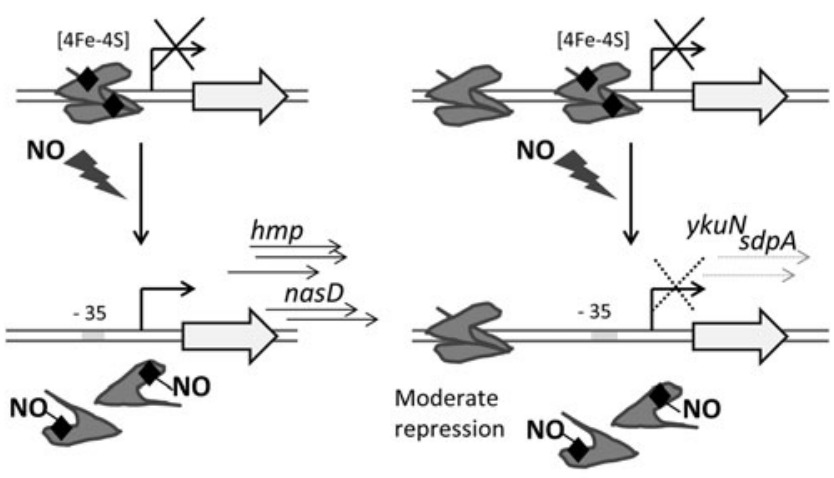

B

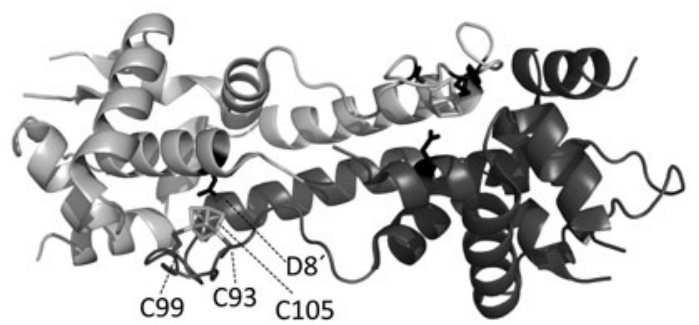

FIG. 3. Molecular basis of transcriptional regulation by NsrR. (A) Model of the two types of regulation by NsrR reported in Bacillus subtilis. Class I promoters are controlled by holo-NsrR in response to NO. Class II promoters may recruit several transcription factors including holo- and apo-NsrR, the latter being insensitive to NO. (B) Model of a Streptomyces coelicolor NsrR dimer showing the assymetric environment of the $[4 \mathrm{Fe}-4 \mathrm{~S}]$ cluster. The structure was taken from PDB (code 5N07) and was produced with PyMol.

activate virulence gene expression in Salmonella typhimurium and in the enterohemorrhagic E. coli $(35,183)$.

In Bacillus subtilis, two different types of regulation by NsrR have been described (Fig. 3A). The so-called class I promoters, such as those upstream of the hmp and nasR genes, are controlled by [4Fe-4S]-NsrR in response to NO (407). Class II promoters are upstream of other genes of the NsrR regulon. DNA binding to class II regulatory sites is weaker, NO insensitive, and involves apo-NsrR $(196,197)$. Class II sites are abundant in the NsrR regulon and many of those genes are controlled by multiple transcription regulators, such as ResD, AbrB, Rok, and Fur. Further work evidenced the importance of combinatorial transcriptional control by NsrR, Fur, and ResD in B. subtilis anaerobic gene regulation (59). NsrR has been shown to work coordinately with other transcription factors in several organisms. In $S$. typhimurium, NsrR controls a set of genes with overlapping binding sites for Fur and FNR (367), whereas in E. coli NsrR participates in the regulation of the sufABCDSE operon together with IscR and Fur (Fig. 2) (50, 213).

The observation of active NsrR with $[2 \mathrm{Fe}-2 \mathrm{~S}]$ and $[4 \mathrm{Fe}-$ 4S] clusters has raised some controversy about the physiologically relevant structure of the iron-sulfur cluster in this regulator. Inactivation of aerobically purified $[2 \mathrm{Fe}-2 \mathrm{~S}] \mathrm{NsrR}$ regulators from S. coelicolor and Neisseria gonorrhoeae only occurred upon nitrosylation of iron in the $[2 \mathrm{Fe}-2 \mathrm{~S}]$ cluster, suggesting that $\mathrm{O}_{2}$ does not affect the redox-sensing module $(167,371)$. However, anaerobically isolated NsrR from $S$. coelicolor and B. subtilis harbors $[4 \mathrm{Fe}-4 \mathrm{~S}]$ clusters that are 
also stable in aerobic cultures. It has been proposed that the [4Fe-4S] cluster in aerobic cultures of $B$. subtilis could be stabilized by glutathione and low-molecular weight thiols, such as bacillithiol (407). In contrast, in NsrR from S. coelicolor, low molecular weight thiols dramatically reduce the $\mathrm{O}_{2}$ stability of the [4Fe-4S] cluster, leading to a fast stoichiometric conversion to the [2Fe-2S] form (66).

Resolution of the crystal structure of [4Fe-4S] NsrR from S. coelicolor (Fig. 3B) revealed an unusual asymmetric cluster coordination by three conserved cysteine residues (Cys93, Cys99, and Cys105) from one of the monomers and the Asp8 residue from the other, which is displaced by NO as a cluster ligand (385). Nitrosylation [4Fe-4S] disrupts several $\mathrm{H}$ bonds causing the displacement of the DNA recognition helix and preventing apo-NsrR binding (385). This unique coordination of the redox center in holo-ScNsrR suggests that the breaking of both intermonomer Asp8-[4Fe$4 \mathrm{~S}$ ] bonds, caused by their substitution with $\mathrm{NO}$, will initiate both cluster degradation and structural changes.

4. RsrR. The Rrf2 regulator RsrR (Sven6563) was initially annotated as an NsrR homologue in Streptomyces venezuelae. However, comparative in vivo mapping of RsrR binding sites in $S$. venezuelae and a $\Delta r s r R$ mutant indicates that this regulator controls a large set of genes with different functions than NsrR (256). Targets of RsrR exhibit either an 11-3-11 bp inverted repeat motif (class I genes) or a single repeat/half site (class II genes). Class I genes represent around $2.7 \%$ of RsrR targets, including the bidirectional promoter located between $r s r R$ and $n m r A$ and other genes mainly involved in signal transduction and $\mathrm{NAD}(\mathrm{P}) \mathrm{H}$ metabolism. Class II targets comprise $>600$ genes with diverse functions, including 21 putative transcriptional regulators, genes involved in $S$. venezuelae metabolism, RNA/DNA replication and modification, small molecule transporters, and proteases, among others (256).

RrsR DNA-binding activity is controlled by the status of its $[2 \mathrm{Fe}-2 \mathrm{~S}]$ cluster that works as a redox switch in a manner similar to SoxR. Under anaerobic conditions, RsrR is a dimer with each monomer containing a reduced $[2 \mathrm{Fe}-2 \mathrm{~S}]^{+1}$ cluster that is rapidly oxidized to $[2 \mathrm{Fe}-2 \mathrm{~S}]^{+2}$ by $\mathrm{O}_{2}$, increasing in vitro DNA-binding activity. This redox transition controls the affinity of RrsR for its DNA targets, whereas apo-RrsR in inactive in DNA binding. Since RrsR mechanism and target genes differ from those of NsrR, it has been proposed that RsrR displays a novel sensing domain for an Rrf2 protein and, therefore, represents a new member of this superfamily (256).

5. FNR. FNR is a widespread sensor of environmental $\mathrm{O}_{2}$ that switches the transition between aerobic and anaerobic respiration. Identified in E. coli in the 1970s (204), FNR is a member of the CRP family of transcriptional regulators. Its structure comprises a sensory domain at the $\mathrm{N}$-terminus with a $\beta$-roll motif and a long $\alpha$-helix involved in subunit dimerization, and a C-terminal DNA binding domain that contains a helix-turn-helix (HTH) motif. Unlike CRP, FNR holds an $\mathrm{N}$-terminal extension that contains four cysteines involved in the coordination of the iron-sulfur cluster, which functions as a direct sensor of $\mathrm{O}_{2}(133)$.

In anaerobic conditions, FNR contains one $[4 \mathrm{Fe}-4 \mathrm{~S}]^{2+}$ cluster per monomer that in the presence of $\mathrm{O}_{2}$ is rapidly converted into a $[2 \mathrm{Fe}-2 \mathrm{~S}]^{2+}$ form through a $[3 \mathrm{Fe}-4 \mathrm{~S}]^{1+}$ interme-
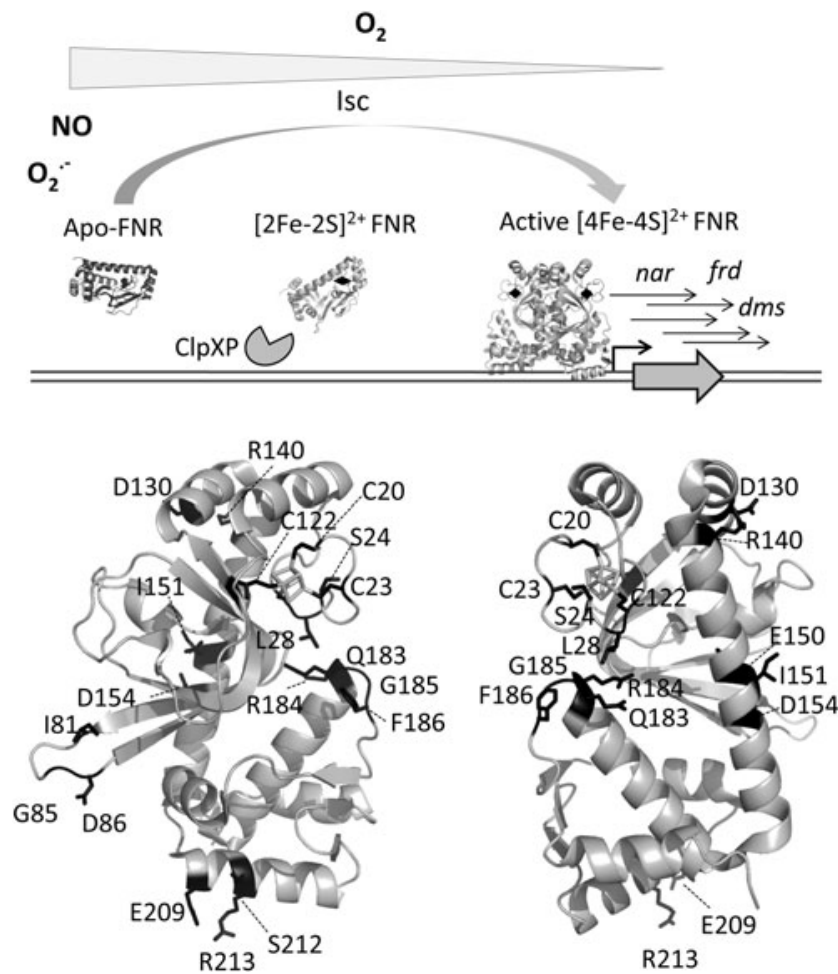

FIG. 4. Molecular basis of transcriptional regulation by FNR. Upper panel: Redox response of FNR in E. coli depending of $\mathrm{O}_{2}$ tension. The lower panel shows a model of the E. coli FNR monomer in two different orientations. Relevant amino acids for its sensing mechanism according to Mettert and Kiley (244) are indicated. The figure is based on the structure of FNR from Aliivibrio fischeri (PDB code 5E44) and was produced with PyMol.

diate, releasing $\mathrm{Fe}^{2+}$ and $\mathrm{O}_{2}^{-}$with the subsequent DNA damage $(63,64)$. The conversion of the cubic $[4 \mathrm{Fe}-4 \mathrm{~S}]^{2+}$ center to planar $[2 \mathrm{Fe}-2 \mathrm{~S}]^{2+}$ requires a series of rearrangements in the proximity of the cluster that, in turn, modifies the dimerization interface, causing dimer dissociation and release from DNA (64). This process may be reverted under low $\mathrm{O}_{2}$ tension. However, if $\mathrm{O}_{2}$ persists in the environment, the $[2 \mathrm{Fe}-2 \mathrm{~S}]^{2+}$ clusters are slowly degraded to produce inactive apo-FNR that, depending of the redox status in the cell, will either work as a scaffold for the incorporation of novel $[4 \mathrm{Fe}-4 \mathrm{~S}]^{2+}$ clusters or will be degraded by the ClpXP protease (Fig. 4) $(104,245)$.

The active dimeric $[4 \mathrm{Fe}-4 \mathrm{~S}]^{2+}-\mathrm{FNR}$ is also sensitive to $\mathrm{NO}$, which generates a mixture of monomeric and dimeric dinitrosyl-iron-cysteine complexes suppressing its ability to bind DNA (69). Therefore, the behavior of FNR differs considerably from that of most CRP family members, which are stable homodimers and bind DNA upon activation by their corresponding effectors. In contrast, a dimer-monomer transition driven by ligation of one $[4 \mathrm{Fe}-4 \mathrm{~S}]^{2+}$ cluster per subunit and/or $\mathrm{O}_{2}$ tension is critical for precise FNR activity. Exceptions to this general working model are the FNR regulators from Bacillus spp. FNR from B. subtilis is a permanent dimer activated by the ligation of one $[4 \mathrm{Fe}-4 \mathrm{~S}]^{2+}$ per cluster, coordinated by three cysteine residues and one aspartate (136). Conversely, B. cereus apo-FNR appeared active in DNA binding in both dimeric and monomer forms. Although further work should be done to fully understand the 
mechanism used by B. cereus FNR, it has been shown that the interaction with ResD and PicR of both the holo-form and the cluster-free FNR is involved in the control of enterotoxin production by this pathogen (91).

FNR can work as either a repressor or an activator of a different set of genes. For positive regulation, FNR contains three individual activating regions that mediate contacts with RNAP depending on the promoter architecture (324). Class II promoters, whose FNR binding site is around 41.5-bp upstream of the transcription start site, predominate over class I with the recognition site at $-61.5-b p$. Different studies have unveiled the complexity of the FNR regulon in E. coli. Although FNR can bind up to 207 sites across the $E$. coli chromosome, the in vivo FNR occupancy is restricted by nucleoid-binding proteins, as well as by the larger number of other regulators bound at FNRregulated promoters. Thus, changes in accessibility of FNR would occur under the appropriate growth conditions, resulting in a highly ductile gene regulation (258).

The core of the FNR regulon appears to be conserved across many facultative anaerobes and, typically, contains operons associated with anaerobic respiration (e.g., nar, dms, and $f r d$ ), including glycolytic and fermentative enzymes, whose transcription is activated by FNR. In contrast, FNR represses a set of genes encoding several aerobic respiratory enzymes, such as cytochrome oxidase and NADH dehydrogenase, among others. Most of these FNR-repressed genes in E. coli are coregulated by ArcA and other FNR-regulatory networks that may involve the pyruvate-sensing PdhR and the GadE regulators $(244,258)$. Furthermore, as part of the strategy to overcome changes in $\mathrm{O}_{2}$ tension suffered during the course of infection, FNR triggers virulence gene expression during host colonization and infection in many facultative anaerobic pathogens $(134,248)$.

Before the resolution of the FNR structure from Alivibibio fischeri (384), a CRP-based model from the E. coli FNR was used in numerous studies to understand the mechanism of this regulator. Thus, the characterization of a series of sitedirected mutants has provided valuable information about the conformational alterations driven by $\mathrm{O}_{2}$ that mediate FNR activity. In particular, some of those involving mutations with altered $\mathrm{O}_{2}$-sensing mechanisms or mutants with missregulated FNR dimerization deserve to be highlighted (Fig. 4). Although the Leu28His variant showed increased resistance to $\mathrm{O}_{2}$, substitution of Ser24 for different amino acids enhanced the aerobic activity of FNR in vivo $(20,172)$. Furthermore, residues Asp154 and Ile151 were critical for proper monomer-dimer transition $(252,253)$.

A detailed comparison between the structural information provided by $A$. fischeri crystals in relation to these results obtained from FNR mutants can be found in a recent review by Mettert and Kiley (244). The authors dissect the protein in four main regions, namely cluster-binding, dimerization, DNA binding, and interaction with RNAP.

The N-terminal region, which contains the four cysteine ligands of the $[4 \mathrm{Fe}-4 \mathrm{~S}]^{2+}$ cluster, exhibits high conformational flexibility and is more disordered than the rest of the protein. Cluster assembly seems to organize the FNR Nterminal region eliciting $\mathrm{O}_{2}$ accessibility to the redox center. A network of hydrophobic interactions proximal to the redox cluster that involves residues of the A, B, and C $\alpha$-helices would serve as a signaling relay between $\mathrm{O}_{2}$ mediated cluster oxidation and dimer dissociation $(244,384)$. Residue Asp154, which has an inhibitory effect on dimerization, together with Glu150 forms a negatively charged pocket in holo-FNR, proximal to Ile151. In contrast to what was previously proposed, Ile151 does not shelter Asp154 to afford dimerization, but establishes intersubunit van der Waals contacts that are critical for dimer stability. Another important amino acid is Arg140, which enables the $\mathrm{O}_{2}$ sensitivity of the FNR monomer-dimer equilibrium through the formation of a salt bridge with Asp130 belonging to the $\alpha \mathrm{B}$ helix of the opposite subunit (244).

Previous studies as well as a comparison with the structure of the FNR-homologue FixK $_{2}$ from Bradyrhizobium japonicum in a complex with DNA point to Glu209, Ser212, and Arg213, located in the $\alpha \mathrm{F}$ helix of the HTH motif, as key residues involved in FNR-DNA interaction (29, 244). Furthermore, it is well established that activating regions denoted as AR1 and AR3 have predominant roles in the interaction of FNR with RNAP. The Arg184 residue located in AR1 stabilizes FNR in a conformation optimal for interaction with RNAP, allowing AR1 to hasten RNAP isomerization from a closed to an open complex (392). Notably, the region consisting of residues $183-186$ is in the vicinity of the $[4 \mathrm{Fe}-4 \mathrm{~S}]^{2+}$ cluster binding domain, suggesting that this proximity could permit communication between the cluster binding domain and AR1 upon cluster ligation (244). Furthermore, Ile81, Gly85, and Asp86 were found to be relevant residues for proper interaction of AR3 with $\sigma^{70}$ (205).

The variability across species of the residues composing the cluster-binding domain in the vicinity of the four conserved cysteines likely determines cluster sensitivity to $\mathrm{O}_{2}$ in each organism, according to the environment $(86,244,396)$. Moreover, the occurrence of multiple FNR proteins in several organisms, such as Pseudomonas putida and Burkholderia, exhibiting different reactivities extends the range of $\mathrm{O}_{2}$ responsive gene expression within a single bacterium (158). More complex is the situation in B. japonicum and other bacterial species that use nitrate as a respiratory substrate, which need to adapt their respiratory pathways not only to $\mathrm{O}_{2}$ tension but also to the available sources of nitrogen (242).

6. WhiB/Wbl. WhiB and Wbl (WhiB-like) are a family of multifunctional proteins exclusive to actinomycetes. Wbl proteins play diverse roles in morphogenesis, cell division, metabolism, virulence, and antibiotic production. WhiB was first discovered in Streptomyces as an essential regulator of sporulation (76). Further studies expanded this family, which in Mycobacterium tuberculosis consists of seven WhiB paralogs $(24,169)$.

Anaerobically isolated $\mathrm{Wbl}$ proteins contain a C-terminal DNA-binding domain and a $[4 \mathrm{Fe}-4 \mathrm{~S}]^{1+}$ redox cluster at the $\mathrm{N}$ terminus. The DNA-binding domain contains a Trp/Gly-rich motif, predicted to form a $\beta$-turn, followed by two positively charged amino acid motifs with different degrees of similarity with the DNA-binding motif known as AT-hook (11, 300, 314, $345)$. The $[4 \mathrm{Fe}-4 \mathrm{~S}]^{1+}$ cluster is NO sensitive, although in some paralogs it also becomes oxidized upon exposure to $\mathrm{O}_{2}$. The redox cluster is coordinated by four conserved cysteines, two of them in a CysXXCys motif, commonly found in the thioredoxin fold and in oxidoreductases.

Nitrosylation of the $[4 \mathrm{Fe}-4 \mathrm{~S}]^{1+}$ cluster is a multistep process that consumes up to eight NO molecules, and if the stress persists, it is followed by complete loss of the cluster 
(67). Depending on the environment, the coordinating cysteine residues may then remain as $-\mathrm{SH}$, or establish intramolecular disulfide bridges. Unlike other transcriptional regulators containing iron-sulfur clusters, nitrosylated and apo-Wbl strongly bind DNA. The oxidized disulfidecontaining apo-protein exhibits the highest DNA-binding affinity. In contrast, DNA interaction with the holo-form is very weak or null (314). Therefore, besides gene regulation mediated by the redox status of the cluster, changes in the redox state of the cysteines provide $\mathrm{Wbl}$ with an additional layer of regulation. Moreover, most Wbl proteins present disulfide reductase activity, representing a novel redox system in M. tuberculosis (4).

The increasing knowledge of this intriguing family of proteins has revealed significant differences among them, possibly related to their functional diversity. The chromosome of $S$. coelicolor contains $11 \mathrm{wbl}$ genes. Nevertheless, not all of them are $[4 \mathrm{Fe}-4 \mathrm{~S}]^{2+}$ transcription factors and the functions of some Wbl proteins still remain controversial $(3,105,186)$. A recent Streptomyces genome-wide chromatin immunoprecipitation sequencing analysis evidenced that WhiA and WhiB cooperatively control the expression of a common set of WhiAB target genes (40). Characterization of the holo and the clusterfree forms of WhiD identified an ROS-sensitive [4Fe-4S] cluster whose disassembly was partially protected by low molecular weight thiols. Unlike other Wbl proteins, WhiD did not show disulfide reductase activity (62). Functional and mechanistic analyses of WhiB proteins from M. tuberculosis reveal a variety of roles for the seven paralogs (Table 1).

Several important differences may account for the functional divergence among them. First, the variability in cluster environments and exposure to oxidants indicate differences in the redox potentials, consistent with the unequal $\mathrm{O}_{2}$ sensitivity among WhiB paralogs (5). Their similar behavior against NO is supported by mechanistic studies evidencing that nitrosylation takes place through a common mechanism in phylogenetically unrelated regulatory proteins (65). Second, unconserved amino acid residues between the key $\mathrm{Cy}$ sXXCys motifs will certainly result in different redox potentials for each WhiB paralog and, therefore, different disulfide reductase activities. As an exception, the WhiB2 paralog lacks disulfide reductase activity and, instead, has a chaperone-like function (Table 1) (198).

Furthermore, a comparative study of the thermal stability of all seven WhiB proteins from $M$. tuberculosis evidences important structural differences among them (5). Besides, the variability in the sequences of their AT-hook motifs results in different DNA-binding patterns (24). Furthermore, the function of some members, namely WhiB3 and WhiB7, depends on their direct interaction with $\operatorname{SigA}(38,353)$. Finally, the different responses upon induction with CRP as part of the diversity of factors influencing their regulation under different redox environments $(115,209,411)$ endow $M$. tuberculosis with a robust versatile redox-responsive system to successfully infect and survive in hostile environments.

\section{B. Redox sensing by thiol-based targets}

The activity of transcriptional regulators with thiol-based switches builds on the oxidation state of cysteine thiol groups. Thus, $-\mathrm{SH}$ groups can be reversibly oxidized upon exposure to redox-active compounds so that a chemical signal is trans- formed into a biological signal through a conformational change in the regulator that modifies its DNA binding affinity. Several classes of structural changes undergone by the regulator can be observed: major reorganization of the polypeptide backbone in association with disulfide redox activity, order/ disorder transitions, changes in the quaternary structure, or disulfide oxidation after the expulsion of metals (95).

A comprehensive review of a large number of bacterial thiol-based redox sensors that specifically sense ROS, reactive electrophile species (RES), and $\mathrm{HOCl}$ via thiol-based mechanisms and regulate gene transcription is available (149). In the next section, an overview of how these proteins are structurally influenced by the formation of disulfide bonds or other oxidative modifications is provided.

\section{Sensors involving cysteine-zinc clusters}

a. DksA. Prolonged oxidative stress leads to the inactivation of key enzymes of the central metabolism, leading to nutritional starvation. As a response, a transcriptional program known as the stringent response provides bacteria with survival advantages and efficient environmental adaptation (295).

The major regulatory component of the stringent response is hyperphosphorylated guanine [guanosine pentaphosphate, (p)ppGpp] whose accumulation in the bacterial cell modifies the transcriptional profile through the binding to RNAP, inducing a large-scale restructuration of metabolic gene expression (366). Together with the alarmone (p)ppGpp, the global regulator DksA is critical for the stringent response of most Gram-negative bacteria. Without binding to DNA, as a consequence of amino acid limitation, DksA binds to the RNAP secondary channel, destabilizing the open promoter complex and impairing transcriptional initiation. In this way, bacteria quickly reprogram transcription in response to changes in nutrient availability (287).

Beyond its participation in the stringent response and independently of (p)ppGpp, DksA works as a redox-dependent global regulator that has different organism-specific functions (Fig. 5). In Legionella pneumophila, DksA is required for pathogenicity and is critical for differentiation, flagellar gene activation, lysosome avoidance, and macrophage resistance (74). DksA also contributes to efficient symbiosis between Sinorhizobium meliloti and Medicago sativa (395). In P. aeruginosa, DksA is required for the secretion of extracellular virulence factors through post-transcriptional control of las and $r h l$ quorum-sensing systems (176). In Salmonella enterica, DksA plays a central role in the coordination of antioxidant defenses through the modulation of glutathione biosynthetic genes and the central metabolism (138). In this way, DksA controls the $\mathrm{NAD}(\mathrm{P}) \mathrm{H} / \mathrm{NAD}(\mathrm{P})^{+}$redox balance that, in turn, fuels downstream antioxidant enzymatic systems essential for adaptation to nutrient starvation (138).

In most Gram-negative bacteria, DksA consists of a coiledcoil domain separated from the C-terminal $\alpha$-helix by a hinge region containing a 4-cysteine zinc finger motif (290). The coiled-coil domain presents an AspXXAspXAla motif in the loop at its tip that is essential for the protein function (220), whereas the relationship between the presence of $\mathrm{Zn}^{2+}$ and the functionality of the protein seems more complex.

It has been established that thiols in the 4-cysteine zinc finger motif sense oxidative and nitrosative stresses by releasing the zinc ion, independently of the second messenger 
A holo-DksA
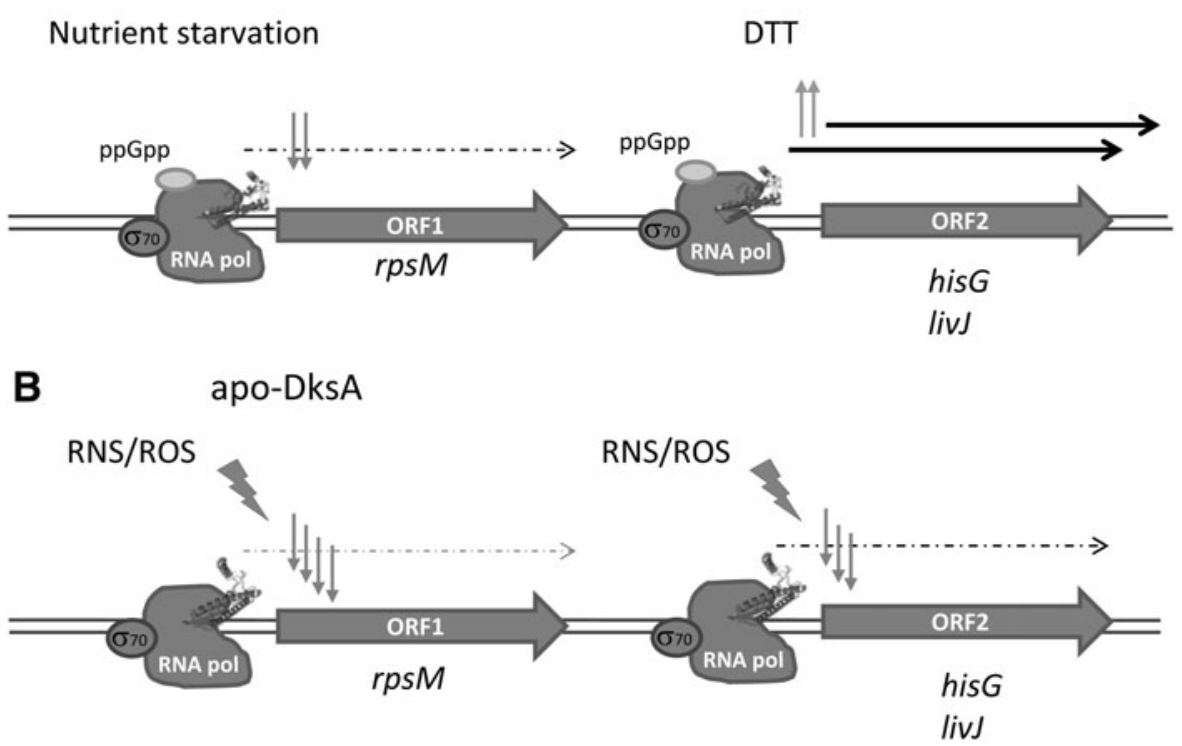

FIG. 5. Scheme summarizing the action of holo- and apo-DksA under different stresses in Salmonella, based on Henard et al. (138). (A) (left) The oxidative stress associated with starvation leads to the downregulation of rps $M$ by ppGpp-bound holo-DksA. Conversely, holo-DksA reduced with DTT supports the activation of livJ and hisG (right). (B) DksA responds to ROS and NRS independently of ppGpp. Oxidative and nitrosative stress releases $\mathrm{Zn}^{2+}$ from the 4-cysteine zinc finger motif of DksA. Then, the free cysteines serve as a thiol switch able of increasing repression of rpsM (left). Oxidized apo-DksA also prevents the activation of livJ and hisG, elicited by reduced holo-DksA (A) (right). DTT, dithiotreitol; ppGpp, guanosine tetraphosphate; RNS, reactive nitrogen species.

guanosine tetraphosphate (ppGpp) (Fig. 5) (139). $\mathrm{Zn}^{2+}$ release causes an evident loss in $\alpha$-helicity of the protein, likely due to disulfide bond formation, since it can be reverted by dithiotreitol (DTT). This oxidation, which has been suggested to occur in the complex DksA-RNAP, converts DksA into a stronger repressor of downregulated genes or, alternatively, fails in the transcriptional activation of DksAactivated promoters, increasing the threshold of the stringent response. These results are consistent with a role for $\mathrm{Zn}^{2+}$ bound thiolates as redox sensors of nitrosative and/or oxidative stress and evidence the ability of 4-cysteine DksA to rapidly integrate nutritional, oxidative, and nitrosative signals into a coordinated transcriptional response $(139,162)$.

Interestingly, under conditions of zinc limitation, some organisms express DksA paralogs that do not contain zinc, such as DksA2 from $P$. aeruginosa, which is functional in regulating RNAP and successfully complements a $d k s A$ deletion mutant in E. coli (109). In Pseudomonadales, DksA2 is also involved in zinc homeostasis under the control of the Zur regulator (25). Both paralogs from Pseudomonas have been used to complement an S. enterica strain defective in $d k s A$ to gain more insights into the relationship between zinc content in DksA and redox homeostasis (68). This study shows that both four-cysteine zinc-bound and two-cysteine zinc-free DksA proteins are functional in mediating the stringent control in S. enterica and conserve the ability to sense reactive species via thiol oxidation. However, zinc-containing DksA proteins were more tolerant to oxidative or nitrosative stresses than cysteine-free DksA homologues, revealing a redox-active sensory function for DksA. Following these observations, the authors proposed that zinc would work as an antioxidant, dampening cysteine reactivity against moderate levels of reactive species.
In addition to DksA2 from Pseudomonas, other atypical DksAs lacking two or three of the four cysteines making up the zinc finger motif have been described in the alphaproteobacteria Caulobacter crescentus, the rhizobia $S$. meliloti and some strains of the purple bacterium $R$. sphaeroides, among others $(139,219,395)$. However, all these DksA proteins contained a highly conserved cysteine, namely C114, surrounded by several charged and hydrophobic residues that stabilize the thiolate form and are usually involved in thiol-mediated sensing of reactive species, as in the cases of thiol-based redox sensing of OhrR and OxyR (379), and cyanobacterial FurA, reviewed in the following section (33).

b. TraR. TraR is a 73-amino acid protein that exhibits $29 \%$ sequence identity with the C-terminal half of DksA (26). TraR is encoded in the E. coli $\mathrm{F}$ element and appears to be ubiquitous in bacteria even in phyla distant from the Proteobacteriaceae. Despite its smaller size, expression of TraR compensates for $d k s A$ activities in vivo, even in the absence of the alarmone ppGpp. TraR contains one zinc ion coordinated by four cysteines that are located in positions equivalent to those of DksA (130). Unlike DksA, TraR variants with single cysteine to alanine substitutions of residues corresponding to the zinc-binding motif in DksA were unable to complement a $\Delta d k s A$ strain for growth in minimal medium, suggesting that zinc coordination is essential for TraR activity. Whether the TraR zinc finger motif can be involved in redox sensing remains to be investigated.

c. RsrA. RsrA functions as a $\sigma^{\mathrm{R}}$-specific zinc-associated antisigma factor that inhibits $\sigma^{\mathrm{R}}$-directed transcription under reducing conditions, regulating the response to thiol oxidative stress in the cytoplasm of Actinobacteria $(7,73,277)$. 
RsrA
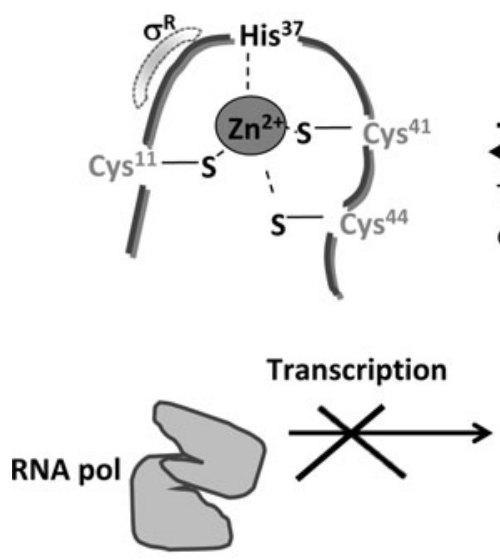
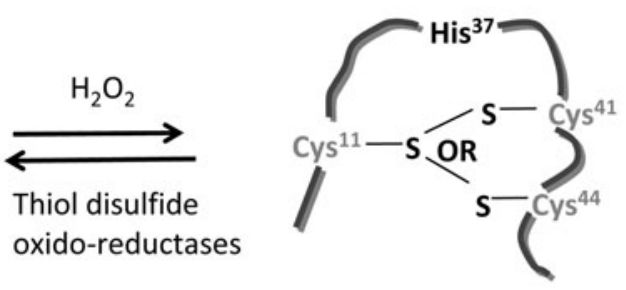

$\operatorname{trx} B A, \operatorname{trx} C, m s h A, m c a, m s r A$, $m s r B$, lon, infC, mpa, engA, tal2, lipA, $\operatorname{mrx} B$, uvrD, hrdB...

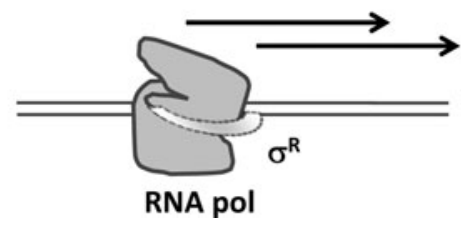

FIG. 6. Model of metal action in RsrA activity. Under reducing conditions, $\mathrm{Zn}^{2+}$ coordination by His37 and reduced Cys11, Cys41, and Cys44 activates RsrA repressor state by sequestering its cognate sigma factor SigR forming an RsrA-SigR complex. Oxidation of either residue Cys41 or residue Cys44 of the Cys41XXCys44 motif by formation of a disulfide bond with residue Cys 11 releases $\mathrm{Zn}^{2+}$ and inactivates RsrA. The regulator undergoes a dramatic change in its 3D structure that sets SigR free. Once released, SigR can interact with RNA polymerase to trancribe the SigR target genes.
S. coelicolor RsrA contains seven cysteines, three of them being Cys11, Cys41, and Cys44, essential for redox sensing in vivo and in vitro. All three cysteines, along with His37, coordinate a single zinc ion in both RsrA and the RsrA- $\sigma^{\mathrm{R}}$ complex [168, 169]. Disulfide stress-inducing compounds lead to the formation of a degenerate trigger disulfide bond between Cys 11 and either Cys41 or Cys44 that displaces the zinc and causes a dramatic structural change. As a result, $\sigma^{\mathrm{R}}$ dissociates from RsrA, thereby allowing $\sigma^{\mathrm{R}}$-dependent transcription (Fig. 6) [170]. RsrA utilizes its hydrophobic core to bind to the sigma factor $\sigma^{\mathrm{R}}$ preventing its association with RNAP. Zinc plays a central role in maintaining this highaffinity complex. The system can be reset by the reduction of RsrA by cellular thiol-disulfide oxidoreductases such as thioredoxins, whose transcription is activated by $\sigma^{\mathrm{R}}$ [171].

Several $\sigma^{\mathrm{R}}$ target genes have been identified. Their products include thioredoxin systems (TrxBA and TrxC), the protein MshA involved in mycothiol synthesis, mycoredoxin1 (MrX-1), proteolytic components (Lon, PepN, and ClpX), ultraviolet (UV) resistance components (UvrA system), and proteins involved in cysteine production (CysM), methionine sulfoxide reduction (MsrA and $\mathrm{MsrB}$ ), guanine synthesis (GuaB), ribosome-associated function (RpmE and RelA), or detoxification of electrophiles $(179,182,189)$. Apart from the control of $\sigma^{\mathrm{R}}$ by the antisigma factor RsrA, SigR activity is also controlled at the translation level (99).

\section{Nonmetallated thiol-based switches}

a. OxyR. OxyR was the first transcriptional regulator discovered to have the ability to sense ROS. It regulates the expression of defensive genes against the harmful effect of $\mathrm{H}_{2} \mathrm{O}_{2}$ such as those encoding catalases $(\mathrm{kat} G)$, alkyl hydroperoxide reductases $(\operatorname{ahpCF})$, or superoxide dismutases (sod) (58), as well as others involved in iron homeostasis, including the master regulator Fur (fur) and the mini-ferritin Dps $(d p s)$ (413). Furthermore, genes related to quorum sensing ( $r s a L)$, protein synthesis ( $r p s L)$, oxidative phosphorylation, and respiration (cyoA and $s n r l$ ) also belong to the OxyR regulon $(387,391)$ (Table 2$)$.

OxyR from $E$. coli is activated in response to peroxide stress via an intramolecular disulfide bond between the conserved cysteines Cys199 and Cys208 (211) (Fig. 7). However, in some bacteria, OxyR functions as a repressor in its reduced form by binding to a more extended region of the target promoters than in its oxidized state, occluding RNAP binding. In particular, it has been demonstrated that the catalase expression in Corynebacterium glutamicum follows a negative regulation by OxyR (365) (Fig. 7C), and a repression/activation mechanism of catalase control by OxyR has been reported in P. aeruginosa PA14 and Neisseria meningitidis $(141,159)$ (Fig. 7D).

As other members of the LysR family of transcriptional regulators, the OxyR fold consists of two domains: the $\mathrm{N}$ terminal DNA binding domain containing a HTH motif and a C-terminal regulatory domain $(319,363)$. In reduced OxyR, the regulatory domain consists of two $\alpha / \beta$ domains that exhibit a similar folding pattern. The redox-active Cys199 resides between two $\alpha / \beta$ domains, whereas Cys 208 is located at the lower part of one of domains separated from Cys199 by $\sim 17 \AA$ (Fig. 7B). Upon disulfide bond formation between Cys199 and Cys208, the short helix formed by residues 199203 in the reduced structure uncoils, leading to a significant rearrangement of the secondary structure of the domain that allocates Cys208 (55).

The oxidation of OxyR involves changes in the orientation of monomers in the dimer, compared to the reduced form, that affect the interdimer orientation in the tetramer and eventually the binding to DNA (Fig. 7A). Oxidation of OxyR by $\mathrm{H}_{2} \mathrm{O}_{2}$ proceeds in a two-step mechanism that involves selective oxidation of Cys199 to form sulfenic acid (Cys199$\mathrm{SOH})$ and its subsequent reaction with Cys208, resulting in an intramolecular disulfide bond (211). The structure of a $P$. aeruginosa OxyR mutant in which the peroxidatic cysteine (Cys 199) was substituted by an aspartate to mimic the sulfinic acid moiety contained an $\mathrm{H}_{2} \mathrm{O}_{2}$ molecule near the mutated 
A

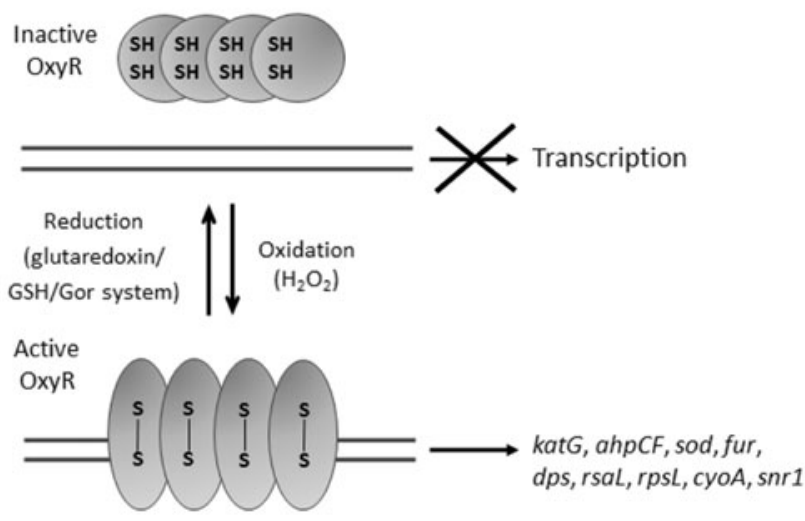

C

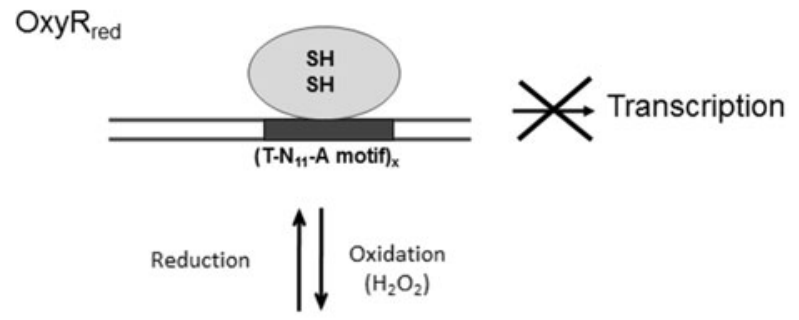

$\mathrm{OxyR}_{\mathrm{ox}}$

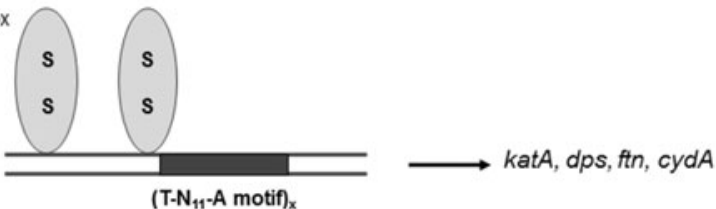

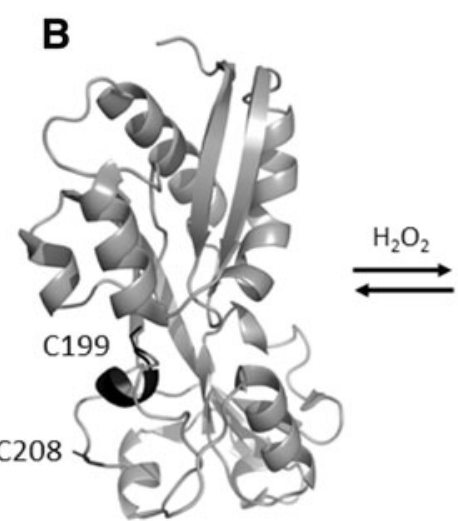

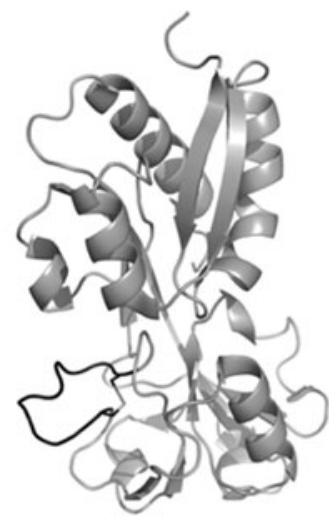

D
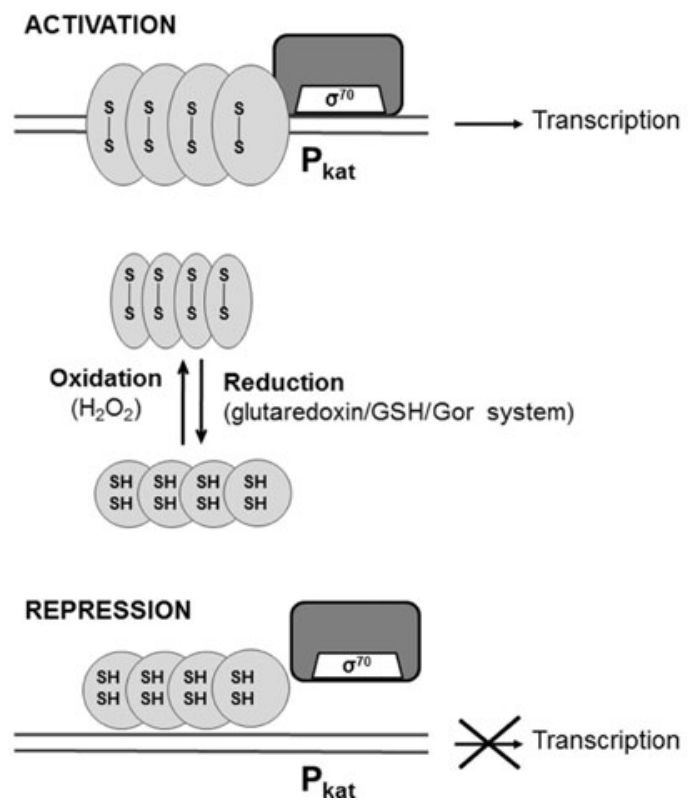

FIG. 7. OxyR-mediated oxidative stress response via intramolecular disulfide formation. (A) E. coli OxyR has a tetrameric arrangement assembled via two distinct dimerization interfaces. The oxidation of a sensing cysteine residue to sulfenic acid in inactive OxyR, followed by formation of an intramolecular disulfide bond with the resolving cysteine, involves a conformational change that affects DNA binding affinity stimulating gene expression. Oxidized OxyR is reduced by reduced glutathione via glutaredoxin/glutathione reductase system, using reducing equivalents supplied by NADPH. (B) Structures of reduced and oxidized OxyR from E. coli (PDB codes: 1169 and 116A). In the reduced state (left), the redoxactive residue Cys199 is separated from residue Cys208 by 17 А. A short helix formed by residues Cys199-Cys208 is highlighted in black. Upon oxidation residue Cys199 transforms into a sulfenic acid intermediate (Cys199-SOH) that rapidly reacts with Cys208 to form an intramolecular disulfide bond. During oxidation the short helix disappears rendering a flexible region that increases the chance of Cys199-SOH and Cys208 meeting to form the disulfide bond. The final result upon disulfide bond formation is a significant rearrangement of the secondary structure $(r i g h t)$. (C) Proposed model for Corynebacterium glutamicum transcriptional repression by OxyR. OxyR specifically binds to the upstrain regions of katA, $d p s$, ftn, and cydA under reducing conditions. OxyR binding site into the four targets is around $50 \mathrm{bp}$ in length and has multiple T-N11-A motifs. Transcriptional repression by reduced OxyR is alleviated under oxidative stress conditions due to the decreased specificity of OxyR DNA binding. (D) Neisseria meningitidis kat gene repression/activation by OxyR. $N$. meningitidis activates the catalase gene as response to $\mathrm{H}_{2} \mathrm{O}_{2}$ increase. After being oxidized, it binds to a region overlapping the -35 hexamer of the single $\sigma^{70}$-dependent promoter $\mathrm{P}_{\text {kat }}$. As a result, a fast and strong activation of the transcription initiation occurs, possibly through direct contact to RNA polymerase. Once the redox state of OxyR is reversed, the reduced form of OxyR represses transcription again. 
aspartic acid residue, suggesting that deprotonation of Cys 199 and the donation of the proton to $\mathrm{H}_{2} \mathrm{O}_{2}$ are coupled. According to this mechanism and the results of susceptibility tests to $\mathrm{H}_{2} \mathrm{O}_{2}$ of different $P$. aeruginosa OxyR variants in vivo, it is required that $\mathrm{H}_{2} \mathrm{O}_{2}$ binds to the catalytic pocket to react with Cys199-SH (174).

Moreover, the crystal structure of the full-length $P$. aeruginosa OxyR shows that it has a tetrameric arrangement assembled via two distinct dimerization interfaces. Thus, the OxyR tetramer consists of two compact subunits and two extended subunits. Each subunit is composed of a DNA binding domain and a regulatory domain that are connected by a short hinge region. Four DNA binding domains are arranged in the bottom of the tetramer. Polar interactions between the DNA binding domain and the regulatory domain occur in the compact subunits, whereas none was observed between those in the extended subunits. The dimeric interface at the DNA binding domain is formed by hydrophobic interactions together with some polar interactions, suggesting that the DNA binding domain dimers are relatively stable even upon structural changes in the regulatory domains (174).

In some pathogenic bacteria, oxy $R$ is found in an operon with $\operatorname{reg} G$ helicase gene. For some of them, such as $P$. aeruginosa, P. putida, and E. coli, it has been reported that purified RecG binds to the promoters of many OxyR controlled genes and that expression of these genes is not induced under conditions of oxidative stress in RecG mutants, suggesting that induction of the OxyR regulon might require unwinding palindromic DNA by RecG for transcription (403).

However, the OxyR thiol-disulfide switch model appears to be more complex since this regulator can be activated by different post-translational thiol modifications. In this way, anaerobic respiration on nitrate of $E$. coli cells revealed that $\mathrm{S}$ nitrosylation of OxyR induced transcription from a regulon that is distinct from the regulon induced by OxyR oxidation. Interestingly, the expression of those anaerobically controlled genes was found to protect against S-nitrosothiols (329).

Moreover, cysteine overoxidation has emerged as a mechanism of regulation of OxyR2 from Vibrio vulnificus. Both OxyR1 and OxyR2 are 2-Cys OxyRs that show different sensitivity to $\mathrm{H}_{2} \mathrm{O}_{2}$ and induce expression of two different peroxidases (Prx1 and Prx2) in defense to oxidative stress (190). Unlike OxyR1, OxyR2 exhibits limited sequence similarity to other OxyR proteins and is more sensitive to $\mathrm{H}_{2} \mathrm{O}_{2}$. Structural data suggest that a glutamic acid (Glu204) (position occupied by glycine in other OxyR proteins) in the vicinity of the peroxidatic cysteine (Cys206) is important to provide in that region the rigidity necessary for different $\mathrm{H}_{2} \mathrm{O}_{2}$ sensing (175). According to mass spectrometry data, high levels of $\mathrm{H}_{2} \mathrm{O}_{2}$ lead to the overoxidation of Cys206 to Ssulfonated cysteine $\left(\mathrm{Cys}-\mathrm{SO}_{3} \mathrm{H}\right)$ in vitro and in vivo, deterring prx 2 transcription. In this way, the production of useless Prx 2 under inactivating levels of $\mathrm{H}_{2} \mathrm{O}_{2}$ is avoided (18).

b. PpsR/CrtJ. PpsR, directly or indirectly, controls the synthesis of all the different components of the photosystem in purple bacteria. It belongs to the LuxR family of transcriptional regulators and is redox sensitive through the formation of an intramolecular disulfide bond (171). Unlike OxyR, formation of this disulfide bond in PpsR is insensitive to the addition of $\mathrm{H}_{2} \mathrm{O}_{2}$ but is sensitive to $\mathrm{O}_{2}$, indicating a different mechanism of disulfide formation from that used by
OxyR, where disulfide bond formation is stimulated by trace amounts of hydrogen peroxide even under reducing conditions (Fig. 8) (12).

The PpsR proteins have been mainly characterized in two related species Rhodobacter capsulatus and $R$. sphaeroides, although in the latter the PpsR orthologue is named CrtJ. PpsR and CrtJ have similar behavior. Under oxidizing conditions, both proteins bind to a palindromic $\left(\mathrm{TGTN}_{12} \mathrm{ACA}\right)$ motif and block transcription of bacteriochlorophyll, carotenoid, light harvesting, or respiratory gene expression ( $p u f$ and $p u h A$ operons) (357). In addition to photosystem genes, direct targets of PpsR repression are genes involved in the early steps of tetrapyrrole biosynthesis (hemC and hemE) in $R$. sphaeroides (254). $R$. capsulatus active site titration data support an octameric PpsR species for DNA binding (Fig. 8) (393).

PpsR and CrtJ share 53\% identity, and both proteins contain a HTH type DNA binding motif placed at the C-terminal region. In PpsR from $R$. sphaeroides, the redox-dependent DNA binding response relies on the formation of an intramolecular disulfide bond between Cys251 and Cys424 (49, 240). However, direct evidence of the formation of this disulfide bond between homologous Cys249 and Cys420 in $R$. capsulatus $\mathrm{CrtJ}$ has not yet been obtained. A comparison with other PpsRs amino acid sequences indicates that only the cysteine residue located in the HTH domain is conserved so that a general scheme for modulating PpsRs includes, apart from disulfide bond formation, the change of the redox state of that thiol into diverse derivatives (sulfenic, sulfinic, or sulfonic acid). Thus, alteration of the redox state of Cys420, beyond disulfide bond formation, is a major contributor to redox regulation of CtrJ DNA activity (49).

In vivo labeling with 4-(3-azidopropyl)cyclohexane-1,3dione indicates that Cys420 is in vivo modified and forms sulfenic acid when cells are exposed to $\mathrm{O}_{2}$. Moreover, the substitution of Cys 420 by serine results in approximately fourfold increase of DNA binding activity. However, Cys420 to alanine mutation leads to $\sim 60$-fold reduction of DNA binding activity. Since mutations of Cys 249 to alanine and serine behave as the wild-type strain, it can be assumed that the stimulation of DNA binding activity is not only achieved by disulfide bond formation between both cysteines (49), suggesting that different homologues are regulated by different types of oxidizing situations.

The DNA binding mechanism of the PpsR proteins from other organisms shows variations. Bradyyrhizobium and Rhodopseudomonas palustris regulation of photosystem synthesis depends on the light quality and $\mathrm{O}_{2}$ tension conditions. It involves the unexpected dual action of two different regulators, PpsR1 and PpsR2, which have a strong similarity with PpsR/CtrJ from the Rhodobacter species in their predicted architectures, DNA recognition sequences, and photosynthesis target genes.

PpsR1 and PpsR2 show fundamental differences with the PpsR/CtrJ family of regulators. In particular, PpsR 1 is a redox-sensitive activator through the formation of a disulfide bond that unlike PpsR is intermolecular. Furthermore, oxidation of PpsR1 remains very limited in response to $\mathrm{O}_{2}$. Unlike PpsR1, PpsR2 does not contain cysteine residues and is not redox sensitive. Therefore, the DNA binding affinity of PpsR2 is redox independent (171). Regulation of this type of regulator can undergo further modulation by its association with other proteins. In $R$. sphaeroides, the light-sensing 
FIG. 8. Schematic model of PpsR and AppA control of gene expression in response to $\mathrm{O}_{2}$ and light. A conserved cysteine in the DNA-b of PpsR undergoes oxidation in the presence of $\mathrm{O}_{2}$. Cysteine oxidation induces binding of PpsR to DNA as an octamer that represses controlled genes. Reduced PspR and reduced AppA form an AppA-PpsrR 2 complex to enable light- and oxygen-dependent regulation. Photon absorption by AppA BLUF domain induces an allosteric structural change in AppA-PspR complex that reduces its affinity for DNA. AppA-PpsR 2 -DNA complex prevents the repressing effect of $\mathrm{PpsR}_{8}$-DNA and promotes gene expression depending on relative AppA-PspR concentrations. An excess of PpsR competes with AppA-PpsR $\mathrm{R}_{2}$ for promoters under light but cannot replace the ternary complex in the dark. The levels of AppA and PpsR are inversely regulated by $\mathrm{O}_{2}$. When the concentration of $\mathrm{O}_{2}$ increases, $\mathrm{PpsR}_{8}-$ DNA is favored with the consequent repression of photosynthetic genes (171). BLUF, blue light sensors using FAD; DNA-b, DNA binding domain.

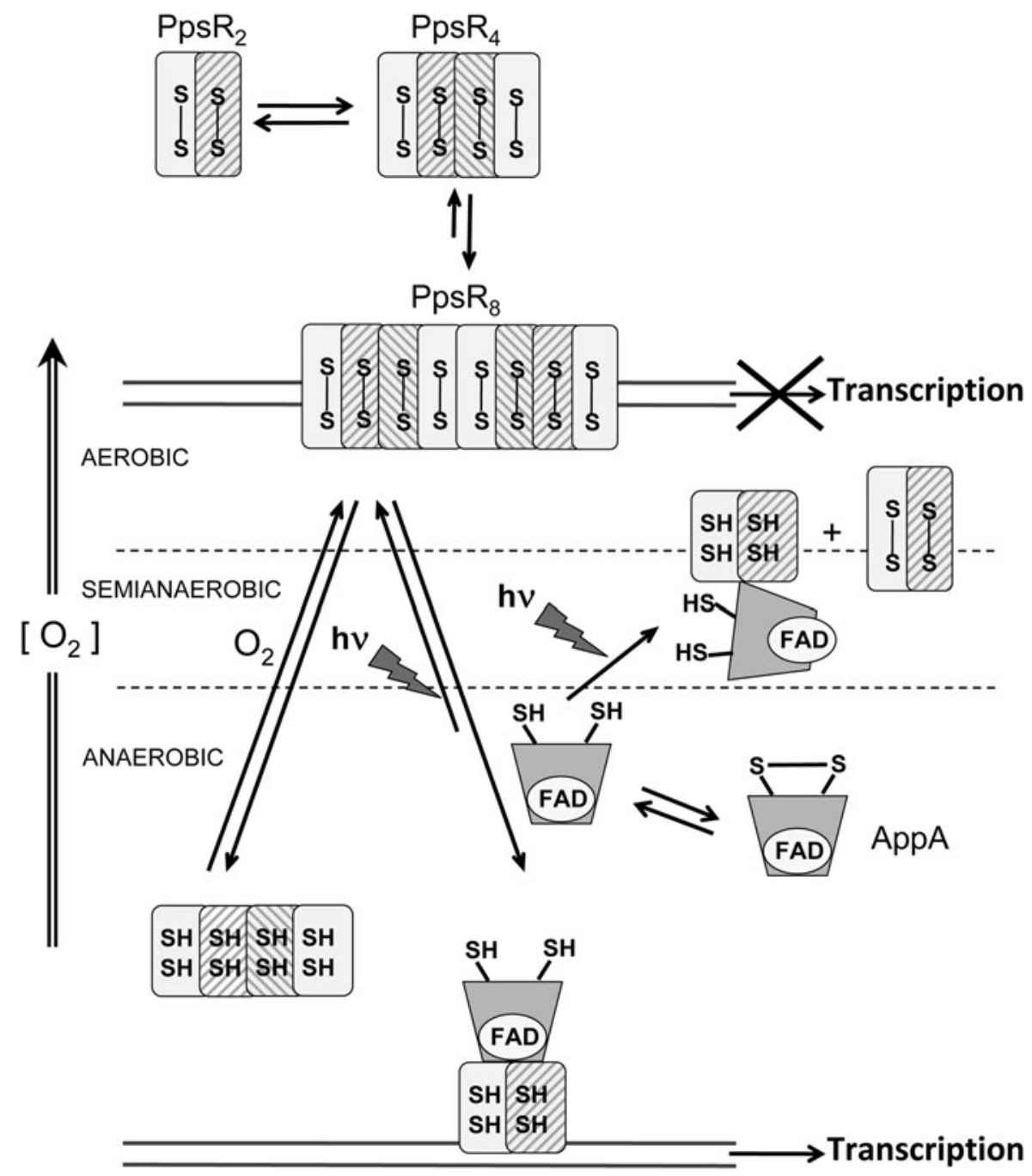

antirepressor AppA inhibits DNA binding of PpsR by two mechanisms. One mechanism involves AppA-mediated reduction of the disulfide bond in PpsR. The second mechanism entails the formation of a stable AppA-Ppsr 2 complex that prevents PspR binding to DNA (Fig. 8) (239). In contrast to PpsR from $R$. sphaeroides, the repressive activity of $\mathrm{CtrJ}$ from $R$. capsulatus is not antagonized by AppA.

c. OhrR. The OhrR family of regulators sense organic hydroperoxides (OHPs) and other ROS by oxidation of a critical and highly conserved cysteine residue. OhrR belongs to the MarR (multiple antibiotic resistance-type regulators) superfamily of transcriptional regulators. It primarily regulates the expression of organic hydroperoxide reductase (Ohr) but also genes related to the detoxification of peroxides (antioxidant enzymes and thiol-reducing systems), the degradation of the aromatic moiety of the model compound cumene hydroperoxide and genes involved in the protection against other secondary stresses (DNA repair, heat shock, iron limitation, and nitrogen starvation responses) or virulence (113, 298, 328). OhrR also responds to $\mathrm{NaOCl}$ stress since transcriptome studies indicated that ohrA gene was the most strongly upregulated gene in $\mathrm{NaOCl}$ stressed $B$. subtilis (52).

Two OhrR subfamilies have been described based on their peroxide sensing mechanism (Fig. 9): the single cysteine class, represented by $B$. subtilis OhrR, whose DNA binding activity is modulated by cysteine oxidation, and the second class, represented by Xanthomonas campestris OhrR that requires the reversible formation of a disulfide bridge between two cysteines, either intersubunit or mixed, to modulate the repressor function (149).

In both 1-Cys and 2-Cys OhrR subfamilies, the initial step leading to transcription derepression mediated by peroxide involves oxidation of a sensing cysteine to sulfenic acid (Cys$\mathrm{SOH})$ that is not sufficient to derepress transcription. In the first case (Fig. 9A), B. subtilis Ohr has a single conserved cysteine (Cys15) that is ionized at physiological pH (151, 216). According to in vitro studies, exposure of OhrR to model OHPs results in oxidation of Cys15 to sulfenic acid (107). The subsequent reaction of the Cys 15 sulfenate with a low-molecular weight thiol, to generate a mixed disulfide, or with the backbone of the protein, to generate a sulfenamide derivative, correlates with transcription derepression (216). In this sense, in vivo changes in the transcriptome and redox proteome of $B$. subtilis caused by the strong oxidant hypochloric acid identified OhrR as an S-bacillithiolated protein, indicating that OhrR forms mixed disulfides with bacillithiol, leading to inactivation of the OhrR repressor and upregulation of the thiol-dependent OhrA peroxiredoxin to protect the cells against OHPs and $\mathrm{NaOCl}(52)$. 
A
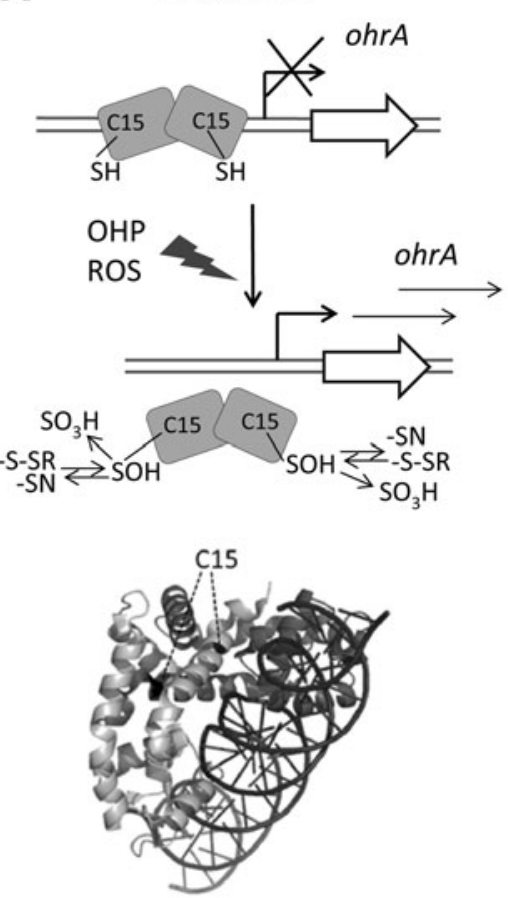

B
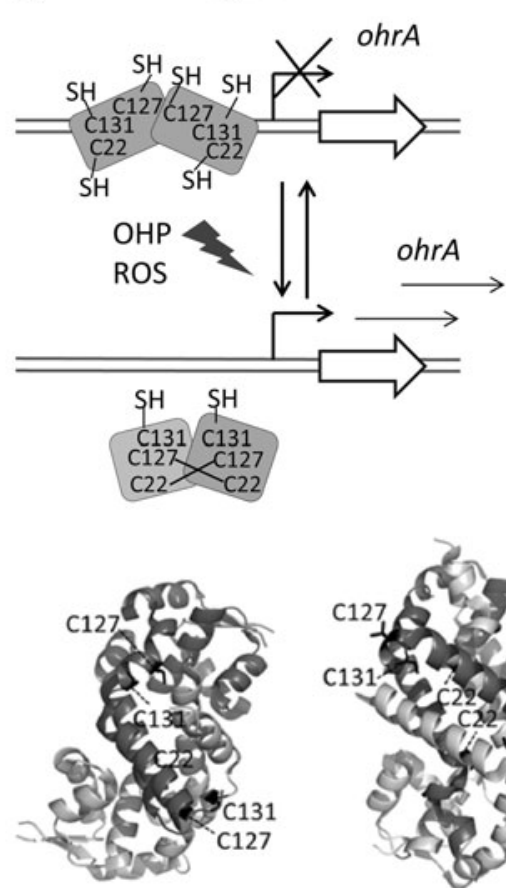

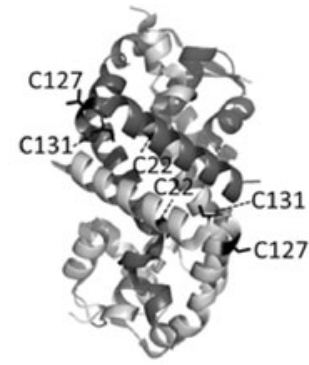

FIG. 9. Scheme of the redox control of the $o h r A$ peroxidase by OhrR. (A) In the 1-Cys OhrR from B. subtilis, peroxides cause the oxidation of the conserved $\mathrm{Cys}_{15}$ to sulfenic acid that, in turn, may undergo reversible S-thiolation or be irreversibly overoxidized in the presence of strong oxidants. The lower panel shows the location of $\mathrm{Cys}_{15}$ in a model based on the PDB structure with code 1Z9C. (B) In the Xanthomonas Campestris, 2Cys OhrR oxidants lead to intersubunit disulfide formation between $\mathrm{Cys}_{22}$ and $\mathrm{Cys}_{127}$ that results in a major structural change of the regulator. The lower panel shows this structural rearrangement, as well as the location of the three conserved cysteines of $X$. campestris in the oxidized 2-Cys $\mathrm{OhrR}$ (left) and the reduced form (right). The structures were produced with PyMol according to the PDB files with codes $2 \mathrm{PFB}$ and $2 \mathrm{PEX}$.
OhrR homologues that contain a single cysteine have been characterized in S. coelicolor (270) or Mycobacterium smegmatis, where OhrR is induced by OHPs in the intracellular environment upon ingestion of the bacteria by macrophages (113). In the 2-Cys OhrR-type described in $X$. campestris OhrR (Fig. 9B), a reactive cysteine (Cys22) located in the N-terminus is oxidized by OHP to a sulfenic acid intermediate and undergoes the rapid formation of an intermolecular disulfide bond with residue Cys127 of the other subunit in the homodimer, leading to major structural change (263, 281). Disulfide-linked dimer formation induces the dissociation of OhrR from DNA and the expression of a peroxidase that reduces OHPs to their corresponding alcohols $(263,281)$. A 2-Cys OhrR-type homologue has been reported in $P$. aeruginosa $(13,14)$.

Therefore, depending on their amino acid content, OhrR proteins isolated from different bacteria can exhibit varied DNA binding properties. Even oligomerization can be important in controlling OhrR activity. Burkholderia thailandesis OhrR forms oligomeric species by virtue of reversible disulfide bonds formed between redox-active cysteines on treatment with organic and inorganic oxidants. These disulfide bonds involve conformational changes that result in attenuated OhrR DNA binding in the presence of oxidants (280). Furthermore, binding of the small molecule 2-aminophenol to Burkholderia xenovorans LB400, which lacks oxidizing properties, attenuates the regulator affinity for its DNA operator sequence by promoting a conformational change in the regulator. In this case, 2-aminophenol functions in $B$. xenovorans as a typical effector molecule. It plays a role in the response to ROS by this organism because 2-aminophenol is an intermediate in tryptophan or nitrobenzene metabolism and can be metabolized to generate ROS but it does not affect the redox state of cysteines (264).

In Staphylococcus aureus, two homologues of the MarR/ OhrR 1-Cys-type repressor are present, the MgrA and SarZ global regulators that confer antibiotic resistance and virulence $(17,178,369)$. The MgrA regulon includes a battery of genes involved in virulence [cap5(8)-locus, hla, coa, spa, $s p l A B C D E F$, and $n u c]$, autolysis (lytM and lytN), antibiotic resistance (nor $A$, nor $B$, and tet $A B$ ), and virulence regulators (agr, lytRS, arlRS, sarS, and sarV) (232).

According to MgrA homodimer crystal structure, a unique cysteine residue located at the protein dimer interface can be oxidized by $\mathrm{H}_{2} \mathrm{O}_{2}$ and OHPs leading to dissociation of MgrA from DNA (47). MgrA activity can also be reversibly regulated by cysteine phosphorylation (355). In the same way, SarZ can be controlled by cysteine phosphorylation (355). SarZ is a global transcriptional regulator that uses a single cysteine (Cys13) to sense peroxide stress and control genes involved in hydroperoxide resistance (ohr, hla, and agr), hemolysin production, and virulence regulation in $S$. aureus and even can be involved in biofilm formation as reported in Staphylococcus epidermidis $(48,178,389)$. Structural data indicate that protein with Cys13 sulfenic acid modified is competent to bind to DNA. A further reaction with an external thiol is necessary to disrupt SarZ DNA binding ability (294). It has been suggested that S. aureus MgrA and SarZ could be controlled by $S$-bacillithiolation (163).

Besides MarR/OhrR family of redox sensors, there are other MarR-type regulators that belong to the MarR/DUF24 subfamily, conserved in Gram-positive bacteria (7). Unlike OhrR, in B. subtilis DUF24 family regulators respond specifically to RES (diamide, quinones, and aldehydes) instead to ROS (6). In particular, YodB regulator (renamed QsrR) controls the azoreductase AzoR1 and also regulates the expression of the catDE operon (catechol-2,3-dioxygenase $\mathrm{CatE}$ and oxidoreductase CatD), which belong to detoxification pathways that confer resistance to quinones and diamide $(53,218)$.

YodB contains three cysteine residues (Cys6, Cys101, and Cys108) that are involved in its mechanism of inactivation. The accepted model of functioning indicates that upon 
treatment with diamide and quinones, YodB is inactivated by formation of a Cys6-Cys101 intersubunit disulfide both in vitro and in vivo (51). B. subtilis also contains HypR (formerly YybR), another MarR/DUF24 protein. It is activated by Cys14-Cys49 intersubunit disulfide formation, entailing reorientation of the monomers and repositioning of $\alpha$ helices that are involved in major groove recognition (278). HypR is a positive regulator of the nitroreductase HypO that confers $\mathrm{NaOCl}$ resistance and is induced by $\mathrm{NaOCl}$, diamide, and quinones (278).

d. NemR. The NemR repressor (formerly named YdhM) belongs to the TetR family of transcriptional regulators and responds to cysteine-modifying electrophiles, alkylation, and reactive chlorine species (RCS) (375). The oxidation of cysteine residues by RCS is a reversible process that leads to a decrease in NemR DNA binding affinity and the consequent derepression of transcription of the NemR-controlled genes gloA and nemA. The gloA gene encodes glyoxalase I (GlxI), the first enzyme of the glyoxalase system for the conversion of toxic alpha ketoaldehydes into nontoxic 2-hydroxycarboxilic acids. The nemA gene encodes $\mathrm{N}$-ethylmaleimide (NEM) reductase, an enzyme involved in reductive degradation of NEM and other nitrous compounds $(132,375)$. Both gene products contribute to detoxification of toxic compounds that can be reused as nitrogen sources. In fact, phenotypic studies suggest that deletion of gloA and nemA increases the $\mathrm{HOCl}$ sensitivity of $E$. coli cells since both contribute to increased bleach resistance in $E$. coli by detoxifying reactive electrophiles produced during RCS stress (132). However, the response in NemR to RCS does not depend on any commonly known oxidative cysteine modifications.

According to crystal structure data of E. coli NemR, RCS treatment of NemR results in the formation of a reversible Cys106-Lys175 sulfenamide bond that is favored by the inherent structural flexibility between the two alpha-helices $\mathrm{E}$ and $\mathrm{F}$ (EF loop). In this case, the formation of the bond allows control of gene expression while the overall architecture of the protein is maintained (131).

e. FurA. Fur is the master regulator of iron homeostasis in most heterotrophic bacteria, where it works as a classical repressor. In a simplified model of regulation, Fur binds to its target sequences using $\mathrm{Fe}^{2+}$ as corepressor to block the transcription of an ample regulon $(92,101)$. Fur belongs to a superfamily including homologues that control processes intimately linked to redox homeostasis, such as PerR (response to peroxide stress) and Zur (control of zinc homeostasis). Remarkably, peroxide transduction by PerR is carried out through a completely different mechanism than that described by Fur (discussed in the next section). Both PerR and Zur can work with Fur to coordinately regulate a set of genes involved in the response to oxidative stress or virulence, among other important processes $(152,325,368)$.

Furthermore, anaerobiosis affects the gene expression programs of Fur and the small RNA regulator RyhB in E coli $\mathrm{K}-12$. The impact of $\mathrm{O}_{2}$ availability on the Fur regulon suggests a change in the set point for iron homeostasis and evidences the relationship between Fur and redox regulation (21, 22). This link has also been reported for Helicobacter pylori where Fur mediates the response to oxidative stress by an allosteric regulatory mechanism that specifically targets ironinducible apo-Fur repressed genes (289).
Usually, Fur proteins contain a structural $\mathrm{Zn}^{2+}$ ion that is absent in the cyanobacterial regulator (142). Thus, the lack of structural $\mathrm{Zn}^{2+}$ in FurA from Anabaena sp. PCC 7120 elicits a redox response controlled by thiol-disulfide interconversion mediated by cysteines belonging to CysXXCys motifs that usually are involved in the coordination of $\mathrm{Zn}^{2+}$ in the regulators from heterotrophic bacteria $(41,101,383)$. In this way, FurA couples iron homeostasis and the response to oxidative stress with major physiological processes in cyanobacteria $(125,126)$.

The cyanobacterial FurA regulon contains genes that belong to diverse functional categories, including iron homeostasis, photosynthesis and respiration, heterocyst differentiation, oxidative stress defense, and light-dependent signal transduction mechanisms, among others (125, 127-129).

FurA contains five cysteine residues, four of them arranged into two active CysXXCys redox motifs (Cys101XXCys104 and Cys141XXCys144) located in the C-terminal domain of the protein (dimerization domain). FurA needs not only metal but also reducing conditions to remain fully active in vitro (143), and both CysXXCys motifs display disulfide reductase activity (31). Notably, Cys 141 is also part of a CysPro heme regulatory motif (HRM) (discussed in Section II.E). Moreover, FurA is mainly a monomer with a single free cysteine in the cytoplasm of Anabaena sp. PCC 7120 at the stationary phase, suggesting the ability of this regulator to form two disulfide bonds.

A mutational study of single cysteines introduced in FurA revealed that Cys101 and its particular redox state are critical for the coordination of the metal corepressor that ultimately controls the FurA ability to bind to DNA in vitro. When Cys101 is oxidized, FurA loses the metal and dissociates from the DNA. Taking into account that the redox status of Cys101 varies with the presence or absence of Cys133 or Cys104 from the Cys101XXCys104 redox motif, the environments of these cysteines are apparently mutually interdependent, suggesting a mechanism of FurA activation/ inactivation based on a thiol-disulfide redox switch that involves these cysteines and controls the redox state of Cys101 that coordinates the corepressor metal. Accordingly, Cys133 would be responsible for maintaining Cys 104 in the oxidized state to avoid Cys101-Cys104 disulfide bond formation and consequent inactivation of the protein (Fig. 10). This thioldisulfide exchange of FurA responds to the alteration of the cellular redox potential (33).

Apparently, this mechanism is specific for cyanobacterial Fur homologues since it relies on Cys133, a residue conserved in cyanobacterial Fur homologues but absent in Fur homologues from heterotrophic bacteria. The FurA redox switch resembles that described for RsrA in the previous section. In both cases, a disulfide bond between both cysteines of a CysXXCys motif controls the redox state of a third cysteine that coordinates the metal ion. However, although in RsrA the coordination of $\mathrm{Zn}^{2+}$ keeps cysteines in a reduced state determining oxidation kinetics of this regulator, in FurA the $\mathrm{Fe}^{2+}$ that binds to the reduced cysteine plays a role as corepressor metal, coordinating in this way iron homeostasis and redox responses.

\section{Regulation by metal-catalyzed oxidation: PerR}

The metal-catalyzed oxidation of histidine to 2-oxohistidine is an important marker of oxidative stress 
FurA

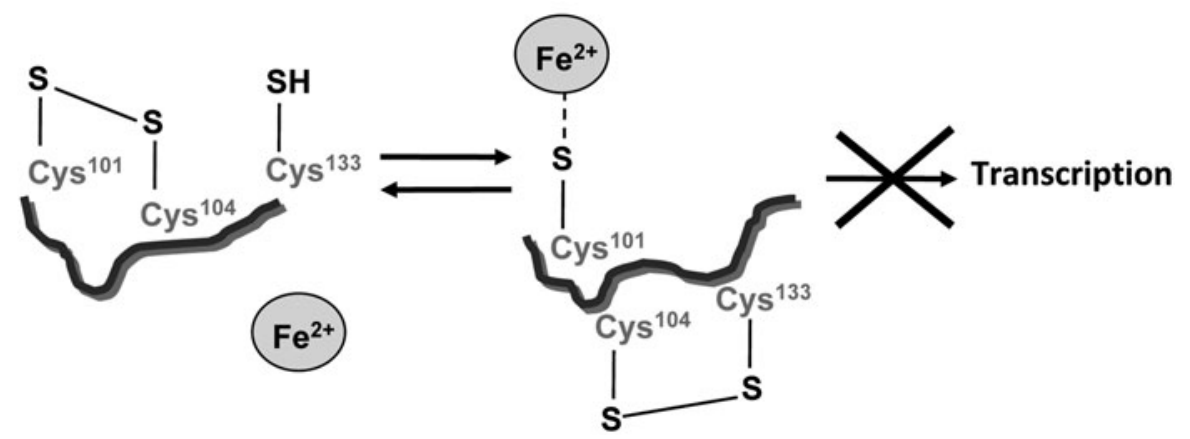

FIG. 10. Model of metal involvement in the activity of cyanobacterial FurA. The $\mathrm{Cys}_{101}-$ $\mathrm{Cys}_{104}$ disulfide bridge of the $\mathrm{Cys}_{101} \mathrm{XXCys}_{104}$ motif keeps the residue $\mathrm{Cys}_{101}$ in the oxidized state and, therefore, unable to coordinate the metal corepressor, rendering inactive FurA.

commonly associated with the regulation of enzyme activity (322). Unlike other Fur paralogs that regulate their target genes in response to the availability of different metals, PerR activity is based on metal-catalyzed oxidation of a histidine residue located in the conserved HisHisHis $\mathrm{XHisX}_{2} \mathrm{Cys}_{2} \mathrm{Cys}$ motif positioned at the hinge between the metal-sensing C-terminus and the DNA-binding domain of Fur proteins (173). Oxidation of PerR leads to loss of the iron cofactor and its dissociation from DNA to derepress transcription of genes involved in the antioxidant response. The mechanistic differences between Fur and PerR from heterotrophic bacteria have recently been reviewed (291). PerR may function as both activator and repressor of gene expression. Targets include antioxidant enzymes, virulence genes, and other regulators $(36,306,377)$.

\section{Methionine oxidation-based transcriptional regulation: HypT}

The E. coli hypochlorite-responsive transcription factor HypT (formerly YjiE) positively and negatively regulates the expression of several genes in response to $\mathrm{HOCl}$ oxidation (83). HypT belongs to the LysR family of transcriptional regulators (319), and is activated through the oxidation of three methionine residues (Met123, Met206, and Met230) to methionine sulfoxide. Most of the genes that are positively regulated are involved in the biosynthesis of cysteine and methionine, whereas most of the genes that are negatively regulated are involved in iron acquisition and homeostasis (114). This could indicate that the intracellular pool of cysteine and methionine must be replenished in response to oxidative damage, whereas the intracellular concentration of iron, which could enhance the production of superoxide and hydroxyl radicals, must be kept at low levels (94).

HypT has different multimeric forms. On binding to DNA, the dodecameric ring-like structure of HypT dissociates into an active tetrameric form that acts as a transcriptional activator. The current model proposes that the oxidation of methionine residues promotes the transition of the inactive dodecameric form of HypT to the active tetrameric form (83). MsrA and MsrB are required to reverse the oxidation state of the oxidized methionine residues, thus inactivating the activity of HypT1 (83).

\section{E. Redox sensing by heme-based sensor proteins}

Bacterial heme-based sensor proteins exploit the redox chemistry of heme to sense environmental gases (e.g., $\mathrm{O}_{2}$,
$\mathrm{CO}$, and NO) (96) and the intracellular redox state of the bacterium. These particular sensor proteins typically contain two distinct domains, a heme-containing regulatory domain and a catalytic domain. Gas binding to the heme-containing regulatory domain regulates the catalytic domain function, including binding to DNA (153).

1. CooA. CooA (bacterial $\mathrm{CO}$ oxidation transcriptional activator) is a heme-binding protein that controls the expression of a regulon allowing anaerobic growth of Rhodospirillum rubrum upon CO oxidation (331). It belongs to the CAP/CRP superfamily and is distantly related to the $\mathrm{O}_{2}$ sensor FNR and the denitrification regulator/nitric oxide reductase regulator (DnrD/NNR) group of NO sensors. Its heme binding is an example of a heme-containing regulatory domain where the intracellular redox status, heme, and DNAbinding activity are related.

CooA is a homodimer and each monomer contains a $b$-type heme as the active site for sensing $\mathrm{CO}$. The structure of COfree $\mathrm{Fe}^{2+} \mathrm{CooA}$ (inactive for DNA binding) has been solved and although the structure of the $\mathrm{CO}$-bound $\mathrm{Fe}^{2+} \mathrm{CooA}$ (active for DNA binding) has not yet been determined, experimental data and comparisons with the crystal structure of the active form of the CRP homologue bound to DNA have enabled a model of operation to be proposed $(10,206)$.

Apparently, this protein exists in the cell in three general heme states (Fig. 11). Under oxidizing conditions, low-spin $\mathrm{Fe}^{3+}$ heme is axially coordinated by Cys75 and Pro2, a residue located in the $\mathrm{N}$-terminus of each protein monomer. In this situation, the protein is unable to associate with $\mathrm{CO}$ and consequently to bind to specific DNA sequences efficiently.

In reducing conditions, $\mathrm{Fe}^{2+}$ heme is obtained and Cys 75 is replaced by His77 as an axial ligand of ferrous iron. Therefore, a redox-dependent axial ligand exchange between Cys75 (ferric form) and His77 (ferrous form) occurs on reduction of the heme iron (332). After exposure of RrCooA to $\mathrm{CO}$ under anaerobic conditions, $\mathrm{CO}$ binds to $\mathrm{Fe}^{2+}$ heme and displaces the Pro2 iron ligand (Fig. 11A) (9). Displacement of Pro2 entails a conformational change leading to a reposition of the heme, exposing the CO-bound heme to the long $\alpha$-helices (C-helices) that extend along the homodimer interface (Fig. 11B) $(188,406)$. This interaction stabilizes an alternative conformation of the domain containing these $\mathrm{C}$-helices that alters the hinge region separating the DNA- and CO-binding domains. When the geometry of the hinge region alters, the inactive form of CooA destabilizes and the active form stabilizes (405). Reorientation of CooA DNAbinding domains is necessary to produce a transcriptionally active state (157). 
A

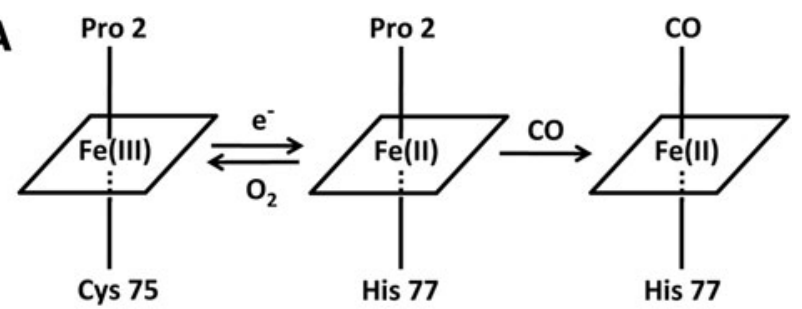

Ferric

Ferrous

CO-bound
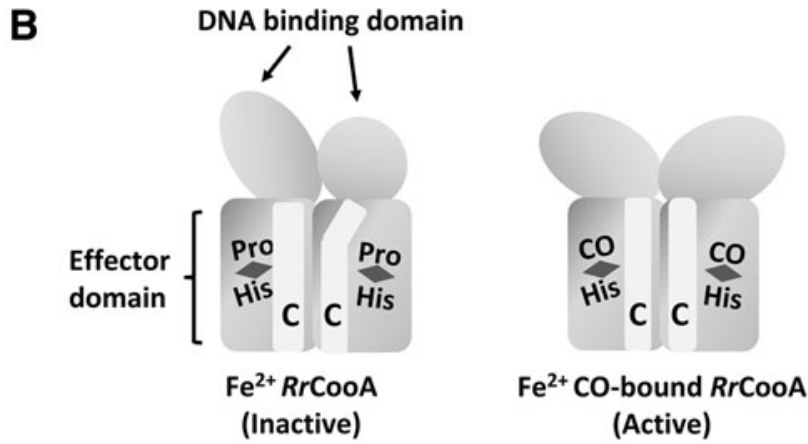

FIG. 11. Features of $\operatorname{RrCooA}$ redox and CO-mediated activation. (A) One of the axial ligands of the heme ferric state undergoes a redox-mediated ligand switch upon reduction. The displacement of the axial ligand in the reduced form by $\mathrm{CO}$ apparently causes a conformational change that induces $\operatorname{Rr}$ CooA to bind its target site in a site-specific manner. (B) Schematic models of oxidized $R r$-CooA and CO-bound $\operatorname{RrCooA}$. The C-helix is shown as a light gray rectangular box.

A semi-apo state of the CooA dimer, with a heme-bound monomer in a CO-bound form of Carboxydothermus hydrogenformans CooA structures, reveals a heme and C-helix displacement that supports this model (30). The reduction midpoint potential of ferric CooA with cysteine thiolate as an axial ligand is $-320 \mathrm{mV}$, whereas the heme having histidyl imidazole as an axial ligand shows an oxidation midpoint potential of $-260 \mathrm{mV}$ (259). The difference between the reduction and oxidation midpoint potentials seems to be caused by the redox-controlled ligand exchange of the heme between Cys75 and His77. Since only ferrous CooA binds CO, the low oxidation potential of $\mathrm{CoOA}$ would facilitate the oxidation of the heme to prevent CooA activation in vivo, once $\mathrm{O}_{2}$ is present in the cells. Therefore, $\mathrm{RrCooA}$ is an example wherein the binding of $\mathrm{O}_{2}$ leads to the oxidation of heme iron $\mathrm{Fe}^{3+}$ and the inactivation of the protein function under normoxic conditions. This oxidation links the redox state of the cell to the sensing capability of CooA. Oxidized CooA must be reduced upon anoxia to bind $\mathrm{CO}$ (96).

CooA modulates the expression of the coo regulon, which allows the CO-dependent anaerobic growth of $R$. rubrum (405). The CO oxidation system is encoded by two COregulated transcriptional units, cooMKLXUH and cooFSCTJ. The key products of this regulon are the $\mathrm{O}_{2}$-sensitive $\mathrm{CO}$ dehydrogenase $\mathrm{CooS}$, the $\mathrm{CooS}$-associated $\mathrm{Fe}-\mathrm{S}$ protein $\mathrm{CooF}$, and the CO-tolerant hydrogenase $\mathrm{CooH}$.

2. RcoM. RcoM (regulator of $\mathrm{CO}$ metabolism) is a COsensing transcription factor that undergoes a redox-mediated ligand switch and may utilize redox-active heme to sense the redox state of the cell. It couples an N-terminal Per-Arnt-Sim (PAS) fold (like the mammalian NPAS2 CO sensor) to a Cterminal DNA-binding LytTR domain, but its particular heme ligation characteristics, DNA binding modules, and organization of domains are different from those reported for mammalian sensors (187). In different organisms, it appears to regulate coo (encoding proteins of the $\mathrm{CO}$-oxidizing $\mathrm{H}_{2-}$ producing enzymatic complex) and cox (encoding the aerobic $\mathrm{CO}$ oxidation system) gene expression.

RcoM1 and RcoM2 from B. xenovorans are the most extensively characterized RcoM proteins. Both activate the expression of the coxM gene according to in vivo reporter assays where lac $Z$ is fused to the coxM promoter (187). Similar to the CO-sensing $R$. rubrum CooA, B. xenovorans RcoM-2 undergoes redox-dependent ligand switching and $\mathrm{CO}$-induced ligand displacement. In the $\mathrm{Fe}^{3+}$ oxidation state, the heme is low-spin and six-coordinate with a cysteine (thiolate) as one of the two ligands. The sixth ligand is a histidine (His74), which is present in all states of the protein. Reduction to the $\mathrm{Fe}^{2+}$ oxidation state results in replacement of the cysteine (thiolate) with a neutral thioether ligand, Met104. CO binds to the $\mathrm{Fe}^{2+} B x \mathrm{RcoM}-2$ heme opposite the histidine ligand. Thus, coordination state changes involve redox-dependent loss of a cysteine (thiolate) ligand and displacement of a relatively weakly bound axial ligand by the effector gas molecule (236). Electronic absorption, resonance Raman, and electron paramagnetic resonance spectroscopies have revealed that Cys94 is the distal $\mathrm{Fe}^{3+}$ heme ligand in $B x \mathrm{RcoM}-2$ (344).

In the aforementioned heme proteins, heme exists as a stable and essential prosthetic group. However, recent studies reveal that the function of some proteins is acutely modulated by the reversible binding of heme that acts as a cellular signaling messenger (257). The association/dissociation of the heme iron complex to/from the protein regulates(s) its functions, including catalytic reactions (kinase and proteolysis) or DNA binding. In contrast to heme-based gas sensors wherein gas molecules $\left(\mathrm{O}_{2}\right.$ and $\left.\mathrm{CO}\right)$ bind only to the heme $\mathrm{Fe}^{2+}$ complex, proteins that are regulated by the reversible binding of heme associate/dissociate to the heme $\mathrm{Fe}^{3+}$ complex. Under reducing conditions, a heme-responsive heme sensor can be converted into a heme-based gas sensor (337).

3. Heme sensing by thiol-based switch sensors. Some of the previously described regulators whose mechanism of action relies on a thiol-based switch have also shown the ability to bind heme through redox-sensing cysteines affecting their DNA-binding activity. In these cases, the reversible binding of heme plays a pivotal role in up- and downregulation of transcription factors. Heme-responsive proteins of this type display fast easy heme association and dissociation. They contain a HRM characterized by the presence of a CysPro sequence. The cysteine of the CysPro motif is an axial ligand of $\mathrm{Fe}^{3+}$ heme, but upon reduction, a redox-dependent ligand switch occurs and the cysteine of the CysPro sequence is no longer a ligand of $\mathrm{Fe}^{+2}$-heme (160).

It has been demonstrated for both PpsR and FurA that the binding of heme alters their DNA-binding pattern and inhibits their ability to form higher order complexes with DNA. Cyanobacterial FurA binds heme in the micromolar concentration range and this interaction negatively affects its in vitro DNA binding ability in a concentration-dependent 
manner (144). Cys141, within a CysPro motif or HRM (409), is an axial ligand of the $\mathrm{Fe}^{3+}$ high-spin heme but it does not bind the $\mathrm{Fe}^{2+}$ heme center, suggesting a redox-dependent ligand switch (288). FurA exhibits the typical physicochemical characteristics just described for a heme sensor protein $(160,161)$.

In the case of PpsR, the Cys424 present in its DNA binding domain is critical for heme interaction. The binding of heme changes PpsR-DNA binding pattern, inhibiting the formation of higher order PpsR-DNA complexes and inducing increased transcription of several PpsR regulated genes. This interaction seems to provide a mechanism for bacteria to react to the unbound tetrapyrrole products since in this way excess heme can quickly change the state of photosynthetic gene expression from inhibition to activation (404). Oxidation of Cys424 in the absence of heme stimulates the DNA binding of PpsR. This redox regulation is also observed while heme is present. It appears that Cys 424 could be a versatile target for different types of modification such as forming/ breaking disulfide bridges (239), coordinating heme, and potentially being oxidized into different oxidation states.

One notable difference with FurA is that an Ile residue follows Cys424 instead of Pro, as would be expected for a typical heme-sensing protein. However, PpsR utilizes cysteine as the critical axial residue as is the case for FurA and other HRM-containing heme sensors. Thus it is feasible that Cys coordinated to $\mathrm{Fe}^{2+} / \mathrm{Fe}^{3+}$ in heme is a conserved strategy for heme sensing (404).

\section{F. Sensors of the $N A D^{+} / N A D H$ balance: $R e x$}

Beyond working as a cofactor for oxidoreductase enzymes, $\mathrm{NAD}^{+} / \mathrm{NADH}$ serves as a substrate for a wide range of proteins and provides a direct link between the cellular redox status and the control of signaling and transcriptional events. The ratio of $\mathrm{NAD}^{+}$to NADH inside the cell is mainly affected by substrate availability and $\mathrm{O}_{2}$ tension, driving a set of responses aimed at maintaining redox homeostasis. Modification of this ratio is often used in industrial processes to improve the productivity of certain metabolites $(225,333,410)$.

The main actor that converts the redox signal provided by the $\mathrm{NAD}^{+} / \mathrm{NADH}$ balance into a regulatory input is the tran- scriptional regulator Rex, whose ability to bind DNA is modulated specifically by the $\mathrm{NAD}^{+} / \mathrm{NADH}$ ratio (Fig. 12) (133). Rex has been identified and characterized in archaea and eubacteria regardless of their $\mathrm{O}_{2}$ requirements (154). Overall, Rex is a transcriptional repressor that remains bound to its DNA targets when the $\mathrm{NAD}^{+} / \mathrm{NADH}$ ratio is sufficiently high.

Under microaerobic or anoxic conditions, NADH competitively binds to the Rex C-terminal domain, causing a conformational change of the Rex homodimer and subsequent release from its recognition sites on DNA, allowing transcription of downstream genes. An estimated value of this ratio for transcription derepression has been calculated in S. coelicolor, where the level of NADH has to rise by $\sim 2 \%$ to impair the binding of Rex to DNA $\sim 50 \%$ (133). Further characterization studies of the B. subtilis repressor show that its affinity for $\mathrm{NAD}^{+}$is 20.000 times lower than that for $\mathrm{NADH}$. Interestingly, the affinity for $\mathrm{NAD}^{+}$increased around 30-fold upon DNA binding, suggesting that there is a positive allosteric coupling between DNA binding and $\mathrm{NAD}^{+}$binding (388).

The available crystal structures of Rex in complex with DNA and/or NADH (PDB code 2VT3) indicate that Rex comprises an N-terminal wHTH-fold domain interacting with DNA and a C-terminal Rossmann-fold domain binding NADH and mediating subunit dimerization $(241,339,388)$.

Key domains involved in DNA binding and NAD sensing are broadly conserved in Rex orthologs identified in the phyla Firmicutes, Thermotogales, Actinobacteria, Chloroflexi, Deinococcus-Thermus, and Proteobacteria (302). Similarly, the DNA-binding motifs harbor the conserved consensus TTGTGAANNNNTTCACAA.

In anaerobic bacteria, a different Rex regulation mechanism has been proposed (414), which could be the result of subtle variations in the $\mathrm{NAD}^{+} / \mathrm{NADH}$ binding motifs of the Rex family, such as the substitution of Tyr98 by histidine in the regulator characterized from anaerobes. The Tyr98 residue, highly conserved in aerobic bacteria, has been proposed to play a key role in the switching mechanism between open and closed dimers through the interaction with a conserved Asp residue that is essential for binding DNA. Furthermore, the DNA-binding motifs recognized by anaerobic Rexfamily members exhibit consistent deviations from the

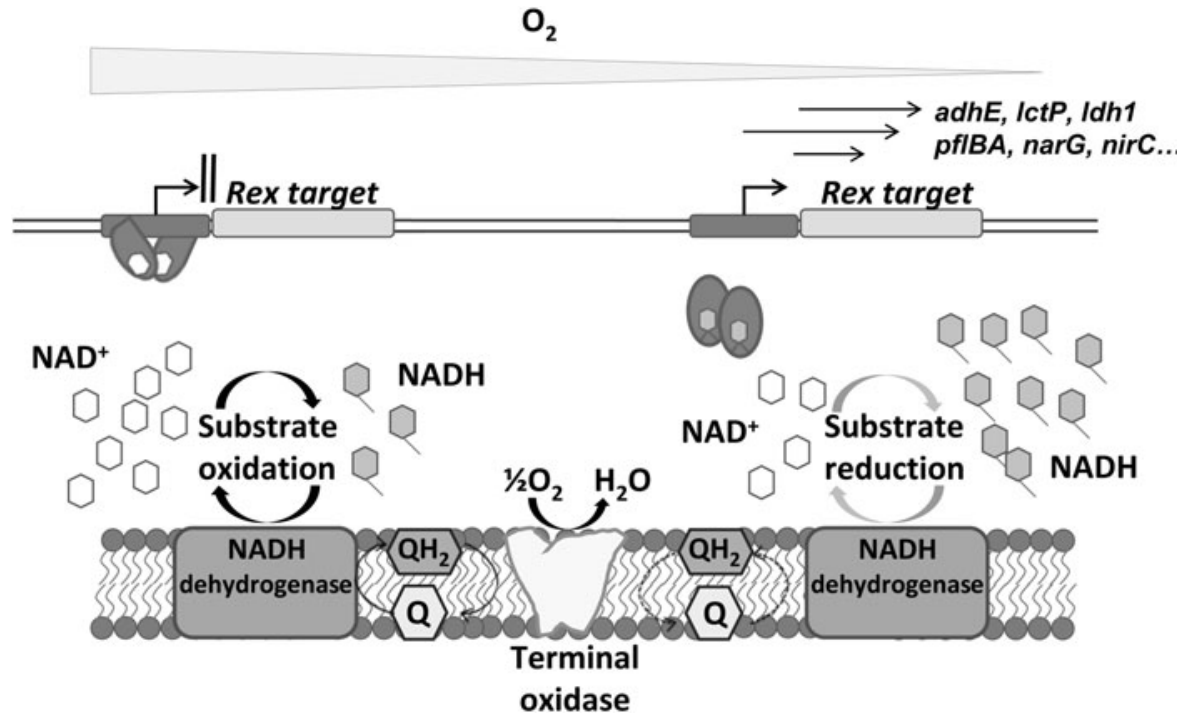

FIG. 12. Modulation of Rex DNA-binding activity in response to the ratio of $\mathrm{NADH} / \mathrm{NAD}^{+}$and its relationship with the respiratory chain [adapted from Green and Paget (133)]. Under aerobic conditions, NADH is rapidly reoxidized and the concentration of $\mathrm{NAD}^{+}$is higher than that of NADH and Rex becomes activated by the binding of $\mathrm{NAD}^{+}$, blocking the transcription of target genes. In contrast, when $\mathrm{O}_{2}$ availability decreases, $\mathrm{NADH}>\mathrm{NAD}^{+}$and Rex repression is relieved, leading to the transcription of its regulon. Q, oxidized quinone; $\mathrm{QH}_{2}$, reduced quinone. 
consensus established for aerobic bacteria $(302,414)$. These substitutions in the operator motifs seem essential for optimal protein-DNA interaction and a settling factor for the different structural bases for $\mathrm{NAD}^{+} / \mathrm{NADH}$ sensing between aerobic and anaerobic Rex proteins.

Rex regulons have been identified in several bacteria, highlighting the importance of this protein in the control of redox homeostasis, central metabolism, or hydrogen production, among other processes $(207,302)$. In Clostridium kluyveri, Rex has been described as a global redox-sensing transcriptional regulator (154). In $S$. aureus, Rex acts as a central regulator of anaerobic metabolism leading to anaerobic $\mathrm{NAD}^{+}$regeneration. Its regulon comprises at least 19 genes, some of them involved in lactate, formate, and ethanol fermentation ( $a d h 1, a d h E, l c t P$, $l d h 1$, and $p f B A$ ) and nitrate respiration (narG, nirC, and nirR) (276). In Streptomyces avermitilis, in addition to regulating aerobic metabolism, Rex also controls avermectin production and morphological differentiation (226). However, a bioinformatic reconstruction of the sets of Rex-regulated genes in 119 genomes from 11 taxonomic groups also revealed remarkable variations in the functional repertoires of candidate Rexregulated genes in various microorganisms (302), most of them being lineage specific.

\section{Two-Component Systems: Redox Control of Sensor Kinase Regulation}

One of the main mechanisms that allow bacteria to overcome changes in the physicochemical parameters of natural environments is the regulation mediated by two-component systems (199). These systems are usually composed of a sensory protein called sensor kinase or $\mathrm{HK}$ and a response regulator (RReg) protein. The sensor kinase is able to sense the signal and as a consequence the protein performs autophosphorylation of a conserved histidine residue located in the HK domain. The phosphate is then transferred to an aspartate residue of the RReg through a process called transphosphorylation. The phosphorylation of the RReg causes its activation and then the RReg binds to promoters of target genes modulating their transcription. However, sometimes the RReg promotes other cellular responses in the cell different to transcriptional modulation. For example, some RRegs contain catalytic domains that once activated by phosphorylation are able to carry out enzymatic activities (111).

Canonical two-component systems perform transphosporylation in one step, whereas phosphorelays work in multistage processes to allow a fine-tune regulation of the system. Phosphorelays are found in nonorthodox two-component systems and in hybrid sensor kinases (199).

Sensor kinases may sense a wide variety of environmental signals including single molecules, such as nitrate or citrate, and more complex signals such as light or gas molecules $\left(\mathrm{O}_{2}\right.$, $\mathrm{CO}$, or NO) $(34,121,184,210)$. In this review, we focus on sensor kinases that perceive redox signals and respond to these signals modulating the transcriptional regulation of the cell. A summary of the two-component systems reviewed in this work can be found in Table 3 .

Table 3. Summary of Two-Component Systems Involved in Redox Sensing

\begin{tabular}{|c|c|c|c|c|c|}
\hline System & Redox signal & $\begin{array}{l}\text { Domain/mechanism } \\
\text { involved in } \\
\text { redox sensing }\end{array}$ & $\begin{array}{l}P D B \\
\text { code }\end{array}$ & Function/some target genes & References \\
\hline FixL-FixJ & $\mathrm{O}_{2}$ & PAS domain heme & 1DP6 & $\begin{array}{l}\text { Nitrogen fixation genes (fix), heme } \\
\text { biosynthetic genes (hem), } \\
\text { denitrification genes (napEDABC, } \\
\text { nirK, norCBDQ, and nosRZDFYLX) } \\
\text { and some hydrogen oxidation genes } \\
\text { (hup). }\end{array}$ & $\begin{array}{l}(85,275 \\
296,308)\end{array}$ \\
\hline DosS-DosR & $\mathrm{O}_{2}, \mathrm{NO}$, and $\mathrm{CO}$ & GAF domain heme & 2W3D & $\operatorname{dev} R S, h s p X, n a r K 2$, and $\operatorname{tgs} 1$ genes. & $(44-46)$ \\
\hline NreB-NreC & & $\begin{array}{l}\text { PAS domain } \\
\text { Fe-S cluster }\end{array}$ & NR & $\begin{array}{l}\text { Nitrate reductase genes (narGHJI), } \\
\text { nitrite reductase genes }(\text { nir } D B)\end{array}$ & $(98,321)$ \\
\hline AirS-AirR & $\mathrm{O}_{2}$ & $\begin{array}{l}\text { GAF domain } \\
\text { Fe-S cluster }\end{array}$ & NR & $\begin{array}{l}\text { saeRS genes, genes encoding stress- } \\
\text { associated factors ( } r s b U \text { and } r s b W \text { ) } \\
\text { and virulence factors (cap5A, spa, } \\
\text { and } h \lg C) \text {. }\end{array}$ & $(137,356)$ \\
\hline $\begin{array}{l}\text { KinA-KinE- } \\
\text { Spo0A }\end{array}$ & NADH/NAD ${ }^{+}$ratio & PAS-A domain & 2VLG & $\begin{array}{l}\text { Genes implicated in sporulation, } \\
\text { colony morphology, and biofilm } \\
\text { development. }\end{array}$ & $(249)$ \\
\hline MmoS-MmoQ & Unknown & PAS domain FAD & 3EWK & sMMO. & (70) \\
\hline ArcB-ArcA & $\begin{array}{l}\text { Redox state of } \\
\text { quinone pool }\end{array}$ & $\begin{array}{l}\text { PAS domain disulfide } \\
\text { bond formation }\end{array}$ & NR & $\begin{array}{l}\text { Genes involved in the TCA cycle, } \\
\text { glyoxylate shunt, and terminal } \\
\text { oxidases. }\end{array}$ & $(227)$ \\
\hline NifL-NifA & $\mathrm{FADH}_{2} / \mathrm{FAD}$ ratio & PAS domain FAD & $2 \mathrm{GJ} 3$ & Nitrogen fixation genes (nif genes). & $(82,148)$ \\
\hline RegB-RegA & $\mathrm{O}_{2}$ /ubiquinone & $\begin{array}{l}\text { Disulfide bond } \\
\text { formation }\end{array}$ & NR & $\begin{array}{l}\text { Genes involved in carbon and nitrogen } \\
\text { fixation, electron transport chain, } \\
\text { photosynthesis, and aerotaxis. }\end{array}$ & $(320)$ \\
\hline PrrB-PrrA & $\begin{array}{l}\text { Redox state of } \\
\text { Cbb3-1 oxydase }\end{array}$ & $\begin{array}{l}\text { Disulfide bond } \\
\text { formation }\end{array}$ & NR & Photosynthetic genes. & $(90)$ \\
\hline
\end{tabular}

FAD, flavin adenine dinucleotide; GAF, cGMP-specific phosphodiesterases, adenylyl cyclases, and FhlA; PAS, Per-Arnt-Sim; sMMO, soluble methane monooxygenase; TCA, tricarboxylic acids. 


\section{A. Indirect redox sensing based on PAS-GAF domains}

The widespread PAS domain functions as a transduction module, acting as a sensor of environmental stimuli such as light, redox state, respiration, $\mathrm{O}_{2}$, and overall energy level of the cells, among others (364). PAS domains are present in both one-component and two-component systems, as well as in many other proteins that may contain an ample range of different domains simultaneously.

The PAS domains have a highly conserved threedimensional structure, although they exhibit low sequence homology. They consist of $\sim 300$ amino acid regions with several imperfect repeats, sometimes associated with a PAS-associated C-terminal motif. These motifs contain a conserved sequence of $\sim 40$ amino acids at the C-terminal of PAS domains, contributing to the correct structure and folding of the PAS (140).

The highly versatile and multipurpose PAS scaffold can bind a broad range of redox ligands, including heme, flavins, and metal ions (140). PAS domains may also determine the specificity of transcriptional factors in modulating the expression of target genes. Some proteins, such as cGMPspecific phosphodiesterases, adenylyl cyclases, and FhlA (GAF), contain domains with a very similar fold to PAS, known as GAF domains (150).

Classification of the PAS-GAF proteins is difficult because tandem and multiple PAS domains are common in individual proteins, and often many other domains are also present; about one-third of PAS proteins contain two or more PAS domains (140). PAS proteins may include simultaneously PAS domains that bind heme, flavin mononucleotide (FMN), flavin adenine dinucleotide (FAD), 4-hydroxycinnamic acid, C3-C4 carboxylic acids (malonate, malate, and succinate), C6 carboxylic acids (citrate), and divalent metal cations. It has also been suggested that fatty acids may play a role as a PAS ligand (192). In any case, PAS domains have evolved as multifunc- tion protein modules and they have very diverse functions, including redox sensing.

1. Redox control of sensor kinase regulation involving metal clusters. Sensor kinases are able to sense the presence of signal molecules by using sensor domains (e.g., TodS or CitA) $(39,303)$, transmembrane domains (e.g., DesK) (72), or even through accessory proteins (e.g., CheA) (273). Redox sensing is conducted mainly by PAS or GAF domains containing cofactors such as heme, iron-sulfur clusters, or FAD and FMN, or using mechanisms based on the oxidation or reduction of cysteine residues. These redox-sensing mechanisms are described in detail hereunder using some model sensor kinases.

a. PAS domain heme: FixL-FixJ two-component system. The FixL-FixJ two-component system is involved in the regulation of nitrogen fixation genes that are tightly controlled by $\mathrm{O}_{2}$ availability. This system has been widely studied in symbiotic bacteria $S$. meliloti and B. japonicum $(121,318)$.

Once the activation of FixL sensor kinase occurs in $S$. meliloti, the RReg FixJ activates the transcription of two transcriptional factors, NifA and FixK, which induce the expression of nif and fix genes involved in nitrogen fixation (2, $75,110,305)$. The expression of these genes must be induced in the developing nodule of symbiotic bacteria when the concentration of $\mathrm{O}_{2}$ remains $<50 \mu M$ (349). In B. japonicum, FixJ activates the transcription of the FixK2 transcriptional regulator whose targets are fixNOPQ and fixGHIS operons (296), heme biosynthetic genes (hemA, hemB, hem $N_{l}$, and $\left.h_{e m N_{2}}\right)(43,102,275)$, denitrification genes (napEDABC, nirK, norCBDQ, and nosRZDFYLX) (77, 243, 308, 380, 381), and some hydrogen oxidation genes (hup) (85).

FixL in S. meliloti (SmFixL) contains four transmembrane regions in the $\mathrm{N}$-terminal domain followed by a PAS domain, a HK domain and an ATPase domain (Fig. 13A) (120, 228).

A

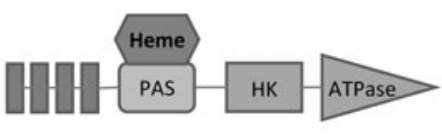

B

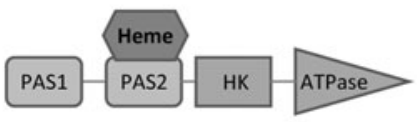

C

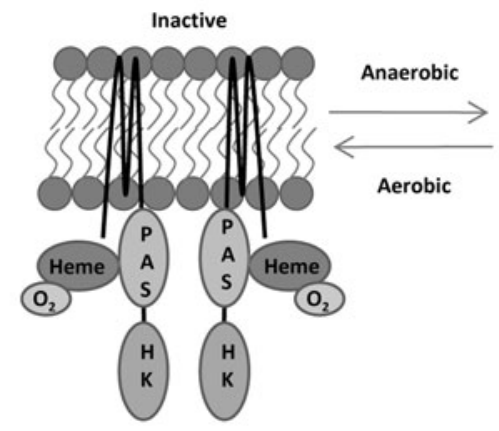

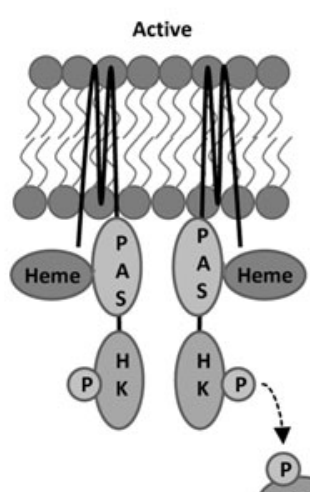

RR
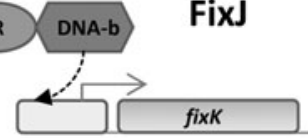

Gene transcriptional regulation
FIG. 13. Sinorhizobium meliloti and Bradyrhizobium japonicum FixL domain architecture and proposed model of action of the FixLFixJ two-component system in S. meliloti. (A) Domain organization in the sensor kinase FixL in S. meliloti and (B) in B. japonicum. (C) Redoxdependent phosphotransfer mechanism in the $S$. meliloti FixL-FixJ two-component system. ATPase, ATPase domain; HK, histidine kinase; PAS, Per-Arnt-Sim; RR, receiver domain. 
In contrast, its ortholog in B. japonicum BjFixL apparently does not contain transmembrane regions (8), but holds two PAS domains and the HK domain (Fig. 13B). SmFixL contains a heme moiety located inside its PAS domain (Fig. 13A) and BjFixL inside its PAS2 domain (Fig. 13B). In SmFixL, heme is noncovalently attached to the His194 of the PAS domain (251).

Biochemical studies revealed that changes in the spin state of $\mathrm{Fe}$ inside the heme moiety can modulate the regulatory effect mediated by the sensor domain (123). The authors proposed that under oxygen-limiting conditions, no $\mathrm{O}_{2}$ was bound to the sensory domain and the heme assumed a highspin state. In this configuration, the autophosphorylation of FixL was allowed, after which FixL phosphorylated FixJ that, in turn, activated the transcription of nifA and fixK genes (Fig. 13C). Conversely, when $\mathrm{O}_{2}$ was bound to heme, the autophosphorylation of FixL was inhibited (Fig. 13C) (122). More recently, a model of an allosteric transduction pathway for SmFixL has been proposed. The authors suggest that the PAS domain undergoes structural changes in the presence of $\mathrm{O}_{2}$ that are transmitted to the $\mathrm{HK}$ domain. In this model, changes in the Tyr201 residue when $\mathrm{O}_{2}$ is dissociated from FixL trigger conformational changes that increase kinase activity and initiate the signaling cascade $(400,401)$.

b. GAF domain heme: DosS-DosR two-component system. DosS-DosR is a two-component system involved in the dormancy process of $M$. tuberculosis. The dormant state of this pathogenic bacterium has been related to anaerobic conditions and $\mathrm{CO}$ or NO presence, since these conditions are found in infected macrophages (202). DosS (also known as DevS) HK contains two GAF domains called GAF-A and GAF-B, followed by a HK domain and an ATPase domain (Fig. 14A). The GAF-A domain contains a heme moiety and GAF-B seems to be essential to the folding of GAF-A in the conformation that allows the inhibition of kinase activity (408). The GAF-A heme domain is able to bind different gas molecules such as $\mathrm{O}_{2}$, NO, and CO $(203,215,317)$.

It has been reported that the hydrogen-bonding network is a key factor in gas molecule recognition. Two amino acids, Tyr171 and Glu87, seem to play an important role in gas discrimination (19). DosS shows kinase activity in $\mathrm{Fe}^{2+}$ deoxy,
$\mathrm{Fe}^{2+}-\mathrm{CO}$, and $\mathrm{Fe}^{3+}-\mathrm{NO}$ forms and has little activity in the $\mathrm{Fe}^{3+}$ and $\mathrm{Fe}^{2+}-\mathrm{O}_{2}$ forms (Fig. 14B) $(165,166)$. The formation of $\mathrm{Fe}^{2+}-\mathrm{O}_{2}$ complex has been described, but other groups have described the oxidation of $\mathrm{Fe}^{2+}$ to $\mathrm{Fe}^{3+}$ when it is exposed to $\mathrm{O}_{2}$ $(54,165,203,285,350)$. In view of these contradictory reports, the detailed mechanism of $\mathrm{O}_{2}$ sensing remains unknown. In contrast, it has been reported that DosS can act as a bifunctional enzyme, showing both kinase and phosphatase activities (185). In response to the availability of $\mathrm{O}_{2}, \mathrm{NO}, \mathrm{CO}$, and ascorbic acid, the DosS-DosR two-component system induces the expression of $\sim 50$ genes $(202,282,336,362)$. The role of DosR in the regulation of $\operatorname{dev} R S, h s p X, \operatorname{narK} 2$, and tgs 1 gene expression, among others, has been investigated (Fig. 14B) (44-46).

c. PAS domain Fe-S cluster: NreB-NreC two-component system. Some sensor kinases use FeS-containing PAS domains to sense changes in $\mathrm{O}_{2}$ tension. NreB sensor kinase is the cognate partner of the NreC RReg, both present in Staphylococcus carnosus and in S. aureus. The NreB-NreC two-component system is able to regulate nitrate/nitrite respiration under $\mathrm{O}_{2}$-limiting conditions (98). S. carnosus grows preferentially by aerobic respiration but nitrate can be used as a terminal electron acceptor in the electron transport chain under anaerobic conditions. Nitrate and nitrite reduction are catalyzed by a membrane-bound nitrate reductase NarG (narGHJI genes) and a cytoplasmic nitrite reductase, respectively $(98,321)$. The expression of both operons is controlled by the NreB-NreC two-component system (98). NreB is a classical sensor kinase containing a PAS domain followed by a HK domain and an ATPase domain (Fig. 15A).

Under anoxic conditions, the PAS domain holds an [4Fe$4 \mathrm{~S}]^{2+}$ iron-sulfur cluster coordinated by four conserved cysteines $(180,255)$. In this configuration, it performs autophosphorylation and transphosphorylation of its RReg NreC. Once activated, this RReg achieves transcriptional regulation (Fig. 15B). In the presence of $\mathrm{O}_{2}$, the $[4 \mathrm{Fe}-4 \mathrm{~S}]^{2+}$ cluster is converted into $[2 \mathrm{Fe}-2 \mathrm{~S}]^{2+}$, which is unstable and becomes degraded (Fig. 15B). Recently, it has been reported that a third protein called NreA interacts with NreB and is involved in the regulation of the NreB phosphorylation level. The NreA crystal structure shows that the protein binds one

A

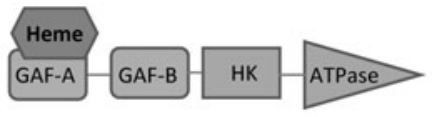

FIG. 14. Mycobacterium tuberculosis DosS domain architecture and proposed model of action of the DosSDosR two-component system. (A) DosR domain organization. (B) Redox-dependent phosphotransfer mechanism in the DosS-DosR twocomponent system from $M$. tuberculosis. GAF, cGMPspecific phosphodiesterases, adenylyl cyclases, and FhlA.

B

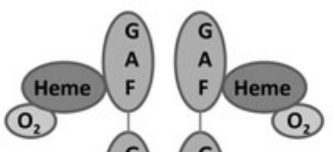

DosS

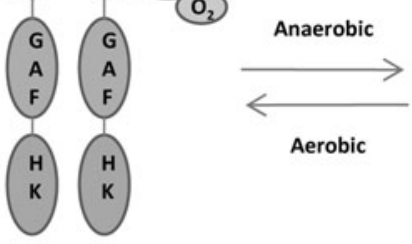

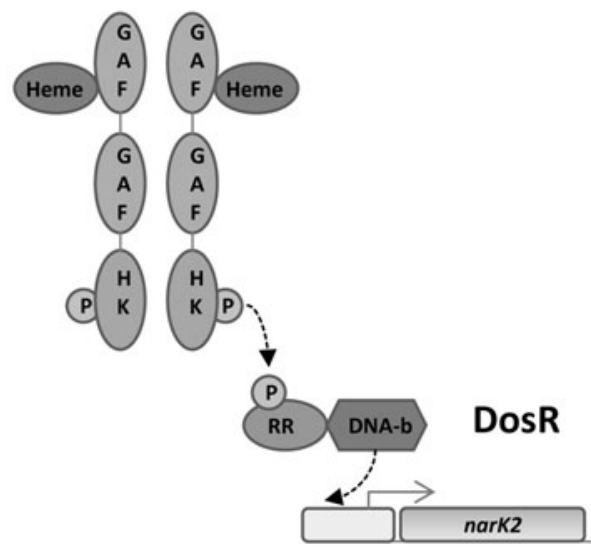

Gene transcriptional regulation 
A

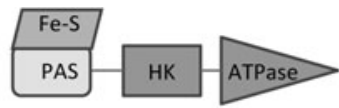

\section{B Iron sulfur cluster}

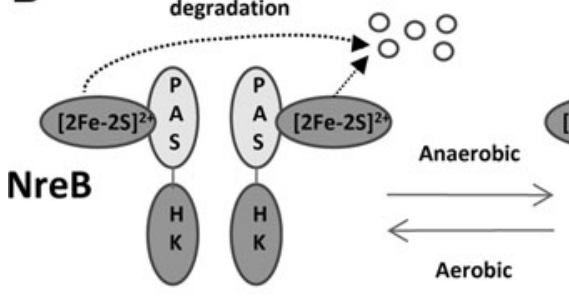

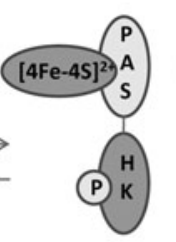
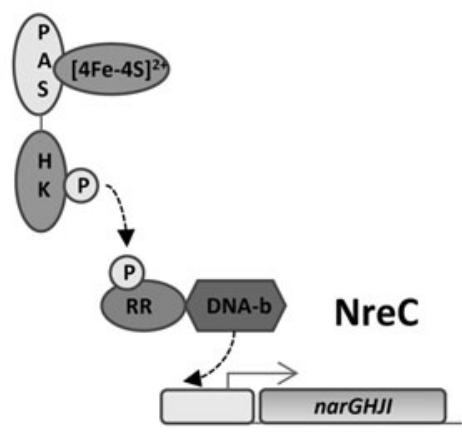

Gene transcriptional regulation
FIG. 15. Staphylococcus carnosus NreB domain architecture and proposed model of action of the NreB-NreC two-component system. (A) NreB domain organization. (B) Redox-dependent phosphotransfer mechanism in the S. carnosus $\mathrm{NreB}-\mathrm{NreC}$ two-component system. molecule of nitrate at its GAF domain. The authors suggested a nitrate $/ \mathrm{O}_{2}$ cosensing by NreA-NreB system as part of what is called the NreABC system $(265,266)$.

d. GAF domain Fe-S cluster: AirS-AirR two-component system. The AirS-AirR two-component system (formerly called YhcS-YhcR) contains an [Fe-S] cluster inside a GAF domain. This system has been described in $S$. aureus and responds to redox signals. AirR regulates directly or indirectly the expression of the Agr two-component system involved in quorum sensing, the two-component system SaeRS implicated in virulence, stress-associated factors (RsbU and RsbW), and virulence factors (Cap5A, Spa, and HlgC) (356). Recently the AirSR system was reported to be involved in the transcriptional regulation of staphyloxanthin production (137).

AirS contains an N-terminal domain that holds the GAF domain followed by the HK domain and the ATPase domain (Fig. 16A). The GAF domain holds a Fe-S cluster-binding motif with four conserved cysteines $\left(\mathrm{Cys}-\mathrm{X}_{7}-\mathrm{Cys} \mathrm{XCys}-\mathrm{X}_{17^{-}}\right.$ Cys). Experiments performed by Sun et al. suggested that the iron-sulfur cluster was critical for AirS autophosphorylation (356). The model proposes that oxidized $[2 \mathrm{Fe}-2 \mathrm{~S}]^{2+}-\mathrm{AirS}$ is the active form that is autophosphorylated and then phosphorylates AirR, stimulating the transcriptional response. Thus the oxidation of $[2 \mathrm{Fe}-2 \mathrm{~S}]^{+}$to $[2 \mathrm{Fe}-2 \mathrm{~S}]^{2+}$ seems to be the signal that initiates the signaling cascade. However, the prolonged exposure to $\mathrm{O}_{2}$ or the presence of strong oxidants such as $\mathrm{H}_{2} \mathrm{O}_{2}$ as well as the presence of NO inhibits the autokinase activity of AirS (Fig. 16B). The authors suggested that these situations may cause overoxidation and loss of the Fe-S cluster, thus inhibiting AirS activity (Fig. 16B) (356).

2. Sensing by NAD-binding PAS domains: KinA-KinESpo0A system. The KinA-KinE-Spo0A system has been described in Gram-positive bacteria such as Bacillus and Clostridium spp. $(155,212,249,352,382)$. This complex

A

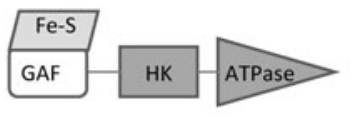

B Fully active

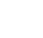

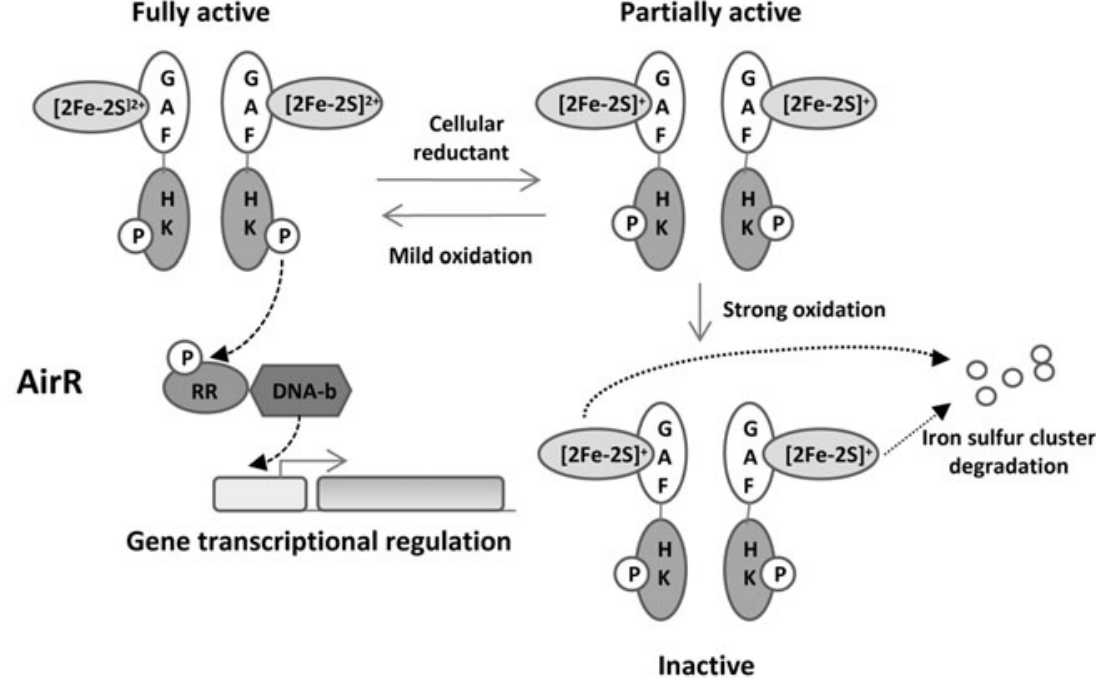

FIG. 16. Staphylococcus aureus AirS domain architecture and proposed model of action of the AirS-AirR two-component system. (A) AirS domain organization. (B) Redox-dependent phosphotransfer mechanism in the $S$. aureus AirS-AirR two-component system. This figure is adapted from Sun et al. (356). 
system is composed of five HKs (KinA-KinE), two intermediary proteins (Spo0F and Spo0B), and one RReg (Spo0A). The regulon of Spo0A comprises $>100$ genes. Among these genes, those deeply implicated in sporulation, colony morphology, and biofilm development can be found (250).

KinA is a cytoplasmic sensor kinase containing three PAS domains called PAS-A, PAS-B, and PAS-C. It has been shown that PAS-A was able to bind $\mathrm{NAD}^{+}$. This binding allowed KinA to sense the intracellular NADH/NAD ${ }^{+}$ratio (195). The authors proposed that KinA is inhibited by $\mathrm{NAD}^{+}$when respiration levels are high. Conversely, when the $\mathrm{NAD}^{+} / \mathrm{NADH}$ ratio decreases (low respiration levels), the kinase is activated, stimulating the Spo0B phosphorylation (195).

3. Flavin-binding PAS-based HK sensors: MmoS-MmoQ two-component system. Flavin-binding PAS domains are abundant in signaling proteins. The redox state of FAD and FMN cofactors senses the redox state of cytoplasm, the electron transfer chains or the visible light perception, and allows a response to readapt the metabolism to new conditions. In the past few years, several FAD/FMN-containing primary redox sensors have been described. These sensors transmit the redox signal to a secondary downstream effector domain or protein. The MmoSMmoQ system constitutes a suitable model for the study of sensor kinases containing an FAD-binding PAS domain.

$\mathrm{MmoS}$ is a sensor kinase that regulates the expression of a soluble methane monooxygenase (sMMO) in a process that depends on copper availability. sMMO catalyzes the oxidation of methane to methanol. This enzyme is found in methanotrophs such as Methylococcus capsulatus (Bath) (222). In this bacterium, the $m m o S$ gene forms an operon with its cognate RReg gene $m m o Q$ that is divergently transcribed to $m m o R$. The working model proposes that MmoS sensor kinase phosphorylates MmoQ, which does not contain DNAbinding domains and it is able to phosphorylate MmoR that finally binds to the target promoters and regulates gene transcription (Fig. 17). Another gene located next to $m m o Q$ called $m m o G$ encodes a putative chaperonine that seems to facilitate the folding of MmoR and/or the sMMO complex (70).
MmoS is a nonorthodox sensor kinase that contains two PAS domains (PAS-A and PAS-B) and a GAF domain followed by a HK domain, two receiver domains and a histidine phosphotransfer domain (Fig. 17A). MmoR is activated by MmoS at low copper levels, activating, in turn, the expression of $m m o X Y B Z$ genes that encode structural genes of sMMO. The PAS domains of MmoS appear not to contain copper ions so that a redox-sensing mechanism has been proposed. This mechanism is based on the idea of MmoS holding a reduced $\mathrm{FADH}_{2}$ at low copper levels. This configuration triggers autophosphorylation in sensor kinase and, in turn, the phosphorylation of MmoR that finally induces the expression of sMMO genes (Fig. 17B). At high concentrations of copper, $\mathrm{FADH}_{2}$ is oxidized to FAD, and a conformational change inhibits the phosphotransfer to MmoR and then the activation of sMMO expression $(70,373)$.

The crystal structure of MmoS was resolved by Ukaegbu and Rosenzweig in 2009 (374). A single FAD molecule was found in the PAS-A domain, which is in agreement with the model proposed by the same authors in 2006 . Nowadays, the redox signal sensed by MmoS remains unknown. Several hypotheses have been proposed such as MmoS direct sensing of copper reduction or indirect sensing via the quinone pool or the copper chelator methanobactin (16). Recent studies suggest that methanobactin together with a polypeptide called MmoD is involved in the copper switch of methanotrophs. This last model proposed that MmoD regulates the transcription of the methanobactin synthesis gene cluster, MmoR and MmoG. Then methanobactin, MmoR and MmoG, interact to induce the expression of the MmoX operon (Fig. 17B). When copper is present, it binds to $\mathrm{MmoD}$, preventing the expression of the methanobactin gene cluster $(81,327)$.

4. Signal modulation by disulfide bond formation: ArcBArcA two-component system. Sometimes sensor kinases sense changes in $\mathrm{O}_{2}$ availability indirectly. In these cases, they are able to sense the redox status of elements that make up part of the electron transport chain such as quinones or cytochrome oxidases and, in turn, activate or repress the

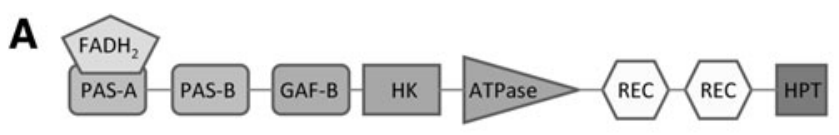

FIG. 17. Methylococcus capsulatus (Bath) MmoS domain architecture and proposed model of action of the MmoS-MmoQ twocomponent system. (A) $\mathrm{MmoS}$ domain organization (B) Redoxdependent phosphotransfer mechanism in the $M$. capsulatus $\mathrm{MmoS}$ MmoQ two-component system. HPT, histidine phosphotransfer domain; REC, receiver domain.

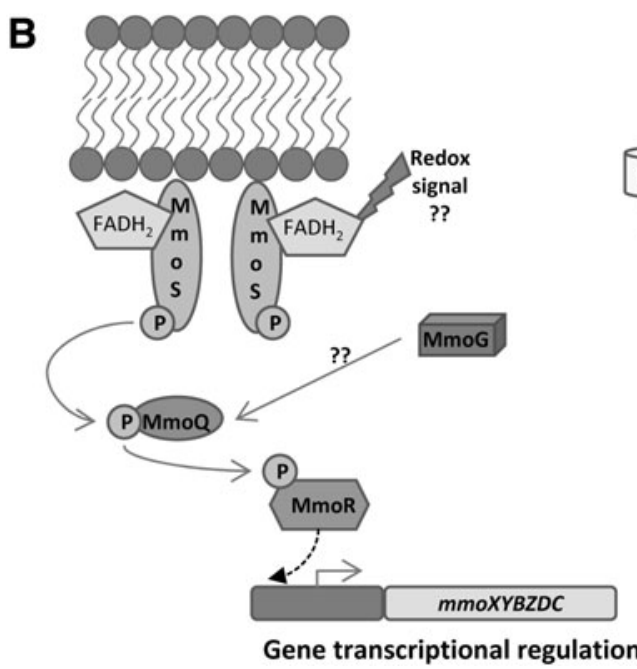

Low cooper::biomass ratio

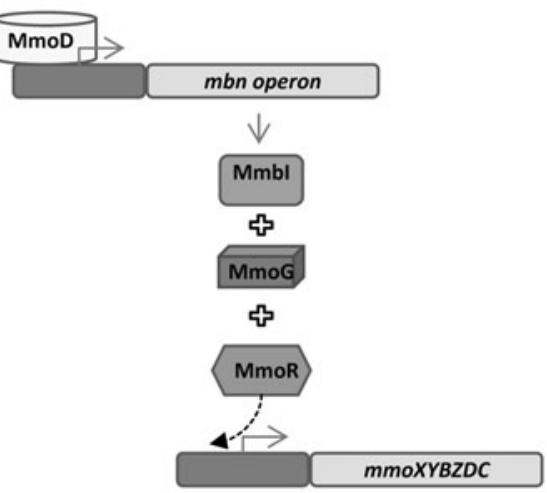

Gene transcriptional regulation 

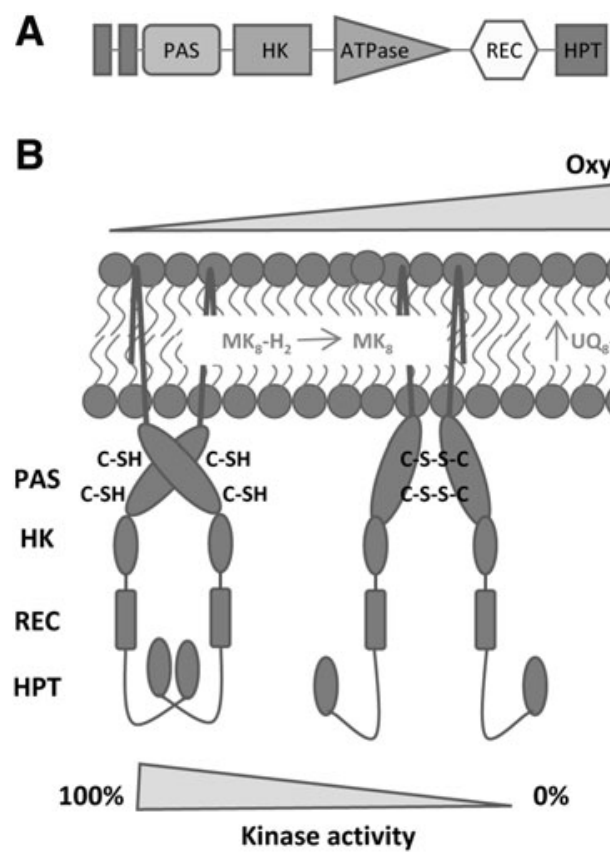

Oxygen
FIG. 18. E. coli ArcB domain architecture and proposed model of action of the ArcB-ArcA twocomponent system. (A) ArcB domain organization. (B) Redoxdependent phosphotransfer mechanism by $\mathrm{ArcB}$ in E. coli. MK8, menaquinone; UQ8, ubiquinone. This figure is adapted from Bekker et al. (23). transcription. These redox molecules/proteins are able to oxidize or reduce some cysteines in sensor kinases, generating the redox switch. An increasing number of sensor kinases that perform this type of indirect redox sensing are being described in the literature. The best characterized examples are ArcB and RegB sensor kinases.

ArcB senses the redox state of the quinone pool by using a complex and delicate mechanism, whereas RegA kinase seems to be able to sense the redox state of the cell by using two different mechanisms. ArcB is addressed in detail hereunder since its redox-sensing mechanism involves PAS domains. However, RegB sensor kinase is included in Section III.B entitled "Non-PAS domain redox sensing based on disulfide bond formation" because although RegB uses a cysteine-based switch, these cysteines are not held in a PAS domain. Indeed, neither RegB nor its ortholog PrrB includes PAS domains in their architecture.

$\mathrm{ArcB}$ is a nonorthodox sensor kinase since it contains a histidine phosphotransfer domain after the receiver domain (Fig. 18A). ArcB also holds a PAS domain in the N-terminal region containing two cysteines, Cys180 and Cys241, which are responsible for autophosphorylation. ArcB has a crucial role in the adaptation of $E$. coli to anaerobic environments (168). This complex transition from aerobic to anaerobic environments in E. coli is coordinated with the FNR, SoxRs, and OxyR redox regulators previously described in this review. The genes regulated by the $\mathrm{ArcB}-\mathrm{ArcA}$ system are mainly involved in respiratory metabolism such as enzymes of the TCA (tricarboxylic acids) cycle, the glyoxylate shunt and terminal oxidases (227). As already stated, anaerobic conditions are sensed by ArcB indirectly.

Autophosphorylation of $\mathrm{ArcB}$ is inhibited by oxidized ubiquinone- 0 and menadione (117). These molecules are soluble analogues of ubiquinone- 8 and menaquinone- 8 . The authors proposed that under anaerobic conditions when the quinone pool was mainly formed by oxidized ubiquinone and menaquinone, the activity of ArcB was silenced. In contrast, when $\mathrm{O}_{2}$ became limited, the quinone pool was transformed into ubiquinol and menaquinol and the autophosphorylation was triggered $(117,233)$.

Afterward, a more sophisticated mechanism of regulation was proposed, in which $\mathrm{ArcB}$ is able to respond to the redox state of the ubiquinone/ubiquinol pool and the menaquinone/ menaquinol pool depending on $\mathrm{O}_{2}$ availability (23). The authors suggested that after a transition from anaerobic $\left(0 \% \mathrm{O}_{2}\right)$ to low aerobiosis conditions $\left(20 \% \mathrm{O}_{2}\right)$, the menaquinone pool is oxidized resulting in the inactivation of ArcB. Upon a shift from low aerobiosis conditions $\left(20 \% \mathrm{O}_{2}\right)$ to high aerobiosis conditions $\left(80 \% \mathrm{O}_{2}\right)$, the total ubiquinone pool increases and, therefore, ubiquinol reduces disulfide bonds and activates ArcB (Fig. 18B). In aerobic conditions, the quinone pool decreases, the oxidation of cysteines occurs, and the inactivation of ArcB takes place (Fig. 18B) (23). Recently, it has been reported that a third type of quinone (demethyl menaquinone) is involved in ArcB phosphorylation modulation. It seems that demethyl menaquinone is also able to oxydize ArcB and that demethyl menaquinol is able to reduce ArcB (376).

In recent years, several sensor kinases such as EvgS, TodS, and HskA have been found that also respond to the redox state of quinone pool although the detailed mechanisms are not as well understood as for $\operatorname{ArcB}(27,330,340)$.

5. Atypical signal transduction PAS-GAF-based mechanisms: NifL-NifA system. The NifL protein in nitrogenfixing organisms senses both the redox and fixed nitrogen status to regulate nitrogen fixation by controlling the activity of the transcriptional activator NifA $(82,148)$.

In Azotobacter vinelandii, NifL contains two N-terminal PAS domains and a $\mathrm{C}$-terminal transmitter region containing a conserved histidine residue ( $\mathrm{H}$ domain) and a GHKL (Gyrase, Hsp90, HK, and MutL) nucleotide-binding domain corresponding to the catalytic core of the HKs. Despite these similarities, NifL does not exhibit kinase activity and regulates its partner NifA by direct protein-protein interactions rather than phosphorylation (223). The amino terminal PAS1 domain of NifL from A. vinelandii accommodates a redox- 
active FAD group; the elevation of cytosolic $\mathrm{O}_{2}$ concentrations results in FAD oxidation and a concomitant conformational rearrangement that is relayed via a short downstream linker to the second PAS domain, PAS2. At PAS2, the signal is amplified and passed on to effector domains generating the "on" (inhibitory) state of the protein (224).

The NifA protein from $A$. vinelandii belongs to a family of enhancer binding proteins that activate transcription by RNAP containing the sigma factor $\sigma^{54}$. These proteins have conserved AAA+ domains that catalyze ATP hydrolysis to drive the conformational changes necessary for open complex formation by $\sigma^{54}$-RNAP (235). The activity of the NifA protein is highly regulated in response to redox and fixed nitrogen through interaction with the antiactivator protein NifL. Binding of NifL to NifA inhibits the ATPase activity of NifA, and this interaction is controlled by the amino-terminal GAF domain of NifA that binds 2-oxoglutarate (348).

\section{B. Non-PAS domain redox sensing based on disulfide bond formation}

1. RegB-RegA two-component system. RegB-RegA in $R$. capsulatus is a two-component system that responds to redox signals and regulates important cellular processes such as carbon and nitrogen fixation, electron transport chain configuration, photosynthesis, and aerotaxis $(87,320,358,397)$.

$\mathrm{RegB}$ protein is a classical sensor kinase that contains five transmembrane regions, a HK domain and an ATPase domain (Fig. 19A). RegB sensor kinase is able to autophosphorylate in the presence of specific redox signals and then phosphorylates its cognate RReg RegA that binds its target promoters activating or inhibiting the transcription. RegB senses redox signals by using the complex mechanism shown in Figure 19B and C.

The RegB HK domain holds a highly conserved quinone binding site GlyGlyXXAsnProPhe and a conserved cysteine in position 265. At high $\mathrm{O}_{2}$ conditions, the Cys 265 forms an intermolecular disulfide bond that inactivates the autophosphorylation activity of RegB. This molecular bond converts the RegB dimers into inactive tetramers (Fig. 19B). In addition, ubiquinone molecules are able to bind to the quinonebinding site of $\mathrm{RegB}$, inhibiting $\mathrm{RegB}$ activity in vitro (Fig. 19C) (359, 398). This second mechanism is independent of Cys265 because a protein mutant lacking this residue maintains the ability to respond to redox changes in the presence of ubiquinone (398). Both mechanisms contribute then to the redox sensing. Moreover, it has also been reported that the sulfenic acid modification at Cys 265 as a consequence of high $\mathrm{O}_{2}$ tension led to inactivation of RegB kinase (399).
FIG. 19. Rhodobacter capsulatus RegB domain architecture and proposed model of action of the RegB-RegA two-component system. (A) $\operatorname{RegB}$ domain organization. (B, C) Redox-dependent phosphotransfer mechanism in the $R$. capsulatus $\operatorname{RegB}-\operatorname{Reg} \mathrm{A}$ twocomponent system. This figure is adapted from $\mathrm{Wu}$ and Bauer (398).
A

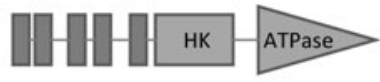

B

RegB

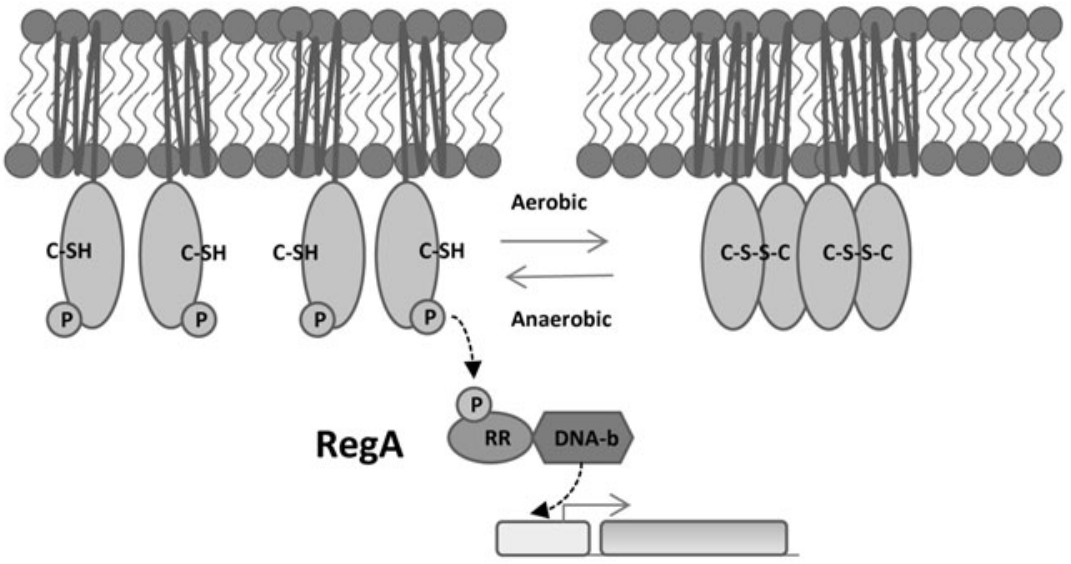

Gene transcriptional regulation

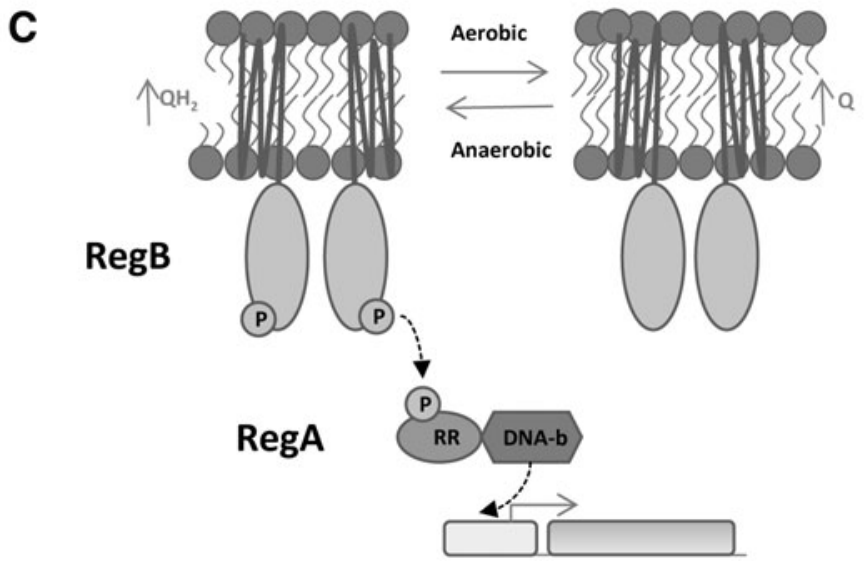

Gene transcriptional regulation 
2. PrrB-PrrA two-component system. A homologue system of RegB-RegA in $R$. capsulatus is the PrrB-PrrA system in $R$. sphaeroides, a purple nonsulfur photosynthetic bacterium with a versatile metabolism, since it is able to grow aerobically, anaerobically, photosynthetically, fermentatively, and lithotrophically (90). The PrB-PrrA two-component system has a pivotal role controlling the expression of photosynthetic genes $(89,214)$, but also regulates directly or indirectly $25 \%$ of the total genes present in $R$. sphaeroides, suggesting that it is a global regulator system (90).

PrrB is a redox sensor whose model of action is based on the Cbb3-1 terminal oxidase redox state, although the underlying mechanism that controls HK activity is unknown (191). The model suggests that Cbb3-1 oxidase generates an inhibitory signal on PrrB sensor kinase under aerobic conditions $(268,269)$. This inhibition of PrrB triggers a silencing of genes related to photosynthesis. Other HKs among the family of RegB and PrrB sensor kinases are ActS in S. meliloti (88) and Agrobacterium tumefaciens (15), and RoxS in $P$. aeruginosa and $P$. putida $(60,100)$. However, in these cases, the redox-sensing mechanisms of both ActS and RoxS sensor kinases remain unknown.

\section{Redox Photosensors Based on Flavins}

There are three main classes of flavin-based photosensors attending to domain receptor type, namely light-oxygenvoltage-sensing (LOV) domains, blue light sensors using FAD (BLUF) domains, and cryptochromes. They regulate many physiological responses to blue light. Changes induced by the light promote conversion between different redox and protonation states of the flavin, which are then coupled to conformational or other changes that signal physiological responses (61). For both the photolyase/cryptochrome and LOV domain photosensors, photoexcitation leads to changes to the flavin that are common in flavin-dependent enzyme reactions: an alteration in the oxidation state of the flavin or the formation of a covalent adduct (119). However, it is not yet clear whether there is a mechanism linking flavin excitation to photoreceptor activation in the BLUF protein family. The formation of a flavin adduct is not involved in BLUF domain activation; therefore, the role of electron transfer and accompanying changes in the flavin redox state remains a subject of controversy (119). A summary of the redox photosensors reviewed in this work can be found in Table 4 .

\section{A. LOV domains, a special class of PAS domains}

LOV domains are ubiquitous regulators of phototropic responses, described as a class of PAS domains that binds FMN or FAD noncovalently (57). LOV domains are present in both chemotrophic and phototrophic bacterial species. They have been found in regulatory domains of sensor HKs, diguanylate cyclases-phosphodiesterases, DNA-binding domains, and regulators of RNAP sigma factors (145). LOV proteins exhibit the typical PAS fold, with a globular $\alpha / \beta$-fold (LOV core) flanked by variable and often helical $\mathrm{N}$ - and $\mathrm{C}$ terminal extensions (140). This kind of domain may be found as a single or multiple domain or associated with additional sensor domains such as GAF, cyclases, and HKs-associated sensory extracellular domains, or other PAS domains (145).

As a consequence of the light signal and changes in the flavin state, a conserved cysteine residue in the LOV domain forms a flavin adduct. Details of the photocycle of this kind of photosensors are extensively discussed in an excellent recent review (231). The LOV domain signaling involves the generation of conformational changes triggered by the conserved photochemistry of the LOV core (61). The mechanism depends on the oligomeric state, structural changes, and the type of effector domain (61). In these processes, blue light induces the unfolding of flanking helices, dimerization, and rotation of the LOV modules (61).

Two major groups of LOV proteins have been described (145). The first group, LOV-HKs, corresponds to $\sim 50 \%$ of bacterial LOV proteins. The second group comprises the socalled LOV-GGDEF-EAL proteins that contain conserved GlyGlyAsp/GluAsp/GluPhe and GluAlaLeu motifs. These domains could participate in metal binding and might form the phosphodiesterase active site. LOV-GGDEF-EAL proteins are predicted to regulate the synthesis and hydrolysis of cyclic di-GMP and constitute $\sim 20 \%$ of bacterial LOV proteins. Other less common LOV signaling proteins include LOV STAS (sulfate transporter anti- $\sigma$ antagonist) proteins ( $\sim 10 \%)$, LOV HTH proteins $(\sim 3.5 \%)$, and the LOV SpoIIE (sporulation stage II protein E) proteins $(\sim 2 \%)$. A small number of LOV proteins with a globin domain, a CheB or CheR chemotaxis domain, or a cyclase 4 domain have also been reported (230).

Several LOV proteins have a specific DNA binding domain, activated by changes in the flavin state. In bacteria, a certain number of LOV proteins with a HTH effector domain have been identified in recent years. However, no bacterial

Table 4. Summary of Redox Photosensors

\begin{tabular}{|c|c|c|c|c|c|}
\hline Protein & Signal & $\begin{array}{l}\text { Domain/family } \\
\text { involved in } \\
\text { redox sensing }\end{array}$ & $P D B$ code & Function/some target genes & References \\
\hline EL222 & Blue light & LOV domain & $3 \mathrm{P} 7 \mathrm{~N}$ & $\begin{array}{l}\text { Radical SAM protein putative pyrimidine } \\
\text { dimer lyase (ELI_05380), putative } \\
\text { indoleamine 2,3-dioxygenase } \\
\text { (ELI_06040), and NAD synthetase } \\
\text { (ELI_08405), among others }\end{array}$ & $(307)$ \\
\hline PpSB1 & Blue light & LOV domain & $5 \mathrm{~J} 3 \mathrm{~W}$ & Photosynthetic genes & $(247)$ \\
\hline YtvA & Blue light & LOV domain & 2MWG & General stress transcription factor $\operatorname{sig} B$ & $(231,272)$ \\
\hline AppA & Blue light and $\mathrm{O}_{2}$ & BLUF domain & 1YRX & Photosynthetic genes & $(246)$ \\
\hline SynCry & Blue light and UVA & Cry-DASH & 1NP7 & Genes involved in PSII repair & $(378)$ \\
\hline
\end{tabular}

BLUF, blue light sensors using FAD; DASH, Drosophila-Arabidopsis-Synechocystis-Homo; LOV, light-oxygen-voltage sensing. 
LOV proteins have been described with a zinc finger DNA binding motif similar to the Neurospora crassa white collar complex. Neither have been described aureochromes (LOV and C-terminal with leucine zipper domain) in bacteria. To date, aureochromes have been detected only in a single group of algae, photosynthetic stramenopiles, but not in any other prokaryotic or eukaryotic organisms (201). However, constructs using this type of domains, LOV and DNAbinding motifs, have been engineered for design experimental approaches based on light-inducible gene regulation (292, 293).

1. LOV/helix-turn-helix DNA-binding proteins. Among the light-regulated transcriptional regulators bearing the LOV domain, there is an interesting class in which the LOV domain is fused to a HTH DNA-binding domain. Although these proteins have been well described in plants and animals, the information for bacteria is scarce. They have been described in the alphaproteobacterium Erythrobacter litoralis (Q2NB98) (307, 415), whereas others have been identified at the genomic level (www.orthodb.org).

In the light-activated EL222 transcription factor from $E$. litoralis, blue light drives conformational changes of the LOV sensor domain and the signal is transmitted to the DNAbinding effector domain (LuxR-type HTH domain) to allow photoactivation of gene transcription (261). The mechanism occurs through changes that induce dimerization, and the dimer then recognizes specific promoters, affecting the transcription of target genes (415). EL222 acts as a light-dependent transcriptional factor. The photochemical reactions of EL222 and the light-sensing properties of the LOV domain have been investigated. Concentration-dependent experiments revealed that the EL-LOV domain is in equilibrium between the dimer and the monomer in the dark state, and the main photoreaction is the dimerization reaction between a monomer in the ground state and that in the excited state (360).

Light-driven allosteric changes are interesting tools to control gene expression or biochemical activities. LOV/HTH proteins have also been proposed as good candidates for the design of light-controlled systems (415).

2. Short-LOV proteins. Several LOV proteins have been identified in bacteria and fungi as so-called "short" LOV proteins composed of a conserved LOV core and N- and/or Cterminal helical extensions. Owing to the absence of fused effector domain(s), the next step in signal propagation in short LOV proteins is expected to involve partner proteins, which remain unidentified (310). Interestingly, the genes encoding PpSB1-LOV (Q88E39) and PPSB2-LOV (Q88JB0) from $P$. putida are contiguous to putative DNA-binding proteins, and they could perhaps represent their molecular partners (230). In $R$. sphaeroides, the short LOV protein, RsLOV, lacking a C-terminal output domain, similarly to PpSB2 in $P$. putida, has been shown to be responsible for controlling the expression of photosynthetic genes (247). "Short" LOV proteins could represent suitable building blocks for the design of genetically encoded photoswitches (i.e., LOVbased optogenetic tools) (301).

3. Phototropins: YtvA (PfyP) and stress response. Phototropins are membrane-associated LOV proteins that usually possess two N-terminal photoactive LOV domains (LOV1 and LOV2) and a C-terminal serine/threonine kinase domain (229). Blue light photoexcitation of the LOV domains results in the receptor autophosphorylation and initiation of the phototropin signaling (56). Phototropins are ubiquitous and they are especially abundant in plants.

YtvA from B. subtilis is one of the more widely studied bacterial phototropines, involved in transcriptional regulation. B. subtilis YtvA acts as a positive regulator of the general stress transcription factor $\sigma^{\mathrm{B}}$, sigB. The $\mathrm{N}$-terminal LOV domain is followed by a STAS, carrying a nucleoside triphosphate binding site $(42,229)$. It is noticeable that the blue light receptor YtvA from B. subtilis is permanently incorporated into the stressosome independent of the illumination state (177). This is consistent with the data observed in Listeria monocytogenes YtvA-like photoreceptor where blue light induces responses via the upregulation of $\sigma^{\mathrm{B}}$. The effect depends on blue light-induced generation of ROS in the medium $(231,272)$.

\section{B. Non-PAS domain photosensors}

1. BLUF domains. BLUF domains are light-triggered switches that control enzyme activity or gene expression in response to blue light, remaining activated for seconds or even minutes after stimulation (283). BLUF was initially described in purple bacteria for its role in photosynthetic gene expression (238). Well-studied BLUF domains are present in proteins such as AppA, PAC-a/PAC-b, BlsA, BlrB, BlrP (YegF), and PixD (61).

The secondary structure of the BLUF domain is dissimilar to those of the PAS domains or DNA photolyases. Furthermore, no significant similarity was found between the fold of its FAD-binding region and those from other FAD-binding protein families (124). For this reason, the BLUF domain was considered a novel FAD-binding domain involved in blue light- or redox-dependent sensory transduction, with a novel FAD-binding fold (124).

BLUF proteins are unique in being the only family of photoreceptors known to show photo-induced protoncoupled electron transfer (283). The photoresponse of BLUF sensing depends on interactions of the flavin with several conserved residues of the domain. Using ultrafast timeresolved infrared spectroscopy to investigate the primary photophysics of the BLUF domain of the light-activated antirepressor AppA, Laptenok et al. established that the electron donor is the Trp104 residue (208). The photocycle is initiated by light causing an electron and then a proton to transfer from the conserved tyrosine to the flavin, yielding a biradical (283). The reaction is not photoreversible, and within $10 \mathrm{~ns}$ the photoexcited state falls back to the signaling state with recombination of the biradical (283).

AppA, a light- and $\mathrm{O}_{2}$-sensor antirepressor from $R$. sphaeroides, is the best characterized BLUF protein (124, 239). It carries a C-terminal sensor containing heme instead of cobalamin (SCHIC) responsible for $\mathrm{O}_{2}$-sensing domain that senses redox conditions. AppA interacts with the transcription repressor PpsR in the dark and AppA modulates DNA binding of PpsR in a ternary complex (393). Previously, Masuda and Bauer (239) suggested that AppA could convert PpsR from an active DNA-binding tetramer to an inactive dimer by reducing a disulfide bond in the PpsR tetramer. Blue light inactivates the DNA-binding activity of the complex so 
gene expression occurs only under suitable conditions of light and redox potential $(283,393)$.

Crystal structures and hydrogen-deuterium exchange of AppA complexed with PpsR suggested that blue light dissociated multimeric AppA-PpsR complex from DNA but did not appreciably alter the affinity of the two protein components. Figure 8 shows the current model for the mechanism of the AppA-PpsR system (393).

BLUF domains are abundant in cyanobacteria, and several AppA homologues are annotated in the cyanobase. The PixD-PixE system is the best studied, as for instance PixD (slr1694) from Synechocystis sp. PCC6803 (119, 271). In this case, PixD lacks the SCHIC C-terminal domain present in AppA, and in fact is a short BLUF protein, with its partner PixE bearing the response regulatory domain. The light-induced change in the PixD-PixE interaction is a crucial part of the early signal transduction process, but the downstream signaling, involving gene expression changes, remains largely unresolved (361). Genome-wide sequencing of mutants has revealed that an uncharacterized Synechocystis gene product (sll2003) may be involved in the signal transduction of phototaxis in response to light intensity (354).

2. Cryptochromes. Cryptochromes are blue light/UVA photoreceptors involved in regulatory processes. They are closely related to photolyases (involved in DNA repair functions, they use light to repair UV-damaged DNA) and form the cryptochrome-photolyase family. Cryptochromes and photolyases bear a conserved $\mathrm{N}$-terminal $\alpha / \beta$ domain and an $\alpha$-helical domain that noncovalently binds an FAD in their catalytic center. The catalytic activity of photolyases requires the FAD to be in its two-electron reduced active state as $\mathrm{FADH}^{-}$(386). The N-terminus might bind other antenna chromophores. Cryptochromes are a relatively heterogeneous group found in different types of organisms, and they are not as well characterized as the photolyases.

Cryptochromes act as photoreceptors and transcriptional regulators, depending on the type of organisms. The classical cryptochromes show high sequence similarity to photolyases, but they lack DNA repair activity and only act as signaling molecules, regulating the circadian clock, growth, or development. However, a distinct group of the classical cryptochromes has been identified. Its homologues were found in diverse organisms (Drosophila sp., Arabidopsis sp., Synechocystis sp., and Homo sapiens) and named cry-DASH (Drosophila-Arabidopsis-Synechocystis-Homo) (378). The most prominent member and initiator of the new group was described in the cyanobacteria Synechocystis (Syn-CRY, encoded by the sll1629 gene), which was the first cryptochrome to be identified from bacteria.

Very few cryptochromes from bacteria have been characterized, and most of them also show photolyase activity. In addition to the Syn-CRY, CryB of $R$. sphaeroides was first described as a cryptochrome that affects light-dependent and singlet oxygen-dependent gene expression (106). Also, $V$. cholerae cryptochrome, VcCry1, has been described as a DASH cryptochome (326). RsCryB exhibits repair activity of [6-4] photoproducts (386), suggesting a dual character combining the functions of cryptochromes and photolyases. Moreover, RsCryB is a close homologue of the photolyase PhrB from A. tumefaciens.
Based on structural data from RsCryB, Geisselbrecht et al. defined a new class of cryptochromes, called CryPro (116). This contains two cofactors only conserved in the CryPro subfamily: 6,7-dimethyl-8-ribityl-lumazine in the antenna-binding domain and a $[4 \mathrm{Fe}-4 \mathrm{~S}]$ cluster within the catalytic domain (116). The key feature of the CryPro subfamily of cryptochromes is a [4Fe4S] cubane cluster in the C-terminal domain, considered characteristic of the bacterial cryptochromes. $\operatorname{cry} B$ transcription of $R$. sphaeroides increases in response to singlet $\mathrm{O}_{2}$, and RsCryB itself affects the regulation of photosynthesis-related genes. Electron paramagnetic resonance spectroscopy has shown that the $[4 \mathrm{Fe}-4 \mathrm{~S}$ ] cluster of RsCryB can readily be oxidized, and thus RsCryB might itself act as a sensor for ROS as a result of photo-oxidative stress. Oxidative changes of the [4Fe-4S] cluster could trigger structural changes of the C-terminal nucleotide-binding domain (116).

\section{Concluding Remarks}

The regulation of redox homeostasis is of paramount importance for the survival of free-living bacteria and species infecting a host. Thus, their ecological success is strongly dependent on the correct performance of a range of transcription factors that trigger the appropriate genetic program in response to different redox signals. Understanding the mechanisms of the different redox-responsive regulators has been hindered by the instability of the redox centers and prosthetic groups that are essential for their activities. It is likely that some of them still remain to be discovered. Moreover, cross talk among several regulators and the diversity of responses displayed against the same signal complicate the identification of their direct gene targets.

Fortunately, in recent decades, the development of novel biophysical tools together with the resolution of the crystal structures of several redox regulators has provided a wealth of knowledge about their response mechanisms. Furthermore, high-throughput transcriptomic analyses have allowed researchers to complete the crossroads of regulatory networks in numerous bacteria. All these data furnish researchers with valuable information that may allow the development of novel drugs and other applications in microbial biotechnology.

\section{Acknowledgments}

The authors acknowledge the support from the Spanish Ministry of Economy, Industry, and Competitiveness (BFU2016-77671-P) and the Government of Aragón-FEDER (B18).

\section{References}

1. Agarwal N, Raghunand TR, and Bishai WR. Regulation of the expression of whiB1 in Mycobacterium tuberculosis: role of cAMP receptor protein. Microbiology 152: 2749-2756, 2006.

2. Agron PG, Ditta GS, and Helinski DR. Oxygen regulation of nifA transcription in vitro. Proc Natl Acad Sci U S A 90: 3506-3510, 1993.

3. Al-Bassam MM, Bibb MJ, Bush MJ, Chandra G, and Buttner MJ. Response regulator heterodimer formation controls a key stage in Streptomyces development. PLoS Genet 10: e1004554, 2014. 
4. Alam MS, Garg SK, and Agrawal P. Molecular function of WhiB4/Rv3681c of Mycobacterium tuberculosis H37Rv: a [4Fe-4S] cluster co-ordinating protein disulphide reductase. Mol Microbiol 63: 1414-1431, 2007.

5. Alam MS, Garg SK, and Agrawal P. Studies on structural and functional divergence among seven WhiB proteins of $M y$ cobacterium tuberculosis H37Rv. FEBS J 276: 76-93, 2009.

6. Antelmann H, Hecker M, and Zuber P. Proteomic signatures uncover thiol-specific electrophile resistance mechanisms in Bacillus subtilis. Expert Rev Proteom 5: 77-90, 2008.

7. Antelmann $\mathrm{H}$ and Helmann JD. Thiol-based redox switches and gene regulation. Antioxid Redox Signal 14: 1049-1063, 2011.

8. Anthamatten D and Hennecke $H$. The regulatory status of the fixL- and fixJ-like genes in Bradyrhizobium japonicum may be different from that in Rhizobium meliloti. Mol Gen Genet 225: 38-48, 1991.

9. Aono S. Biochemical and biophysical properties of the CO-sensing transcriptional activator CooA. Acc Chem Res 36: 825-831, 2003.

10. Aono $S$ and Nakajima H. Structure and function of CooA, a novel transcriptional regulator containing a b-type heme as a CO sensor. Coord Chem Rev 190-192: 267-282, 1999.

11. Aravind L and Landsman D. AT-hook motifs identified in a wide variety of DNA-binding proteins. Nucleic Acids Res 26: 4413-4421, 1998.

12. Aslund F, Zheng M, Beckwith J, and Storz G. Regulation of the OxyR transcription factor by hydrogen peroxide and the cellular thiol-disulfide status. Proc Natl Acad Sci U S A 96: 6161-6165, 1999.

13. Atichartpongkul S, Fuangthong M, Vattanaviboon $P$, and Mongkolsuk S. Analyses of the regulatory mechanism and physiological roles of Pseudomonas aeruginosa OhrR, a transcription regulator and a sensor of organic hydroperoxides. J Bacteriol 192: 2093-2101, 2010.

14. Atichartpongkul S, Vattanaviboon P, Wisitkamol R, Jaroensuk J, Mongkolsuk S, and Fuangthong M. Regulation of organic hydroperoxide stress response by two OhrR homologs in Pseudomonas aeruginosa. PLoS One 11: e0161982, 2016.

15. Baek SH, Hartsock A, and Shapleigh JP. Agrobacterium tumefaciens C58 uses ActR and FnrN to control nirK and nor expression. J Bacteriol 190: 78-86, 2008.

16. Balasubramanian R and Rosenzweig AC. Copper methanobactin: a molecule whose time has come. Curr Opin Chem Biol 12: 245-249, 2008.

17. Ballal A, Ray B, and Manna AC. sarZ, a sarA family gene, is transcriptionally activated by MgrA and is involved in the regulation of genes encoding exoproteins in Staphylococcus aureus. J Bacteriol 191: 1656-1665, 2009.

18. Bang YJ, Lee ZW, Kim D, Jo I, Ha NC, and Choi SH. OxyR2 functions as a three-state redox switch to tightly regulate production of Prx2, a peroxiredoxin of Vibrio vulnificus. J Biol Chem 291: 16038-16047, 2016.

19. Basudhar D, Madrona Y, Yukl ET, Sivaramakrishnan S, Nishida CR, Moënne-Loccoz P, and Ortiz de Montellano PR. Distal hydrogen-bonding interactions in ligand sensing and signaling by Mycobacterium tuberculosis DosS. J Biol Chem 291: 16100-16111, 2016.

20. Bates DM, Popescu CV, Khoroshilova N, Vogt K, Beinert H, Münck E, and Kiley PJ. Substitution of leucine 28 with histidine in the Escherichia coli transcription factor FNR results in increased stability of the $[4 \mathrm{Fe}-4 \mathrm{~S}](2+)$ cluster to oxygen. J Biol Chem 275: 6234-6240, 2000.
21. Beauchene NA, Mettert EL, Moore LJ, Keleş S, Willey $\mathrm{ER}$, and Kiley PJ. $\mathrm{O}_{2}$ availability impacts iron homeostasis in Escherichia coli. Proc Natl Acad Sci U S A 114: 12261-12266, 2017.

22. Beauchene NA, Myers KS, Chung D, Park DM, Weisnicht AM, Keleş S, and Kiley PJ. Impact of anaerobiosis on expression of the iron-responsive Fur and RyhB regulons. mBio 6: e01947-15, 2015.

23. Bekker M, Alexeeva S, Laan W, Sawers G, Teixeira de Mattos J, and Hellingwerf K. The ArcBA two-component system of Escherichia coli is regulated by the redox state of both the ubiquinone and the menaquinone pool. $J$ Bacteriol 192: 746-754, 2010.

24. Bhat SA, Singh N, Trivedi A, Kansal P, Gupta P, and Kumar A. The mechanism of redox sensing in Mycobacterium tuberculosis. Free Radic Biol Med 53: 16251641, 2012.

25. Blaby-Haas CE, Furman R, Rodionov DA, Artsimovitch I, and de Crécy-Lagard V. Role of a Zn-independent DksA in $\mathrm{Zn}$ homeostasis and stringent response. Mol Microbiol 79: 700-715, 2011.

26. Blankschien MD, Potrykus K, Grace E, Choudhary A, Vinella D, Cashel M, and Herman C. TraR, a homolog of a RNAP secondary channel interactor, modulates transcription. PLoS Genet 5: e1000345, 2009.

27. Bock A and Gross R. The unorthodox histidine kinases BvgS and $\mathrm{EvgS}$ are responsive to the oxidation status of a quinone electron carrier. Eur J Biochem 269: 3479-3484, 2002.

28. Bodenmiller DM and Spiro S. The yjeB (nsrR) gene of Escherichia coli encodes a nitric oxide-sensitive transcriptional regulator. J Bacteriol 188: 874-881, 2006.

29. Bonnet M, Kurz M, Mesa S, Briand C, Hennecke H, and Grütter MG. The structure of Bradyrhizobium japonicum transcription factor FixK2 unveils sites of DNA binding and oxidation. J Biol Chem 288: 14238-14246, 2013.

30. Borjigin M, Li H, Lanz ND, Kerby RL, Roberts GP, and Poulos TL. Structure-based hypothesis on the activation of the CO-sensing transcription factor CooA. Acta Crystallogr D Biol Crystallogr 63: 282-287, 2007.

31. Botello-Morte L, Bes MT, Heras B, Fernández-Otal Á, Peleato ML, and Fillat MF. Unraveling the redox properties of the global regulator FurA from Anabaena sp. PCC 7120: disulfide reductase activity based on its CXXC motifs. Antioxid Redox Signal 20: 1396-1406, 2014.

32. Botello-Morte L, Gonzalez A, Bes MT, Peleato ML, and Fillat MF. Functional genomics of metalloregulators in cyanobacteria. In: Genomics of Cyanobacteria. Advances in Botanical Research, Volume 65, edited by Chauvat $\mathrm{F}$ and Cassier-Chauvat C. Chennai, India: Elsevier, 2013, pp. 107-156.

33. Botello-Morte L, Pellicer S, Sein-Echaluce VC, Contreras LM, Neira JL, Abián O, Velázquez-Campoy A, Peleato ML, Fillat MF, and Bes MT. Cysteine mutational studies provide insight into a thiol-based redox switch mechanism of metal and DNA binding in FurA from Anabaena sp. PCC 7120. Antioxid Redox Signal 24: 173-185, 2015.

34. Bott M, Meyer M, and Dimroth P. Regulation of anaerobic citrate metabolism in Klebsiella pneumoniae. Mol Microbiol 18: 533-546, 1995.

35. Branchu P, Matrat S, Vareille M, Garrivier A, Durand A, Crépin S, Harel J, Jubelin G, and Gobert AP. NsrR, GadE, and GadX interplay in repressing expression of the Escherichia coli O157:H7 LEE pathogenicity island in response to nitric oxide. PLoS Pathog 10: e1003874, 2014. 
36. Brenot A, King KY, and Caparon MG. The PerR regulon in peroxide resistance and virulence of Streptococcus pyogenes. Mol Microbiol 55: 221-234, 2005.

37. Brown NL, Stoyanov JV, Kidd SP, and Hobman JL. The MerR family of transcriptional regulators. FEMS Microbiol Rev 27: 145-163, 2003.

38. Burian J, Yim G, Hsing M, Axerio-Cilies P, Cherkasov A, Spiegelman GB, and Thompson CJ. The mycobacterial antibiotic resistance determinant WhiB7 acts as a transcriptional activator by binding the primary sigma factor SigA (RpoV). Nucleic Acids Res 41: 10062-10076, 2013.

39. Busch A, Lacal J, Martos A, Ramos JL, and Krell T. Bacterial sensor kinase TodS interacts with agonistic and antagonistic signals. Proc Natl Acad Sci U S A 104: 13774-13779, 2007.

40. Bush MJ, Chandra G, Bibb MJ, Findlay KC and Buttner MJ. Genome-wide chromatin immunoprecipitation sequencing analysis shows that WhiB is a transcription factor that cocontrols its regulon with WhiA to initiate developmental cell division in Streptomyces. mBio 7: e00523-16, 2016.

41. Butcher J, Sarvan S, Brunzelle JS, Couture JF, and Stintzi A. Structure and regulon of Campylobacter jejuni ferric uptake regulator Fur define apo-Fur regulation. Proc Natl Acad Sci U S A 109: 10047-10052, 2012.

42. Buttani V, Gärtner W, and Losi A. NTP-binding properties of the blue-light receptor YtvA and effects of the E105L mutation. Eur Biophys J 36: 831-839, 2007.

43. Chauhan S and O'Brian MR. Bradyrhizobium japonicum delta-aminolevulinic acid dehydratase is essential for symbiosis with soybean and contains a novel metalbinding domain. J Bacteriol 175: 7222-7227, 1993.

44. Chauhan S and Tyagi JS. Cooperative binding of phosphorylated DevR to upstream sites is necessary and sufficient for activation of the $R v 3134 c-d e v R S$ operon in Mycobacterium tuberculosis: implication in the induction of DevR target genes. J Bacteriol 190: 4301-4312, 2008.

45. Chauhan S and Tyagi JS. Interaction of DevR with multiple binding sites synergistically activates divergent transcription of narK2-Rv1738 genes in Mycobacterium tuberculosis. J Bacteriol 190: 5394-5403, 2008.

46. Chauhan S and Tyagi JS. Powerful induction of divergent tgs1-Rv3131 genes in Mycobacterium tuberculosis is mediated by DevR interaction with a high-affinity site and an adjacent cryptic low-affinity site. J Bacteriol 191: 6075-6081, 2009.

47. Chen PR, Bae T, Williams WA, Duguid EM, Rice PA, Schneewind $\mathrm{O}$, and $\mathrm{He} \mathrm{C}$. An oxidation-sensing mechanism is used by the global regulator MgrA in Staphylococcus aureus. Nat Chem Biol 2: 591-595, 2006.

48. Chen PR, Nishida S, Poor CB, Cheng A, Bae T, Kuechenmeister L, Dunman PM, Missiakas D, and He C. A new oxidative sensing and regulation pathway mediated by the MgrA homologue SarZ in Staphylococcus aureus. Mol Microbiol 71: 198-211, 2009.

49. Cheng Z, Wu J, Setterdahl A, Reddie K, Carroll K, Hammad LA, Karty JA, and Bauer CE. Activity of the tetrapyrrole regulator $\mathrm{CrtJ}$ is controlled by oxidation of a redox active cysteine located in the DNA binding domain. Mol Microbiol 85: 734-746, 2012.

50. Chhabra $\mathrm{S}$ and Spiro S. Inefficient translation of $n s r R$ constrains behaviour of the NsrR regulon in Escherichia coli. Microbiology 161: 2029-2038, 2015.

51. Chi BK, Albrecht D, Gronau K, Becher D, Hecker M, and Antelmann $\mathrm{H}$. The redox-sensing regulator YodB senses quinones and diamide via a thiol-disulfide switch in $B a$ cillus subtilis. Proteomics 10: 3155-3164, 2010.

52. Chi BK, Gronau K, Mäder U, Hessling B, Becher D, and Antelmann H. S-bacillithiolation protects against hypochlorite stress in Bacillus subtilis as revealed by transcriptomics and redox proteomics. Mol Cell Proteomics 10: M111.009506, 2011.

53. Chi BK, Kobayashi K, Albrecht D, Hecker M, and Antelmann H. The paralogous MarR/DUF24-family repressors YodB and CatR control expression of the catechol dioxygenase CatE in Bacillus subtilis. J Bacteriol 192: 4571-4581, 2010.

54. Cho HY, Cho HJ, Kim YM, Oh JI, and Kang BS. Structural insight into the heme-based redox sensing by DosS from Mycobacterium tuberculosis. J Biol Chem 284: 13057-13067, 2009.

55. Choi H, Kim S, Mukhopadhyay P, Cho S, Woo J, Storz G, and Ryu SE. Structural basis of the redox switch in the OxyR transcription factor. Cell 105: 103-113, 2001.

56. Christie JM. Phototropin blue-light receptors. Annu Rev Plant Biol 58: 21-45, 2007.

57. Christie JM, Salomon M, Nozue K, Wada M, and Briggs WR. LOV (light, oxygen, or voltage) domains of the bluelight photoreceptor phototropin (nph1): binding sites for the chromophore flavin mononucleotide. Proc Natl Acad Sci U S A 96: 8779-8783, 1999.

58. Christman MF, Morgan RW, Jacobson FS, and Ames BN. Positive control of a regulon for defenses against oxidative stress and some heat-shock proteins in Salmonella typhimurium. Cell 41: 753-762, 1985.

59. Chumsakul O, Anantsri DP, Quirke T, Oshima T, Nakamura K, Ishikawa S, and Nakano MM. Genome-wide analysis of ResD, NsrR, and Fur binding in Bacillus subtilis during anaerobic fermentative growth by in vivo footprinting. J Bacteriol 199: e00086-17, 2017.

60. Comolli JC and Donohue TJ. Pseudomonas aeruginosa RoxR, a response regulator related to Rhodobacter sphaeroides PrrA, activates expression of the cyanide-insensitive terminal oxidase. Mol Microbiol 45: 755-768, 2002.

61. Conrad KS, Manahan CC, and Crane BR. Photochemistry of flavoprotein light sensors. Nat Chem Biol 10: 801-809, 2014.

62. Crack JC, den Hengst CD, Jakimowicz P, Subramanian S, Johnson MK, Buttner MJ, Thomson AJ, and Le Brun NE. Characterization of $[4 \mathrm{Fe}-4 \mathrm{~S}]$-containing and cluster-free forms of Streptomyces WhiD. Biochemistry 48: 1225212264, 2009.

63. Crack JC, Green J, Cheesman MR, Le Brun NE, and Thomson AJ. Superoxide-mediated amplification of the oxygen-induced switch from [4Fe-4S] to [2Fe-2S] clusters in the transcriptional regulator FNR. Proc Natl Acad Sci U S A 104: 2092-2097, 2007.

64. Crack JC, Green J, Thomson AJ, and Le Brun NE. Ironsulfur cluster sensor-regulators. Curr Opin Chem Biol 16: 35-44, 2012.

65. Crack JC, Green J, Thomson AJ, and Le Brun NE. Ironsulfur clusters as biological sensors: the chemistry of reactions with molecular oxygen and nitric oxide. Acc Chem Res 47: 3196-3205, 2014.

66. Crack JC, Munnoch J, Dodd EL, Knowles F, Al Bassam MM, Kamali S, Holland AA, Cramer SP, Hamilton CJ, Johnson MK, Thomson AJ, Hutchings MI, and Le Brun NE. NsrR from Streptomyces coelicolor is a nitric oxidesensing [4Fe-4S] cluster protein with a specialized regulatory function. J Biol Chem 290: 12689-12704, 2015. 
67. Crack JC, Smith LJ, Stapleton MR, Peck J, Watmough NJ, Buttner MJ, Buxton RS, Green J, Oganesyan VS, Thomson AJ, and Le Brun NE. Mechanistic insight into the nitrosylation of the [4Fe-4S] cluster of WhiB-like proteins. J Am Chem Soc 133: 1112-1121, 2011.

68. Crawford MA, Tapscott T, Fitzsimmons LF, Liu L, Reyes AM, Libby SJ, Trujillo M, Fang FC, Radi R, and Vázquez-Torres A. Redox-active sensing by bacterial DksA transcription factors is determined by cysteine and zinc content. mBio 7: e02161-15, 2016.

69. Cruz-Ramos H, Crack J, Wu G, Hughes MN, Scott C, Thomson AJ, Green J, and Poole RK. NO sensing by FNR: regulation of the Escherichia coli NO-detoxifying flavohaemoglobin, Hmp. EMBO J 21: 3235-3244, 2002.

70. Csáki R, Bodrossy L, Klem J, Murrell JC, and Kovács KL. Genes involved in the copper-dependent regulation of soluble methane monooxygenase of Methylococcus capsulatus (Bath): cloning, sequencing and mutational analysis. Microbiology 149: 1785-1795, 2003.

71. Culotta VC and Daly MJ. Manganese complexes: diverse metabolic routes to oxidative stress resistance in prokaryotes and yeast. Antioxid Redox Signal 19: 933-944, 2013.

72. Cybulski LE, del Solar G, Craig PO, Espinosa M, and de Mendoza D. Bacillus subtilis DesR functions as a phosphorylation-activated switch to control membrane lipid fluidity. J Biol Chem 279: 39340-39347, 2004.

73. D'Autréaux B and Toledano MB. ROS as signalling molecules: mechanisms that generate specificity in ROS homeostasis. Nat Rev Mol Cell Biol 8: 813-824, 2007.

74. Dalebroux ZD, Yagi BF, Sahr T, Buchrieser C, and Swanson MS. Distinct roles of ppGpp and DksA in Legionella pneumophila differentiation. Mol Microbiol 76: 200-219, 2010.

75. David M, Daveran ML, Batut J, Dedieu A, Domergue O, Ghai J, Hertig C, Boistard P, and Kahn D. Cascade regulation of nif gene expression in Rhizobium meliloti. Cell 54: 671-683, 1988.

76. Davis NK and Chater KF. The Streptomyces coelicolor whiB gene encodes a small transcription factor-like protein dispensable for growth but essential for sporulation. Mol Gen Genet 232: 351-358, 1992.

77. Delgado MJ, Bonnard N, Tresierra-Ayala A, Bedmar EJ, and Müller P. The Bradyrhizobium japonicum napEDABC genes encoding the periplasmic nitrate reductase are essential for nitrate respiration. Microbiology 149: 33953403, 2003.

78. Demple B. Redox signaling and gene control in the Escherichia coli SoxRS oxidative stress regulon-a review. Gene 179: 53-57, 1996.

79. Dietrich LE, Price-Whelan A, Petersen A, Whiteley M, and Newman DK. The phenazine pyocyanin is a terminal signalling factor in the quorum sensing network of Pseudomonas aeruginosa. Mol Microbiol 61: 1308-1321, 2006.

80. Ding H, Hidalgo E, and Demple B. The redox state of the [2Fe-2S] clusters in SoxR protein regulates its activity as a transcription factor. J Biol Chem 271: 33173-33175, 1996.

81. DiSpirito AA, Semrau JD, Murrell JC, Gallagher WH, Dennison C, and Vuilleumier S. Methanobactin and the link between copper and bacterial methane oxidation. Microbiol Mol Biol Rev 80: 387-409, 2016.

82. Dixon R. The oxygen-responsive NIFL-NIFA complex: a novel two-component regulatory system controlling nitrogenase synthesis in gamma-proteobacteria. Arch Microbiol 169: 371-380, 1998.
83. Drazic A, Miura H, Peschek J, Le Y, Bach NC, Kriehuber $\mathrm{T}$, and Winter J. Methionine oxidation activates a transcription factor in response to oxidative stress. Proc Natl Acad Sci U S A 110: 9493-9498, 2013.

84. Dubbs JM and Mongkolsuk S. Peroxide-sensing transcriptional regulators in bacteria. J Bacteriol 194: 54955503, 2012.

85. Durmowicz MC and Maier RJ. The FixK2 protein is involved in regulation of symbiotic hydrogenase expression in Bradyrhizobium japonicum. J Bacteriol 180: $3253-$ 3256, 1998.

86. Edwards J, Cole LJ, Green JB, Thomson MJ, Wood AJ, Whittingham JL, and Moir JW. Binding to DNA protects Neisseria meningitidis fumarate and nitrate reductase regulator (FNR) from oxygen. J Biol Chem 285: 1105$1112,2010$.

87. Elsen S, Swem LR, Swem DL, and Bauer CE. RegB/ RegA, a highly conserved redox-responding global twocomponent regulatory system. Microbiol Mol Biol Rev 68: 263-279, 2004.

88. Emmerich R, Hennecke H, and Fischer HM. Evidence for a functional similarity between the two-component regulatory systems RegSR, ActSR, and RegBA (PrrBA) in alpha-proteobacteria. Arch Microbiol 174: 307-313, 2000.

89. Eraso JM and Kaplan S. prrA, a putative response regulator involved in oxygen regulation of photosynthesis gene expression in Rhodobacter sphaeroides. J Bacteriol 176: 32-43, 1994

90. Eraso JM, Roh JH, Zeng X, Callister SJ, Lipton MS, and Kaplan S. Role of the global transcriptional regulator PrrA in Rhodobacter sphaeroides 2.4.1: combined transcriptome and proteome analysis. J Bacteriol 190: 48314848, 2008.

91. Esbelin J, Jouanneau Y, and Duport C. Bacillus cereus Fnr binds a [4Fe-4S] cluster and forms a ternary complex with ResD and PlcR. BMC Microbiol 12: 125, 2012.

92. Escolar L, Pérez-Martín J, and de Lorenzo V. Opening the iron box: transcriptional metalloregulation by the Fur protein. J Bacteriol 181: 6223-6229, 1999.

93. Even S, Burguière P, Auger S, Soutourina O, Danchin A, and Martin-Verstraete I. Global control of cysteine metabolism by CymR in Bacillus subtilis. J Bacteriol 188: 2184-2197, 2006.

94. Ezraty B, Gennaris A, Barras F, and Collet JF. Oxidative stress, protein damage and repair in bacteria. Nat Rev Microbiol 15: 385-396, 2017.

95. Fan SW, George RA, Haworth NL, Feng LL, Liu JY, and Wouters MA. Conformational changes in redox pairs of protein structures. Protein Sci 18: 1745-1765, 2009.

96. Farhana A, Saini V, Kumar A, Lancaster JR, Jr., and Steyn AJ. Environmental heme-based sensor proteins: implications for understanding bacterial pathogenesis. Antioxid Redox Signal 17: 1232-1245, 2012.

97. Farr SB and Kogoma T. Oxidative stress responses in Escherichia coli and Salmonella typhimurium. Microbiol Rev 55: 561-585, 1991.

98. Fedtke I, Kamps A, Krismer B, and Götz F. The nitrate reductase and nitrite reductase operons and the narT gene of Staphylococcus carnosus are positively controlled by the novel two-component system NreBC. J Bacteriol 184: 6624-6634, 2002.

99. Feeney MA, Chandra G, Findlay KC, Paget MSB, and Buttner MJ. Translational control of the SigR-directed oxidative stress response in Streptomyces via IF3- 
mediated repression of a noncanonical GTC start codon. mBio 8: e00815-17, 2017.

100. Fernández-Piñar R, Ramos JL, Rodríguez-Herva JJ, and Espinosa-Urgel M. A two-component regulatory system integrates redox state and population density sensing in Pseudomonas putida. J Bacteriol 190: 7666-7674, 2008.

101. Fillat MF. The FUR (ferric uptake regulator) superfamily: diversity and versatility of key transcriptional regulators. Arch Biochem Biophys 546: 41-52, 2014.

102. Fischer HM, Velasco L, Delgado MJ, Bedmar EJ, Schären $\mathrm{S}$, Zingg D, Göttfert $\mathrm{M}$, and Hennecke $\mathrm{H}$. One of two hemN genes in Bradyrhizobium japonicum is functional during anaerobic growth and in symbiosis. $J$ Bacteriol 183: 1300-1311, 2001.

103. Fleischhacker AS, Stubna A, Hsueh KL, Guo Y, Teter SJ, Rose JC, Brunold TC, Markley JL, Münck E, and Kiley PJ. Characterization of the [2Fe-2S] cluster of Escherichia coli transcription factor IscR. Biochemistry 51: 44534462, 2012.

104. Flynn JM, Neher SB, Kim YI, Sauer RT, and Baker TA. Proteomic discovery of cellular substrates of the ClpXP protease reveals five classes of ClpX-recognition signals. Mol Cell 11: 671-683, 2003.

105. Fowler-Goldsworthy K, Gust B, Mouz S, Chandra G, Findlay KC, and Chater KF. The actinobacteria-specific gene wblA controls major developmental transitions in Streptomyces coelicolor A3(2). Microbiology 157: 13121328, 2011.

106. Frühwirth S, Teich K, and Klug G. Effects of the cryptochrome CryB from Rhodobacter sphaeroides on global gene expression in the dark or blue light or in the presence of singlet oxygen. PloS One 7: e33791, 2012.

107. Fuangthong $\mathrm{M}$ and Helmann JD. The OhrR repressor senses organic hydroperoxides by reversible formation of a cysteine-sulfenic acid derivative. Proc Natl Acad Sci U S A 99: 6690-6695, 2002.

108. Fujikawa M, Kobayashi K, Tsutsui Y, Tanaka T, and Kozawa T. Rational tuning of superoxide sensitivity in SoxR, the [2Fe-2S] transcription factor: implications of species-specific lysine residues. Biochemistry 56: 403410, 2017.

109. Furman R, Biswas T, Danhart EM, Foster MP, Tsodikov $\mathrm{OV}$, and Artsimovitch I. DksA2, a zinc-independent structural analog of the transcription factor DksA. FEBS Lett 587: 614-619, 2013.

110. Galinier A, Garnerone AM, Reyrat JM, Kahn D, Batut J, and Boistard P. Phosphorylation of the Rhizobium meliloti FixJ protein induces its binding to a compound regulatory region at the fixK promoter. J Biol Chem 269: 2378423789, 1994.

111. Gao R, Mack TR, and Stock AM. Bacterial response regulators: versatile regulatory strategies from common domains. Trends Biochem Sci 32: 225-234, 2007.

112. Garg S, Alam MS, Bajpai R, Kishan KR, and Agrawal P. Redox biology of Mycobacterium tuberculosis H37Rv: protein-protein interaction between GlgB and WhiB1 involves exchange of thiol-disulfide. BMC Biochem 10: 1, 2009.

113. Garnica OA, Das K, and Dhandayuthapani S. OhrR of Mycobacterium smegmatis senses and responds to intracellular organic hydroperoxide stress. Sci rep 7: 3922, 2017.

114. Gebendorfer KM, Drazic A, Le Y, Gundlach J, Bepperling A, Kastenmüller A, Ganzinger KA, Braun N, Franzmann $\mathrm{TM}$, and Winter J. Identification of a hypochlorite-specific transcription factor from Escherichia coli. J Biol Chem 287: 6892-6903, 2012.

115. Geiman DE, Raghunand TR, Agarwal N, and Bishai WR. Differential gene expression in response to exposure to antimycobacterial agents and other stress conditions among seven Mycobacterium tuberculosis whiB-like genes. Antimicrob Agents Chemother 50: 2836-2841, 2006.

116. Geisselbrecht Y, Frühwirth S, Schroeder C, Pierik AJ, Klug G, and Essen LO. CryB from Rhodobacter sphaeroides: a unique class of cryptochromes with new cofactors. EMBO Rep 13: 223-229, 2012.

117. Georgellis D, Kwon O, and Lin EC. Quinones as the redox signal for the arc two-component system of bacteria. Science 292: 2314-2316, 2001.

118. Giel JL, Rodionov D, Liu M, Blattner FR, and Kiley PJ. IscR-dependent gene expression links iron-sulphur cluster assembly to the control of $\mathrm{O}_{2}$-regulated genes in Escherichia coli. Mol Microbiol 60: 1058-1075, 2006.

119. Gil AA, Laptenok SP, Iuliano JN, Lukacs A, Verma A, Hall CR, Yoon GE, Brust R, Greetham GM, Towrie M, French JB, Meech SR, and Tonge PJ. Photoactivation of the BLUF protein PixD probed by the site-specific incorporation of fluorotyrosine residues. J Am Chem Soc 139: 14638-14648, 2017.

120. Gilles-Gonzalez MA and Gonzalez G. Regulation of the kinase activity of heme protein FixL from the twocomponent system FixL/FixJ of Rhizobium meliloti. J Biol Chem 268: 16293-16297, 1993.

121. Gilles-Gonzalez MA and Gonzalez G. Heme-based sensors: defining characteristics, recent developments, and regulatory hypotheses. J Inorg Biochem 99: 1-22, 2005.

122. Gilles-González MA, González G, and Perutz MF. Kinase activity of oxygen sensor FixL depends on the spin state of its heme iron. Biochemistry 34: 232-236, 1995.

123. Gilles-Gonzalez MA, Gonzalez G, Perutz MF, Kiger L, Marden MC, and Poyart C. Heme-based sensors, exemplified by the kinase FixL, are a new class of heme protein with distinctive ligand binding and autoxidation. Biochemistry 33: 8067-8073, 1994.

124. Gomelsky M and Klug G. BLUF: a novel FAD-binding domain involved in sensory transduction in microorganisms. Trends Biochem Sci 27: 497-500, 2002.

125. González A, Angarica VE, Sancho J, and Fillat MF. The FurA regulon in Anabaena sp. PCC 7120: in silico prediction and experimental validation of novel target genes. Nucleic Acids Res 42: 4833-4846, 2014.

126. González A, Bes MT, Barja F, Peleato ML, and Fillat MF. Overexpression of FurA in Anabaena sp. PCC 7120 reveals new targets for this regulator involved in photosynthesis, iron uptake and cellular morphology. Plant Cell Physiol 51: 1900-1914, 2010.

127. González A, Bes MT, Peleato ML, and Fillat MF. Unravelling the regulatory function of FurA in Anabaena sp. PCC 7120 through 2-D DIGE proteomic analysis. $J$ Proteom 74: 660-671, 2011.

128. González A, Bes MT, Peleato ML, and Fillat MF. Expanding the role of FurA as essential global regulator in cyanobacteria. PLoS One 11: e0151384, 2016.

129. González A, Valladares A, Peleato ML, and Fillat MF. FurA influences heterocyst differentiation in Anabaena sp. PCC 7120. FEBS Lett 587: 2682-2690, 2013.

130. Gopalkrishnan S, Ross W, Chen AY, and Gourse RL. TraR directly regulates transcription initiation by mimicking the combined effects of the global regulators DksA 
and ppGpp. Proc Natl Acad Sci U S A 114: E5539-E5548, 2017.

131. Gray MJ, Li Y, Leichert LI, Xu Z, and Jakob U. Does the transcription factor NemR use a regulatory sulfenamide bond to sense bleach? Antioxid Redox Signal 23: 747-754, 2015.

132. Gray MJ, Wholey WY, Parker BW, Kim M, and Jakob U. NemR is a bleach-sensing transcription factor. J Biol Chem 288: 13789-13798, 2013.

133. Green J and Paget MS. Bacterial redox sensors. Nat Rev Microbiol 2: 954-966, 2004.

134. Green J, Rolfe MD, and Smith LJ. Transcriptional regulation of bacterial virulence gene expression by molecular oxygen and nitric oxide. Virulence 5: 794-809, 2014.

135. Greenberg JT, Monach P, Chou JH, Josephy PD, and Demple B. Positive control of a global antioxidant defense regulon activated by superoxide-generating agents in Escherichia coli. Proc Natl Acad Sci U S A 87: 6181-6185, 1990.

136. Gruner I, Frädrich C, Böttger LH, Trautwein AX, Jahn D, and Härtig E. Aspartate 141 is the fourth ligand of the oxygen-sensing [4Fe-4S] ${ }^{2+}$ cluster of Bacillus subtilis transcriptional regulator Fnr. J Biol Chem 286: 2017-2021, 2011.

137. Hall JW, Yang J, Guo H, and Ji Y. The Staphylococcus aureus AirSR two-component system mediates reactive oxygen species resistance via transcriptional regulation of staphyloxanthin production. Infect Immun 85: pii: e00838-16, 2017.

138. Henard CA, Bourret TJ, Song M, and Vázquez-Torres A. Control of redox balance by the stringent response regulatory protein promotes antioxidant defenses of Salmonella. J Biol Chem 285: 36785-36793, 2010.

139. Henard CA, Tapscott T, Crawford MA, Husain M, Doulias PT, Porwollik S, Liu L, McClelland M, Ischiropoulos $\mathrm{H}$, and Vázquez-Torres $\mathrm{A}$. The 4-cysteine zinc-finger motif of the RNA polymerase regulator DksA serves as a thiol switch for sensing oxidative and nitrosative stress. Mol Microbiol 91: 790-804, 2014.

140. Henry JT and Crosson S. Ligand-binding PAS domains in a genomic, cellular, and structural context. Аnпu Rev Microbiol 65: 261-286, 2011.

141. Heo YJ, Chung IY, Cho WJ, Lee BY, Kim JH, Choi KH, Lee JW, Hassett DJ, and Cho YH. The major catalase gene (katA) of Pseudomonas aeruginosa PA14 is under both positive and negative control of the global transactivator OxyR in response to hydrogen peroxide. $J$ Bacteriol 192: 381-390, 2010.

142. Hernández JA, Bes MT, Fillat MF, Neira JL, and Peleato ML. Biochemical analysis of the recombinant Fur (ferric uptake regulator) protein from Anabaena PCC 7119: factors affecting its oligomerization state Fur. Biochem $J$ 366: 315-322, 2002.

143. Hernández JA, López-Gomollón S, Muro-Pastor A, Valladares A, Bes MT, Peleato ML, and Fillat MF. Interaction of FurA from Anabaena sp. PCC 7120 with DNA: a reducing environment and the presence of $\mathrm{Mn}(2+)$ are positive effectors in the binding to $i s i B$ and furA promoters. Biometals 19: 259-268, 2006.

144. Hernández JA, Peleato ML, Fillat MF, and Bes MT. Heme binds to and inhibits the DNA-binding activity of the global regulator FurA from Anabaena sp. PCC 7120. FEBS Lett 577: 35-41, 2004.

145. Herrou $\mathbf{J}$ and Crosson S. Function, structure and mechanism of bacterial photosensory LOV proteins. Nat Rev Microbiol 9: 713-723, 2011.

146. Hibbing ME and Fuqua C. Antiparallel and interlinked control of cellular iron levels by the Irr and RirA regu- lators of Agrobacterium tumefaciens. J Bacteriol 193: 3461-3472, 2011.

147. Hidalgo E and Demple B. Spacing of promoter elements regulates the basal expression of the soxS gene and converts SoxR from a transcriptional activator into a repressor. EMBO J 16: 1056-1065, 1997.

148. Hill S, Austin S, Eydmann T, Jones T, and Dixon R. Azotobacter vinelandii NIFL is a flavoprotein that modulates transcriptional activation of nitrogen-fixation genes via a redox-sensitive switch. Proc Natl Acad Sci U S A 93: 2143-2148, 1996.

149. Hillion $\mathrm{M}$ and Antelmann H. Thiol-based redox switches in prokaryotes. Biol Chem 396: 415-444, 2015.

150. Ho YSJ, Burden LM, and Hurley JH. Structure of the GAF domain, a ubiquitous signaling motif and a new class of cyclic GMP receptor. EMBO J 19: 5288-5299, 2000.

151. Hong M, Fuangthong M, Helmann JD, and Brennan RG. Structure of an OhrR-ohrA operator complex reveals the DNA binding mechanism of the MarR family. Mol Cell 20: 131-141, 2005.

152. Horsburgh MJ, Ingham E, and Foster SJ. In Staphylococcus aureus, Fur is an interactive regulator with PerR, contributes to virulence, and is necessary for oxidative stress resistance through positive regulation of catalase and iron homeostasis. J Bacteriol 183: 468-475, 2001.

153. Hou S, Reynolds MF, Horrigan FT, Heinemann SH, and Hoshi T. Reversible binding of heme to proteins in cellular signal transduction. Acc Chem Res 39: 918-924, 2006.

154. Hu L, Huang H, Yuan H, Tao F, Xie H, and Wang S. Rex in Clostridium kluyveri is a global redox-sensing transcriptional regulator. J Biotechnol 233: 17-25, 2016.

155. Huang IH and Sarker MR. Complementation of a Clostridium perfringens spoOA mutant with wild-type spoOA from other Clostridium species. Appl Environ Microbiol 72: 6388-6393, 2006.

156. Hutchings MI, Mandhana N, and Spiro S. The NorR protein of Escherichia coli activates expression of the flavorubredoxin gene norV in response to reactive nitrogen species. J Bacteriol 184: 4640-4643, 2002.

157. Ibrahim M, Kuchinskas M, Youn H, Kerby RL, Roberts GP, Poulos TL, and Spiro TG. Mechanism of the COsensing heme protein CooA: new insights from the truncated heme domain and UVRR spectroscopy. J Inorg Biochem 101: 1776-1785, 2007.

158. Ibrahim SA, Crack JC, Rolfe MD, Borrero-de Acuña JM, Thomson AJ, Le Brun NE, Schobert M, Stapleton MR, and Green J. Three Pseudomonas putida FNR family proteins with different sensitivities to $\mathrm{O}_{2}$. J Biol Chem 290: 16812-16823, 2015.

159. Ieva R, Roncarati D, Metruccio MM, Seib KL, Scarlato V, and Delany I. OxyR tightly regulates catalase expression in Neisseria meningitidis through both repression and activation mechanisms. Mol Microbiol 70: 1152-1165, 2008.

160. Igarashi J, Kitanishi K, Martinkova M, Murase M, Iizuka A, and Shimizu T. The roles of thiolate-heme proteins, other than the P450 cytochromes, in the regulation of heme-sensor proteins. Acta Chim Slov 55: 67-74, 2008.

161. Igarashi J, Kitanishi K, and Shimizu T. Emerging roles of heme as a signal and a gas-sensing site: heme-sensing and gas-sensing proteins. In: Handbook of Porphyrin Science, Volume 15, edited by Kadish KM, Smith KM, and Guilard R. Hackensack, New Jersey: World Scientific Pub Co Inc., 2011, pp. 399-460. 
162. Ilbert M, Graf PC, and Jakob U. Zinc center as redox switch-new function for an old motif. Antioxid Redox Signal 8: 835-846, 2006.

163. Imber M, Huyen NTT, Pietrzyk-Brzezinska AJ, Loi VV, Hillion M, Bernhardt J, Thärichen L, Kolšek K, Saleh M, Hamilton CJ, Adrian L, Gräter F, Wahl MC, and Antelmann $\mathrm{H}$. Protein S-bacillithiolation functions in thiol protection and redox regulation of the glyceraldehyde-3-phosphate dehydrogenase Gap in Staphylococcus aureus under hypochlorite stress. Antioxid Redox Signal 28: 410-430, 2018.

164. Imlay JA. The molecular mechanisms and physiological consequences of oxidative stress: lessons from a model bacterium. Nat Rev Microbiol 11: 443-454, 2013.

165. Ioanoviciu A, Meharenna YT, Poulos TL, and Ortiz de Montellano PR. DevS oxy complex stability identifies this heme protein as a gas sensor in Mycobacterium tuberculosis dormancy. Biochemistry 48: 5839-5848, 2009.

166. Ioanoviciu A, Yukl ET, Moënne-Loccoz P, and de Montellano PR. DevS, a heme-containing two-component oxygen sensor of Mycobacterium tuberculosis. Biochemistry 46: 4250-4260, 2007.

167. Isabella VM, Lapek JD, Jr., Kennedy EM, and Clark VL. Functional analysis of NsrR, a nitric oxide-sensing Rrf2 repressor in Neisseria gonorrhoeae. Mol Microbiol 71: 227-239, 2009.

168. Iuchi $\mathrm{S}$ and Weiner L. Cellular and molecular physiology of Escherichia coli in the adaptation to aerobic environments. J Biochem 120: 1055-1063, 1996.

169. Jakimowicz P, Cheesman MR, Bishai WR, Chater KF, Thomson AJ, and Buttner MJ. Evidence that the Streptomyces developmental protein WhiD, a member of the WhiB family, binds a [4Fe-4S] cluster. J Biol Chem 280: 8309-8315, 2005.

170. Jang S and Imlay JA. Hydrogen peroxide inactivates the Escherichia coli Isc iron-sulphur assembly system, and OxyR induces the Suf system to compensate. Mol Microbiol 78: 1448-1467, 2010.

171. Jaubert M, Zappa S, Fardoux J, Adriano JM, Hannibal L, Elsen S, Lavergne J, Verméglio A, Giraud E, and Pignol D. Light and redox control of photosynthesis gene expression in Bradyrhizobium: dual roles of two PpsR. $J$ Biol Chem 279: 44407-44416, 2004.

172. Jervis AJ, Crack JC, White G, Artymiuk PJ, Cheesman MR, Thomson AJ, Le Brun NE, and Green J. The $\mathrm{O}_{2}$ sensitivity of the transcription factor FNR is controlled by Ser24 modulating the kinetics of $[4 \mathrm{Fe}-4 \mathrm{~S}]$ to $[2 \mathrm{Fe}-2 \mathrm{~S}]$ conversion. Proc Natl Acad Sci U S A 106: 4659-4664, 2009.

173. Ji CJ, Kim JH, Won YB, Lee YE, Choi TW, Ju SY, Youn H, Helmann JD, and Lee JW. Staphylococcus aureus PerR is a hypersensitive hydrogen peroxide sensor using ironmediated histidine oxidation. J Biol Chem 290: 20374 20386, 2015.

174. Jo I, Chung IY, Bae HW, Kim JS, Song S, Cho YH, and Ha NC. Structural details of the OxyR peroxide-sensing mechanism. Proc Natl Acad Sci U S A 112: 6443-6448, 2015.

175. Jo I, Kim D, Bang YJ, Ahn J, Choi SH, and Ha NC. The hydrogen peroxide hypersensitivity of OxyR2 in Vibrio vulnificus depends on conformational constraints. J Biol Chem 292: 7223-7232, 2017.

176. Jude F, Köhler T, Branny P, Perron K, Mayer MP, Comte $\mathrm{R}$, and van Delden C. Posttranscriptional control of quorum-sensing-dependent virulence genes by DksA in Pseudomonas aeruginosa. J Bacteriol 185: 3558-3566, 2003.
177. Jurk M, Schramm $\mathrm{P}$, and Schmieder P. The blue-light receptor YtvA from Bacillus subtilis is permanently incorporated into the stressosome independent of the illumination state. Biochem Biophys Res Commun 432: 499-503, 2013.

178. Kaito C, Morishita D, Matsumoto Y, Kurokawa K, and Sekimizu K. Novel DNA binding protein SarZ contributes to virulence in Staphylococcus aureus. Mol Microbiol 62: 1601-1617, 2006.

179. Kallifidas D, Thomas D, Doughty P, and Paget MS. The sigmaR regulon of Streptomyces coelicolor A32 reveals a key role in protein quality control during disulphide stress. Microbiology 156: 1661-1672, 2010.

180. Kamps A, Achebach S, Fedtke I, Unden G, and Götz F. Staphylococcal NreB: an $\mathrm{O}_{2}$-sensing histidine protein kinase with an $\mathrm{O}_{2}$-labile iron-sulphur cluster of the FNR type. Mol Microbiol 52: 713-723, 2004.

181. Kanesaki Y, Yamamoto H, Paithoonrangsarid K, Shoumskaya M, Suzuki I, Hayashi H, and Murata N. Histidine kinases play important roles in the perception and signal transduction of hydrogen peroxide in the cyanobacterium, Synechocystis sp. PCC 6803. Plant J 49: 313-324, 2007.

182. Kang JG, Paget MS, Seok YJ, Hahn MY, Bae JB, Hahn JS, Kleanthous C, Buttner MJ, and Roe JH. RsrA, an antisigma factor regulated by redox change. EMBO J 18: 4292-4298, 1999.

183. Karlinsey JE, Bang IS, Becker LA, Frawley ER, Porwollik S, Robbins HF, Thomas VC, Urbano R, McClelland M, and Fang FC. The NsrR regulon in nitrosative stress resistance of Salmonella enterica serovar Typhimurium. Mol Microbiol 85: 1179-1193, 2012.

184. Kaspar S, Perozzo R, Reinelt S, Meyer M, Pfister K, Scapozza L, and Bott M. The periplasmic domain of the histidine autokinase CitA functions as a highly specific citrate receptor. Mol Microbiol 33: 858-872, 1999.

185. Kaur K, Kumari P, Sharma S, Sehgal S, and Tyagi JS. DevS/ DosS sensor is bifunctional and its phosphatase activity precludes aerobic DevR/DosR regulon expression in $M y$ cobacterium tuberculosis. FEBS J 283: 2949-2962, 2016.

186. Kelemen GH, Brian P, Flärdh K, Chamberlin L, Chater $\mathrm{KF}$, and Buttner MJ. Developmental regulation of transcription of whiE, a locus specifying the polyketide spore pigment in Streptomyces coelicolor A3 (2). J Bacteriol 180: 2515-2521, 1998.

187. Kerby RL, Youn H, and Roberts GP. RcoM: a new singlecomponent transcriptional regulator of $\mathrm{CO}$ metabolism in bacteria. J Bacteriol 190: 3336-3343, 2008.

188. Kerby RL, Youn H, Thorsteinsson MV, and Roberts GP. Repositioning about the dimer interface of the transcription regulator CooA: a major signal transduction pathway between the effector and DNA-binding domains. $J$ Mol Biol 325: 809-823, 2003.

189. Kim MS, Dufour YS, Yoo JS, Cho YB, Park JH, Nam GB, Kim HM, Lee KL, Donohue TJ, and Roe JH. Conservation of thiol-oxidative stress responses regulated by SigR orthologues in actinomycetes. Mol Microbiol 85: 326-344, 2012.

190. Kim S, Bang YJ, Kim D, Lim JG, Oh MH, and Choi SH. Distinct characteristics of OxyR2, a new OxyR-type regulator, ensuring expression of Peroxiredoxin 2 detoxifying low levels of hydrogen peroxide in Vibrio vulnificus. Mol Microbiol 93: 992-1009, 2014.

191. Kim YJ, Ko IJ, Lee JM, Kang HY, Kim YM, Kaplan S, and $\mathrm{Oh}$ JI. Dominant role of the cbb3 oxidase in regulation of photosynthesis gene expression through the PrrBA 
system in Rhodobacter sphaeroides 2.4.1. J Bacteriol 189: 5617-5625, 2007.

192. King-Scott J, Konarev PV, Panjikar S, Jordanova R, Svergun DI, and Tucker PA. Structural characterization of the multidomain regulatory protein Rv1364c from Mycobacterium tuberculosis. Structure 19: 56-69, 2011.

193. Kobayashi K. Sensing mechanisms in the redox-regulated, [2Fe-2S] cluster-containing, bacterial transcriptional factor SoxR. Acc Chem Res 50: 1672-1678, 2017.

194. Kobayashi K and Tagawa S. Activation of SoxRdependent transcription in Pseudomonas aeruginosa. $J$ Biochem 136: 607-615, 2004.

195. Kolodkin-Gal I, Elsholz AK, Muth C, Girguis PR, Kolter $\mathrm{R}$, and Losick R. Respiration control of multicellularity in Bacillus subtilis by a complex of the cytochrome chain with a membrane-embedded histidine kinase. Genes Dev 27: 887-899, 2013.

196. Kommineni S, Lama A, Popescu B, and Nakano MM. Global transcriptional control by NsrR in Bacillus subtilis. J Bacteriol 194: 1679-1688, 2012.

197. Kommineni S, Yukl E, Hayashi T, Delepine J, Geng H, Moënne-Loccoz P, and Nakano MM. Nitric oxidesensitive and -insensitive interaction of Bacillus subtilis NsrR with a ResDE-controlled promoter. Mol Microbiol 78: 1280-1293, 2010.

198. Konar M, Alam MS, Arora C, and Agrawal P. WhiB2/ Rv3260c, a cell division-associated protein of Mycobacterium tuberculosis $\mathrm{H} 37 \mathrm{Rv}$, has properties of a chaperone. FEBS J 279: 2781-2792, 2012.

199. Krell T, Lacal J, Busch A, Silva-Jiménez H, Guazzaroni ME, and Ramos JL. Bacterial sensor kinases: diversity in the recognition of environmental signals. Annu Rev Microbiol 64: 539-559, 2010.

200. Kröncke KD. Zinc finger proteins as molecular targets for nitric oxide-mediated gene regulation. Antioxid Redox Signal 3: 565-575, 2001.

201. Kroth PG, Wilhelm C, and Kottke T. An update on aureochromes: phylogeny-mechanism-function. J Plant Physiol 217: 20-26, 2017.

202. Kumar A, Deshane JS, Crossman DK, Bolisetty S, Yan BS, Kramnik I, Agarwal A, and Steyn AJ. Heme oxygenase-1-derived carbon monoxide induces the $M y$ cobacterium tuberculosis dormancy regulon. J Biol Chem 283: 18032-18039, 2008.

203. Kumar A, Toledo JC, Patel RP, Lancaster JR, Jr., and Steyn AJ. Mycobacterium tuberculosis DosS is a redox sensor and DosT is a hypoxia sensor. Proc Natl Acad Sci U S A 104: 11568-11573, 2007.

204. Lambden PR and Guest JR. Mutants of Escherichia coli K12 unable to use fumarate as an anaerobic electron acceptor. J Gen Microbiol 97: 145-160, 1976.

205. Lamberg KE, Luther C, Weber KD, and Kiley PJ. Characterization of activating region 3 from Escherichia coli FNR. J Mol Biol 315: 275-283, 2002.

206. Lanzilotta WN, Schuller DJ, Thorsteinsson MV, Kerby RL, Roberts GP, and Poulos TL. Structure of the CO sensing transcription activator CooA. Nat Struct Biol 7: 876-880, 2000.

207. Laouami S, Clair G, Armengaud J, and Duport C. Proteomic evidences for Rex regulation of metabolism in toxin-producing Bacillus cereus ATCC 14579. PLoS One 9: e107354, 2014.

208. Laptenok SP, Lukacs A, Brust R, Haigney A, Gil A, Towrie M, Greetham GM, Tonge PJ, and Meech SR.
Electron transfer quenching in light adapted and mutant forms of the AppA BLUF domain. Faraday Discuss 177: 293-311, 2015.

209. Larsson C, Luna B, Ammerman NC, Maiga M, Agarwal $\mathrm{N}$, and Bishai WR. Gene expression of Mycobacterium tuberculosis putative transcription factors WhiB1-7 in redox environments. PLoS One 7: e37516, 2012.

210. Lee AI, Delgado A, and Gunsalus RP. Signal-dependent phosphorylation of the membrane-bound NarX twocomponent sensor-transmitter protein of Escherichia coli: nitrate elicits a superior anion ligand response compared to nitrite. J Bacteriol 181: 5309-5316, 1999.

211. Lee C, Lee SM, Mukhopadhyay P, Kim SJ, Lee SC, Ahn WS, Yu MH, Storz G, and Ryu SE. Redox regulation of OxyR requires specific disulfide bond formation involving a rapid kinetic reaction path. Nat Struct Mol Biol 11: 1179-1185, 2004.

212. Lee J, Jang YS, Han MJ, Kim JY, and Lee SY. Deciphering Clostridium tyrobutyricum metabolism based on the wholegenome sequence and proteome analyses. $m$ Bio 7: pii: e0074316,2016

213. Lee JH, Yeo WS, and Roe JH. Induction of the sufA operon encoding $\mathrm{Fe}-\mathrm{S}$ assembly proteins by superoxide generators and hydrogen peroxide: involvement of OxyR, IHF and an unidentified oxidant-responsive factor. Mol Microbiol 51: 1745-1755, 2004.

214. Lee JK and Kaplan S. Isolation and characterization of trans-acting mutations involved in oxygen regulation of puc operon transcription in Rhodobacter sphaeroides. $J$ Bacteriol 174: 1158-1171, 1992.

215. Lee JM, Cho HY, Cho HJ, Ko IJ, Park SW, Baik HS, Oh JH, Eom CY, Kim YM, Kang BS, and Oh JI. $\mathrm{O}_{2^{-}}$and NOsensing mechanism through the DevSR two-component system in Mycobacterium smegmatis. J Bacteriol 190: 6795-6804, 2008.

216. Lee JW, Soonsanga S, and Helmann JD. A complex thiolate switch regulates the Bacillus subtilis organic peroxide sensor OhrR. Proc Natl Acad Sci U S A 104: 8743-8748, 2007.

217. Lee PE, Demple B, and Barton JK. DNA-mediated redox signaling for transcriptional activation of SoxR. Proc Natl Acad Sci U S A 106: 13164-13168, 2009.

218. Leelakriangsak M, Huyen NT, Töwe S, van Duy N, Becher D, Hecker M, Antelmann H, and Zuber P. Regulation of quinone detoxification by the thiol stress sensing DUF24/MarR-like repressor, YodB in Bacillus subtilis. Mol Microbiol 67: 1108-1124, 2008.

219. Lennon CW, Lemmer KC, Irons JL, Sellman MI, Donohue TJ, Gourse RL, and Ross W. A Rhodobacter sphaeroides protein mechanistically similar to Escherichia coli DksA regulates photosynthetic growth. mBio 5: e01105-14, 2014.

220. Lennon CW, Ross W, Martin-Tumasz S, Toulokhonov I, Vrentas CE, Rutherford ST, Lee JH, Butcher SE, and Gourse RL. Direct interactions between the coiled-coil tip of DksA and the trigger loop of RNA polymerase mediate transcriptional regulation. Genes Dev 26: 26342646, 2012.

221. Li Z and Demple B. SoxS, an activator of superoxide stress genes in Escherichia coli. Purification and interaction with DNA. J Biol Chem 269: 18371-18377, 1994.

222. Lipscomb JD. Biochemistry of the soluble methane monooxygenase. Annu Rev Microbiol 48: 371-399, 1994. 
223. Little R, Martinez-Argudo I, Perry S, and Dixon R. Role of the $\mathrm{H}$ domain of the histidine kinase-like protein NifL in signal transmission. J Biol Chem 282: 13429-13437, 2007.

224. Little R, Slavny P, and Dixon R. Influence of PAS domain flanking regions on oligomerisation and redox signalling by NifL. PloS One 7: e46651, 2012.

225. Liu L, Li Y, Shi Z, Du G, and Chen J. Enhancement of pyruvate productivity in Torulopsis glabrata: increase of NAD $^{+}$availability. J Biotechnol 126: 173-185, 2006.

226. Liu X, Cheng Y, Lyu M, Wen Y, Song Y, Chen Z, and Li J. Redox-sensing regulator Rex regulates aerobic metabolism, morphological differentiation, and avermectin production in Streptomyces avermitilis. Sci Rep 7: 44567, 2017.

227. Liu X and De Wulf P. Probing the ArcA-P modulon of Escherichia coli by whole genome transcriptional analysis and sequence recognition profiling. J Biol Chem 279: 12588-12597, 2004.

228. Lois AF, Ditta GS, and Helinski DR. The oxygen sensor FixL of Rhizobium meliloti is a membrane protein containing four possible transmembrane segments. J Bacteriol 175: 1103-1109, 1993.

229. Losi A. The bacterial counterparts of plant phototropins. Photochem Photobiol Sci 3: 566-574, 2004.

230. Losi A. Flavin-based photoreceptors in bacteria. In: Chapter 10. Flavins: Photochemistry and Photobiology, Volume 6. edited by Silva E, and Edwards AM. Cambridge, UK: The Royal Society of Chemistry, 2006, pp. 217-269.

231. Losi A and Gärtner W. Solving blue light riddles: new lessons from flavin-binding LOV photoreceptors. Photochem Photobiol 93: 141-158, 2017.

232. Luong TT, Dunman PM, Murphy E, Projan SJ, and Lee CY. Transcription profiling of the mgrA regulon in Staphylococcus aureus. J Bacteriol 188: 1899-1910, 2006.

233. Malpica R, Franco B, Rodriguez C, Kwon O, and Georgellis D. Identification of a quinone-sensitive redox switch in the ArcB sensor kinase. Proc Natl Acad Sci U S A 101: 13318-13323, 2004.

234. Maret W. Zinc coordination environments in proteins as redox sensors and signal transducers. Antioxid Redox Signal 8: 1419-1441, 2006.

235. Martinez-Argudo I, Little R, and Dixon R. Role of the amino-terminal GAF domain of the NifA activator in controlling the response to the antiactivator protein NifL. Mol Microbiol 52: 1731-1744, 2004.

236. Marvin KA, Kerby RL, Youn H, Roberts GP, and Burstyn $\mathrm{JN}$. The transcription regulator RcoM-2 from Burkholderia xenovorans is a cysteine-ligated hemoprotein that undergoes a redox-mediated ligand switch. Biochemistry 47: 9016-9028, 2008.

237. Mascher T, Helmann JD, and Unden G. Stimulus perception in bacterial signal-transducing histidine kinases. Microbiol Mol Biol Rev 70: 910-938, 2006.

238. Masuda S. Light detection and signal transduction in the BLUF photoreceptors. Plant Cell Physiol 54: 171-179, 2013.

239. Masuda S and Bauer CE. AppA is a blue light photoreceptor that antirepresses photosynthesis gene expression in Rhodobacter sphaeroides. Cell 110: 613-623, 2002.

240. Masuda S, Dong C, Swem D, Setterdahl AT, Knaff DB, and Bauer CE. Repression of photosynthesis gene expression by formation of a disulfide bond in CrtJ. Proc Natl Acad Sci U S A 99: 7078-7083, 2002.

241. McLaughlin KJ, Strain-Damerell CM, Xie K, Brekasis D, Soares AS, Paget MS, and Kielkopf CL. Structural basis for NADH/NAD ${ }^{+}$redox sensing by a Rex family repressor. Mol Cell 38: 563-575, 2010.

242. Mesa S, Hennecke H, and Fischer HM. A multitude of CRP/FNR-like transcription proteins in Bradyrhizobium japonicum. Biochem Soc Trans 34: 156-159, 2006.

243. Mesa S, Velasco L, Manzanera ME, Delgado MJ, and Bedmar EJ. Characterization of the nor $C B Q D$ genes, encoding nitric oxide reductase, in the nitrogen fixing bacterium Bradyrhizobium japonicum. Microbiology 148: 3553-3560, 2002.

244. Mettert EL and Kiley P. Reassessing the structure and function relationship of the $\mathrm{O}_{2}$-sensing transcription factor FNR. Antioxid Redox Signal 29: 1830-1840, 2018.

245. Mettert EL and Kiley PJ. ClpXP-dependent proteolysis of FNR upon loss of its $\mathrm{O}_{2}$-sensing [4Fe-4S] cluster. $\mathrm{J} \mathrm{Mol}$ Biol 354: 220-232, 2005.

246. Metz S, Jäger A, and Klug G. In vivo sensitivity of bluelight-dependent signaling mediated by AppA/PpsR or PrrB/PrrA in Rhodobacter sphaeroides. J Bacteriol 191: 4473-4477, 2009.

247. Metz S, Jager A, and Klug G. Role of a short light, oxygen, voltage (LOV) domain protein in blue light- and singlet oxygen-dependent gene regulation in Rhodobacter sphaeroides. Microbiology 158: 368-379, 2012.

248. Miller HK and Auerbuch V. Bacterial iron-sulfur cluster sensors in mammalian pathogens. Metallomics 7: 943956, 2015.

249. Molle V, Fujita M, Jensen ST, Eichenberger P, GonzálezPastor JE, Liu JS, and Losick R. The Spo0A regulon of Bacillus subtilis. Mol Microbiol 50: 1683-1701, 2003.

250. Molle V, Nakaura Y, Shivers RP, Yamaguchi H, Losick R, Fujita Y, and Sonenshein AL. Additional targets of the Bacillus subtilis global regulator CodY identified by chromatin immunoprecipitation and genome-wide transcript analysis. J Bacteriol 185: 1911-1922, 2003.

251. Monson EK, Ditta GS, and Helinski DR. The oxygen sensor protein, FixL, of Rhizobium meliloti. Role of histidine residues in heme binding, phosphorylation, and signal transduction. J Biol Chem 270: 5243-5250, 1995.

252. Moore LJ and Kiley PJ. Characterization of the dimerization domain in the FNR transcription factor. $J$ Biol Chem 276: 45744-45750, 2001.

253. Moore LJ, Mettert EL, and Kiley PJ. Regulation of FNR dimerization by subunit charge repulsion. J Biol Chem 281: 33268-33275, 2006.

254. Moskvin OV, Gomelsky L, and Gomelsky M. Transcriptome analysis of the Rhodobacter sphaeroides PpsR regulon: PpsR as a master regulator of photosystem development. J Bacteriol 187: 2148-2156, 2005.

255. Müllner M, Hammel O, Mienert B, Schlag S, Bill E, and Unden G. A PAS domain with an oxygen labile $[4 \mathrm{Fe}-4 \mathrm{~S}]^{2+}$ cluster in the oxygen sensor kinase NreB of Staphylococcus carnosus. Biochemistry 47: 13921-13932, 2008.

256. Munnoch JT, Martinez MT, Svistunenko DA, Crack JC, Le Brun NE, and Hutchings MI. Characterization of a putative NsrR homologue in Streptomyces venezuelae reveals a new member of the Rrf2 superfamily. Sci Rep 6: 31597, 2016.

257. Muraki N, Kitatsuji C, and Aono S. A new biological function of heme as a signaling molecule. J Porphyrins Phthalocyanines 19: 9-20, 2015.

258. Myers KS, Yan H, Ong IM, Chung D, Liang K, Tran F, Keleş S, Landick R, and Kiley PJ. Genome-scale analysis of Escherichia coli FNR reveals complex features of transcription factor binding. PLoS Genet 9: e1003565, 2013. 
259. Nakajima H, Honma Y, Tawara T, Kato T, Park SY, Miyatake $\mathrm{H}$, Shiro $\mathrm{Y}$, and Aono S. Redox properties and coordination structure of the heme in the co-sensing transcriptional activator CooA. J Biol Chem 276: 7055-7061, 2001.

260. Naseer N, Shapiro JA, and Chander M. RNA-Seq analysis reveals a six-gene SoxR regulon in Streptomyces coelicolor. PLoS One 9: e106181, 2014.

261. Nash AI, McNulty R, Shillito ME, Swartz TE, Bogomolni RA, Luecke H, and Gardner KH. Structural basis of photosensitivity in a bacterial light-oxygen-voltage/helixturn-helix (LOV-HTH) DNA-binding protein. Proc Natl Acad Sci U S A 108: 9449-9454, 2011.

262. Nesbit AD, Giel JL, Rose JC, and Kiley PJ. Sequence-specific binding to a subset of IscR-regulated promoters does not require IscR Fe-S cluster ligation. J Mol Biol 387: 28-41, 2009.

263. Newberry KJ, Fuangthong M, Panmanee W, Mongkolsuk $\mathrm{S}$, and Brennan RG. Structural mechanism of organic hydroperoxide induction of the transcription regulator OhrR. Mol Cell 28: 652-664, 2007.

264. Nguyen TT, Martí-Arbona R, Hall RS, Maity T, Valdez YE, Dunbar JM, Unkefer CJ, and Unkefer PJ. Identification and in-vivo characterization of a novel OhrR transcriptional regulator in Burkholderia xenovorans LB400. JMBR 3: 37-46, 2013.

265. Niemann V, Koch-Singenstreu M, Neu A, Nilkens S, Götz F, Unden G, and Stehle T. The NreA protein functions as a nitrate receptor in the staphylococcal nitrate regulation system. J Mol Biol 426: 1539-1553, 2014.

266. Nilkens S, Koch-Singenstreu M, Niemann V, Götz F, Stehle T, and Unden G. Nitrate/oxygen co-sensing by an NreA/NreB sensor complex of Staphylococcus carnosus. Mol Microbiol 91: 381-393, 2014.

267. Nunoshiba T, deRojas-Walker T, Wishnok JS, Tannenbaum SR, and Demple B. Activation by nitric oxide of an oxidative-stress response that defends Escherichia coli against activated macrophages. Proc Natl Acad Sci U S A 90: 9993-9997, 1993.

268. Oh JI and Kaplan S. The cbb3 terminal oxidase of Rhodobacter sphaeroides 2.4.1: structural and functional implications for the regulation of spectral complex formation. Biochemistry 38: 2688-2696, 1999.

269. Oh JI and Kaplan S. Redox signaling: globalization of gene expression. EMBO J 19: 4237-4247, 2000.

270. Oh SY, Shin JH, and Roe JH. Dual role of OhrR as a repressor and an activator in response to organic hydroperoxides in Streptomyces coelicolor. J Bacteriol 189: 6284-6292, 2007.

271. Okajima K, Yoshihara S, Fukushima Y, Geng XX, Katayama M, Higashi S, Watanabe M, Sato S, Tabata S, Shibata Y, Itoh S, and Ikeuchi M. Biochemical and functional characterization of BLUF-type flavin-binding proteins of two species of cyanobacteria. J Biochem 137: 741-750, 2005.

272. Ondrusch N and Kreft J. Blue and red light modulates SigB-dependent gene transcription, swimming motility and invasiveness in Listeria monocytogenes. PloS One 6: e16151, 2011.

273. Ottemann KM, Xiao W, Shin YK, and Koshland DE, Jr. A piston model for transmembrane signaling of the aspartate receptor. Science 285: 1751-1754, 1999.

274. Outten FW and Theil EC. Iron-based redox switches in biology. Antioxid Redox Signal 11: 1029-1046, 2009.

275. Page KM and Guerinot ML. Oxygen control of the Bradyrhizobium japonicum hemA gene. J Bacteriol 177: 3979-3984, 1995.
276. Pagels M, Fuchs S, Pané-Farré J, Kohler C, Menschner L, Hecker M, McNamarra PJ, Bauer MC, von Wachenfeldt C, Liebeke M, Lalk M, Sander G, von Eiff C, Proctor RA, and Engelmann S. Redox sensing by a Rex-family repressor is involved in the regulation of anaerobic gene expression in Staphylococcus aureus. Mol Microbiol 76: 1142-1161, 2010.

277. Paget MS and Buttner MJ. Thiol-based regulatory switches. Annu Rev Genet 37: 91-121, 2003.

278. Palm GJ, Khanh Chi B, Waack P, Gronau K, Becher D, Albrecht D, Hinrichs W, Read RJ, and Antelmann H. Structural insights into the redox-switch mechanism of the MarR/DUF24-type regulator HypR. Nucleic Acids Res 40: 4178-4192, 2012.

279. Palma M, Zurita J, Ferreras JA, Worgall S, Larone DH, Shi L, Campagne F, and Quadri LE. Pseudomonas aeruginosa SoxR does not conform to the archetypal paradigm for SoxR-dependent regulation of the bacterial oxidative stress adaptive response. Infect Immun 73: 2958-2966, 2005.

280. Pande A and Grove A. Oxidative stress based response of a transcriptional regulator, OhrR, from Burkholderia thailandensis. FASEB J 28(Suppl): LB252, 2014.

281. Panmanee W, Vattanaviboon P, Poole LB, and Mongkolsuk S. Novel organic hydroperoxide-sensing and responding mechanisms for OhrR, a major bacterial sensor and regulator of organic hydroperoxide stress. J Bacteriol 188: 1389-1395, 2006.

282. Park HD, Guinn KM, Harrell MI, Liao R, Voskuil MI, Tompa M, Schoolnik GK, and Sherman DR. Rv3133c/ dosR is a transcription factor that mediates the hypoxic response of Mycobacterium tuberculosis. Mol Microbiol 48: 833-843, 2003.

283. Park SY and Tame JRH. Seeing the light with BLUF proteins. Biophys Rev 9: 169-176, 2017.

284. Park W, Peña-Llopis S, Lee Y, and Demple B. Regulation of superoxide stress in Pseudomonas putida KT2440 is different from the SoxR paradigm in Escherichia coli. Biochem Biophys Res Commun 341: 51-56, 2006.

285. Parrish NM, Dick JD, and Bishai WR. Mechanisms of latency in Mycobacterium tuberculosis. Trends Microbiol 6: 107-112, 1998.

286. Partridge JD, Bodenmiller DM, Humphrys MS, and Spiro S. NsrR targets in the Escherichia coli genome: new insights into DNA sequence requirements for binding and a role for NsrR in the regulation of motility. Mol Microbiol 73: 680-694, 2009.

287. Paul BJ, Barker MM, Ross W, Schneider DA, Webb C, Foster JW, and Gourse RL. DksA: a critical component of the transcription initiation machinery that potentiates the regulation of rRNA promoters by ppGpp and the initiating NTP. Cell 118: 311-322, 2004.

288. Pellicer S, González A, Peleato ML, Martinez JI, Fillat MF, and Bes MT. Site-directed mutagenesis and spectral studies suggest a putative role of FurA from Anabaena sp. PCC 7120 as a heme sensor protein. FEBS J 279: 2231-2246, 2012.

289. Pelliciari S, Vannini A, Roncarati D, and Danielli A. The allosteric behavior of Fur mediates oxidative stress signal transduction in Helicobacter pylori. Front Microbiol 6: 840, 2015.

290. Perederina A, Svetlov V, Vassylyeva MN, Tahirov TH, Yokoyama S, Artsimovitch I, and Vassylyev DG. Regulation through the secondary channel-structural framework for ppGpp-DksA synergism during transcription. Cell 118: 297309, 2004. 
291. Pinochet-Barros A and Helmann JD. Redox sensing by $\mathrm{Fe} 2^{+}$in bacterial Fur family metalloregulators. Antioxid Redox Signal 29: 1858-1871, 2018.

292. Polstein LR and Gersbach CA. Light-inducible spatiotemporal gene regulation using engineered transcription factors. Mol Ther 20: S193-S194, 2012.

293. Polstein LR and Gersbach CA. Light-inducible gene regulation with engineered zinc finger proteins. Methods Mol Biol 1148: 89-107, 2014.

294. Poor CB, Chen PR, Duguid E, Rice PA, and He C. Crystal structures of the reduced, sulfenic acid, and mixed disulfide forms of SarZ, a redox active global regulator in Staphylococcus aureus. J Biol Chem 284: 23517-23524, 2009.

295. Potrykus K and Cashel M. (p)ppGpp: still magical? Annu Rev Microbiol 62: 35-51, 2008.

296. Preisig O, Zufferey R, and Hennecke H. The Bradyrhizobium japonicum fixGHIS genes are required for the formation of the high-affinity cbb3-type cytochrome oxidase. Arch Microbiol 165: 297-305, 1996.

297. Prestel E, Noirot P, and Auger S. Genome-wide identification of Bacillus subtilis Zur-binding sites associated with a Zur box expands its known regulatory network. BMC Microbiol 15: 13, 2015.

298. Previato-Mello M, Meireles DA, Netto LES, and da Silva Neto JF. Global transcriptional response to organic hydroperoxide and the role of OhrR in the control of virulence traits in Chromobacterium violaceum. Infect Immun 85: e0001717, 2017.

299. Rajagopalan S, Teter SJ, Zwart PH, Brennan RG, Phillips KJ, and Kiley PJ. Studies of IscR reveal a unique mechanism for metal-dependent regulation of DNA binding specificity. Nat Struct Mol Biol 20: 740-747, 2013.

300. Ramón-García S, Ng C, Jensen PR, Dosanjh M, Burian J, Morris RP, Folcher M, Eltis LD, Grzesiek S, Nguyen L, and Thompson CJ. WhiB7, an Fe-S-dependent transcription factor that activates species-specific repertoires of drug resistance determinants in actinobacteria. $J$ Biol Chem 288: 34514-34528, 2013.

301. Rani R, Jentzsch K, Lecher J, Hartmann R, Willbold D, Jaeger KE, and Krauss U. Conservation of dark recovery kinetic parameters and structural features in the pseudomonadaceae "short" light, oxygen, voltage (LOV) protein family: implications for the design of LOV-based optogenetic tools. Biochemistry 52: 4460-4473, 2013.

302. Ravcheev DA, Li X, Latif H, Zengler K, Leyn SA, Korostelev YD, Kazakov AE, Novichkov PS, Osterman AL, and Rodionov DA. Transcriptional regulation of central carbon and energy metabolism in bacteria by redox-responsive repressor Rex. $J$ Bacteriol 194: 1145-1157, 2012.

303. Reinelt S, Hofmann E, Gerharz T, Bott M, and Madden DR. The structure of the periplasmic ligand-binding domain of the sensor kinase CitA reveals the first extracellular PAS domain. J Biol Chem 278: 39189-39196, 2003.

304. Remes B, Eisenhardt BD, Srinivasan V, and Klug G. IscR of Rhodobacter sphaeroides functions as repressor of genes for iron-sulfur metabolism and represents a new type of ironsulfur-binding protein. Microbiologyopen 4: 790-802, 2015.

305. Reyrat JM, David M, Blonski C, Boistard P, and Batut J. Oxygen-regulated in vitro transcription of Rhizobium meliloti nifA and fixK genes. J Bacteriol 175: 6867-6872, 1993.

306. Ricci S, Janulczyk R, and Björck L. The regulator PerR is involved in oxidative stress response and iron homeostasis and is necessary for full virulence of Streptococcus pyogenes. Infect Immun 70: 4968-4976, 2002.
307. Rivera-Cancel G, Motta-Mena LB, and Gardner KH Identification of natural and artificial DNA substrates for light-activated LOV-HTH transcription factor EL222. Biochemistry 51: 10024-10034, 2012.

308. Robles EF, Sánchez C, Bonnard N, Delgado MJ, and Bedmar EJ. The Bradyrhizobium japonicum napEDABC genes are controlled by the FixLJ-FixK(2)-NnrR regulatory cascade. Biochem Soc Trans 34: 108-110, 2006.

309. Rodionov DA, Dubchak IL, Arkin AP, Alm EJ, and Gelfand MS. Dissimilatory metabolism of nitrogen oxides in bacteria: comparative reconstruction of transcriptional networks. PLoS Comput Biol 1: e55, 2005.

310. Röllen K, Granzin J, Panwalkar V, Arinkin V, Rani R, Hartmann R, Krauss U, Jaeger KE, Willbold D, and BatraSafferling R. Signaling states of a short blue-light photoreceptor protein PpSB1-LOV revealed from crystal structures and solution NMR spectroscopy. J Mol Biol 428: 3721-3736, 2016.

311. Romsang A, Duang-Nkern J, Leesukon P, Saninjuk K, Vattanaviboon P, and Mongkolsuk S. The iron-sulphur cluster biosynthesis regulator IscR contributes to iron homeostasis and resistance to oxidants in Pseudomonas aeruginosa. PLoS One 9: e86763, 2014.

312. Romsang A, Duang-Nkern J, Wirathorn W, Vattanaviboon $\mathrm{P}$, and Mongkolsuk S. Pseudomonas aeruginosa IscR-regulated ferredoxin $\mathrm{NADP}^{+}$reductase gene $(f p r B)$ functions in iron-sulfur cluster biogenesis and multiple stress response. PLoS One 10: e0134374, 2015.

313. Rybniker J, Nowag A, van Gumpel E, Nissen N, Robinson N, Plum G, and Hartmann P. Insights into the function of the WhiB-like protein of mycobacteriophage TM4 - a transcriptional inhibitor of WhiB2. Mol Microbiol 77: 642-657, 2010.

314. Saini V, Farhana A, and Steyn AJ. Mycobacterium tuberculosis WhiB3: a novel iron-sulfur cluster protein that regulates redox homeostasis and virulence. Antioxid Redox Signal 16: 687-697, 2012.

315. Santos JA, Alonso-Garcia N, Macedo-Ribeiro S, and Pereira PJB. The unique regulation of iron-sulfur cluster biogenesis in a Gram-positive bacterium. Proc Natl Acad Sci U S A 111: E2251-E2260, 2014.

316. Santos JA, Pereira PJ, and Macedo-Ribeiro S. What a difference a cluster makes: the multifaceted roles of IscR in gene regulation and DNA recognition. Biochim Biophys Acta 1854: 1101-1112, 2015.

317. Sardiwal S, Kendall SL, Movahedzadeh F, Rison SC, Stoker NG, and Djordjevic S. A GAF domain in the hypoxia/NO-inducible Mycobacterium tuberculosis DosS protein binds haem. J Mol Biol 353: 929-936, 2005.

318. Satterlee JD, Suquet C, Bidwai AK, Erman JE, Schwall L, and Jimenez R. Mass instability in isolated recombinant FixL heme domains of Bradyrhizobium japonicum. Biochemistry 47: 1540-1553, 2008.

319. Schell MA. Molecular biology of the LysR family of transcriptional regulators. Annu Rev Microbiol 47: 597626, 1993.

320. Schindel HS and Bauer CE. The RegA regulon exhibits variability in response to altered growth conditions and differs markedly between Rhodobacter species. Microb Genom 2: e000081, 2016.

321. Schlag S, Fuchs S, Nerz C, Gaupp R, Engelmann S, Liebeke M, Lalk M, Hecker M, and Götz F. Characterization of the oxygen-responsive NreABC regulon of Staphylococcus aureus. J Bacteriol 190: 7847-7858, 2008. 
322. Schöneich C. Mechanisms of metal-catalyzed oxidation of histidine to 2-oxo-histidine in peptides and proteins. $J$ Pharm Biomed Anal 21: 1093-1097, 2000.

323. Schwartz CJ, Giel JL, Patschkowski T, Luther C, Ruzicka FJ, Beinert $\mathrm{H}$, and Kiley PJ. IscR, an Fe-S clustercontaining transcription factor, represses expression of Escherichia coli genes encoding Fe-S cluster assembly proteins. Proc Natl Acad Sci U S A 98: 14895-14900, 2001.

324. Scott C, Partridge JD, Stephenson JR, and Green J. DNA target sequence and FNR-dependent gene expression. FEBS Lett 541: 97-101, 2003.

325. Sein-Echaluce VC, González A, Napolitano M, Luque I, Barja F, Peleato ML, and Fillat MF. Zur (FurB) is a key factor in the control of the oxidative stress response in Anabaena sp. PCC 7120. Environ Microbiol 17: 20062017, 2015.

326. Selby CP and Sancar A. A cryptochrome/photolyase class of enzymes with single-stranded DNA-specific photolyase activity. Proc Natl Acad Sci U S A 103: 17696-17700, 2006.

327. Semrau JD, Jagadevan S, DiSpirito AA, Khalifa A, Scanlan J, Bergman BH, Freemeier BC, Baral BS, Bandow NL, Vorobev A, Haft DH, Vuilleumier S, and Murrell JC. Methanobactin and MmoD work in concert to act as the "copper-switch" in methanotrophs. Environ Microbiol 15: 3077-3086, 2013.

328. Seo SW, Kim D, Szubin R, and Palsson BO. Genomewide reconstruction of OxyR and SoxRS transcriptional regulatory networks under oxidative stress in Escherichia coli K-12 MG1655. Cell Rep 12: 1289-1299, 2015.

329. Seth D, Hausladen A, Wang YJ, and Stamler JS. Endogenous protein S-nitrosylation in E. coli: regulation by OxyR. Science 336: 470-473, 2012.

330. Sevilla E, Alvarez-Ortega C, Krell T, and Rojo F. The Pseudomonas putida HskA hybrid sensor kinase responds to redox signals and contributes to the adaptation of the electron transport chain composition in response to oxygen availability. Environ Microbiol Rep 5: 825-834, 2013.

331. Shelver D, Kerby RL, He Y, and Roberts GP. CooA, a $\mathrm{CO}$-sensing transcription factor from Rhodospirillum rubrum, is a CO-binding heme protein. Proc Natl Acad Sci U S A 94: 11216-11220, 1997.

332. Shelver D, Thorsteinsson MV, Kerby RL, Chung SY, Roberts GP, Reynolds MF, Parks RB, and Burstyn JN. Identification of two important heme site residues (cysteine 75 and histidine 77) in CooA, the CO-sensing transcription factor of Rhodospirillum rubrum. Biochemistry 38: 2669-2678, 1999.

333. Shen CR, Lan EI, Dekishima Y, Baez A, Cho KM, and Liao JC. Driving forces enable high-titer anaerobic 1butanol synthesis in Escherichia coli. Appl Environ Microbiol 77: 2905-2915, 2011.

334. Shen $\mathrm{S}$ and Fang FC. Integrated stress responses in Salmonella. Int J Food Microbiol 152: 75-81, 2012.

335. Sheplock R, Recinos DA, Mackow N, Dietrich LE, and Chander M. Species-specific residues calibrate SoxR sensitivity to redox-active molecules. Mol Microbiol 87: 368-381, 2013.

336. Shiloh MU, Manzanillo P, and Cox JS. Mycobacterium tuberculosis senses host-derived carbon monoxide during macrophage infection. Cell Host Microbe 3: 323-330, 2008.

337. Shimizu T, Huang D, Yan F, Stranava M, Bartosova M, Fojtíková V, and Martínková M. Gaseous $\mathrm{O}_{2}, \mathrm{NO}$, and CO in signal transduction: structure and function relationships of heme-based gas sensors and heme-redox sensors. Chem Rev 115: 6491-6533, 2015.

338. Shin JH, Singh AK, Cheon DJ, and Roe JH. Activation of the SoxR regulon in Streptomyces coelicolor by the extracellular form of the pigmented antibiotic actinorhodin. J Bacteriol 193: 75-81, 2011.

339. Sickmier EA, Brekasis D, Paranawithana S, Bonanno JB, Paget MS, Burley SK, and Kielkopf CL. X-ray structure of a Rex-family repressor/NADH complex insights into the mechanism of redox sensing. Structure 13: 43-54, 2005.

340. Silva-Jiménez H, Ortega Á, García-Fontana C, Ramos JL, and Krell T. Multiple signals modulate the activity of the complex sensor kinase TodS. Microb Biotechnol 8: 103$115,2015$.

341. Singh A, Crossman DK, Mai D, Guidry L, Voskuil MI, Renfrow MB, and Steyn AJ. Mycobacterium tuberculosis WhiB3 maintains redox homeostasis by regulating virulence lipid anabolism to modulate macrophage response. PLoS Pathog 5: e1000545, 2009.

342. Singh A, Guidry L, Narasimhulu KV, Mai D, Trombley J, Redding KE, Giles GI, Lancaster JR, and Steyn AJ. Mycobacterium tuberculosis WhiB3 responds to $\mathrm{O}_{2}$ and nitric oxide via its [4Fe-4S] cluster and is essential for nutrient starvation survival. Proc Natl Acad Sci U S A 104: 1156211567, 2007.

343. Singh AK, Shin JH, Lee KL, Imlay JA, and Roe JH. Comparative study of SoxR activation by redox-active compounds. Mol Microbiol 90: 983-996, 2013.

344. Smith AT, Marvin KA, Freeman KM, Kerby RL, Roberts GP, and Burstyn JN. Identification of Cys94 as the distal ligand to the $\mathrm{Fe}(\mathrm{III})$ heme in the transcriptional regulator RcoM-2 from Burkholderia xenovorans. J Biol Inorg Chem 17: 1071-1082, 2012.

345. Smith LJ, Stapleton MR, Buxton RS, and Green J. Structure-function relationships of the Mycobacterium tuberculosis transcription factor WhiB1. PLoS One 7: e40407, 2012.

346. Smith LJ, Stapleton MR, Fullstone GJ, Crack JC, Thomson AJ, Le Brun NE, Hunt DM, Harvey E, Adinolfi S, Buxton RS, and Green J. Mycobacterium tuberculosis WhiB1 is an essential DNA-binding protein with a nitric oxide-sensitive iron-sulfur cluster. Biochem J 432: 417427, 2010.

347. Somprasong N, Jittawuttipoka T, Duang-Nkern J, Romsang A, Chaiyen P, Schweizer HP, Vattanaviboon P, and Mongkolsuk S. Pseudomonas aeruginosa thiol peroxidase protects against hydrogen peroxide toxicity and displays atypical patterns of gene regulation. J Bacteriol 194: 3904-3912, 2012.

348. Sotomaior P, Araújo LM, Nishikawa CY, Huergo LF, Monteiro RA, Pedrosa FO, Chubatsu LS, and Souza EM. Effect of ATP and 2-oxoglutarate on the in vitro interaction between the NifA GAF domain and the GlnB protein of Azospirillum brasilense. Braz J Med Biol Res 45: 11351140, 2012.

349. Soupène E, Foussard M, Boistard P, Truchet G, and Batut J. Oxygen as a key developmental regulator of Rhizobium meliloti $\mathrm{N}_{2}$-fixation gene expression within the alfalfa root nodule. Proc Natl Acad Sci U S A 92: 3759-3763, 1995.

350. Sousa EH, Tuckerman JR, Gonzalez G, and GillesGonzalez MA. DosT and DevS are oxygen-switched kinases in Mycobacterium tuberculosis. Protein Sci 16: 1708-1719, 2007. 
351. Spiro S. Nitric oxide-sensing mechanisms in Escherichia coli. Biochem Soc Trans 34: 200-202, 2006.

352. Steiner E, Dago AE, Young DI, Heap JT, Minton NP, Hoch JA, and Young M. Multiple orphan histidine kinases interact directly with Spo0A to control the initiation of endospore formation in Clostridium acetobutylicum. Mol Microbiol 80: 641-654, 2011.

353. Steyn AJ, Collins DM, Hondalus MK, Jacobs WR, Jr., Kawakami RP, and Bloom BR. Mycobacterium tuberculosis WhiB3 interacts with RpoV to affect host survival but is dispensable for in vivo growth. Proc Natl Acad Sci U S A 99: 3147-3152, 2002.

354. Sugimoto Y, Nakamura H, Ren S, Hori K, and Masuda S. Genetics of the blue light-dependent signal cascade that controls phototaxis in the cyanobacterium Synechocystis sp. PCC6803. Plant Cell Physiol 58: 458-465, 2017.

355. Sun F, Ding Y, Ji Q, Liang Z, Deng X, Wong CC, Yi C, Zhang L, Xie S, Alvarez S, Hicks LM, Luo C, Jiang H, Lan $\mathrm{L}$, and $\mathrm{He} \mathrm{C}$. Protein cysteine phosphorylation of SarA/MgrA family transcriptional regulators mediates bacterial virulence and antibiotic resistance. Proc Natl Acad Sci U S A 109: 15461-15466, 2012.

356. Sun F, Ji Q, Jones MB, Deng X, Liang H, Frank B, Telser $\mathrm{J}$, Peterson SN, Bae T, and He C. AirSR, a [2Fe-2S] cluster-containing two-component system, mediates global oxygen sensing and redox signaling in Staphylococcus aureus. J Am Chem Soc 134: 305-314, 2012.

357. Swem DL and Bauer CE. Coordination of ubiquinol oxidase and cytochrome $c b b_{(3)}$ oxidase expression by multiple regulators in Rhodobacter capsulatus. J Bacteriol 184: 2815-2820, 2002.

358. Swem LR, Elsen S, Bird TH, Swem DL, Koch HG, Myllykallio H, Daldal F, and Bauer CE. The RegB/RegA twocomponent regulatory system controls synthesis of photosynthesis and respiratory electron transfer components in Rhodobacter capsulatus. J Mol Biol 309: 121-138, 2001.

359. Swem LR, Gong X, Yu CA, and Bauer CE. Identification of a ubiquinone-binding site that affects autophosphorylation of the sensor kinase RegB. J Biol Chem 281: 6768-6775, 2006.

360. Takakado A, Nakasone Y, and Terazima M. Photoinduced dimerization of a photosensory DNA-binding protein EL222 and its LOV domain. Phys Chem Chem Phys 19: 24855-24865, 2017.

361. Tanaka K, Nakasone Y, Okajima K, Ikeuchi M, Tokutomi $\mathrm{S}$, and Terazima $\mathrm{M}$. Time-resolved tracking of interprotein signal transduction: Synechocystis PixD-PixE complex as a sensor of light intensity. J Am Chem Soc 134: 8336-8339, 2012.

362. Taneja NK, Dhingra S, Mittal A, Naresh M, and Tyagi JS. Mycobacterium tuberculosis transcriptional adaptation, growth arrest and dormancy phenotype development is triggered by vitamin C. PLoS One 5: e10860, 2010.

363. Tao K, Makino K, Yonei S, Nakata A, and Shinagawa H. Molecular cloning and nucleotide sequencing of $\operatorname{oxy} R$, the positive regulatory gene of a regulon for an adaptive response to oxidative stress in Escherichia coli: homologies between OxyR protein and a family of bacterial activator proteins. Mol Gen Genet 218: 371-376, 1989.

364. Taylor BL and Zhulin IB. PAS domains: internal sensors of oxygen, redox potential, and light. Microbiol Mol Biol Rev 63: 479-506, 1999.

365. Teramoto $H$, Inui $M$, and Yukawa $H$. OxyR acts as a transcriptional repressor of hydrogen peroxide-inducible antioxidant genes in Corynebacterium glutamicum R. FEBS J 280: 3298-3312, 2013.

366. Traxler MF, Summers SM, Nguyen HT, Zacharia VM, Hightower GA, Smith JT, and Conway T. The global, ppGpp-mediated stringent response to amino acid starvation in Escherichia coli. Mol Microbiol 68: 1128-1148, 2008.

367. Troxell B, Fink RC, Porwollik S, McClelland M, and Hassan HM. The Fur regulon in anaerobically grown Salmonella enterica sv. Typhimurium: identification of new Fur targets. BMC Microbiol 11: 236, 2011.

368. Troxell B and Hassan HM. Transcriptional regulation by ferric uptake regulator (Fur) in pathogenic bacteria. Front Cell Infect Microbiol 3: 59, 2013.

369. Truong-Bolduc QC, Dunman PM, Strahilevitz J, Projan SJ, and Hooper DC. MgrA is a multiple regulator of two new efflux pumps in Staphylococcus aureus. J Bacteriol 187: 2395-2405, 2005.

370. Tsaneva IR and Weiss B. soxR, a locus governing a superoxide response regulon in Escherichia coli K-12. J Bacteriol 172: 4197-4205, 1990.

371. Tucker NP, Hicks MG, Clarke TA, Crack JC, Chandra G, Le Brun NE, Dixon R, and Hutchings MI. The transcriptional repressor protein NsrR senses nitric oxide directly via a [2Fe-2S] cluster. PLoS One 3: e3623, 2008.

372. Tucker NP, Le Brun NE, Dixon R, and Hutchings MI. There's NO stopping NsrR, a global regulator of the bacterial NO stress response. Trends Microbiol 18: 149156, 2010.

373. Ukaegbu UE, Henery S, and Rosenzweig AC. Biochemical characterization of $\mathrm{MmoS}$, a sensor protein involved in copper-dependent regulation of soluble methane monooxygenase. Biochemistry 45: 10191-10198, 2006.

374. Ukaegbu UE and Rosenzweig AC. Structure of the redox sensor domain of Methylococcus capsulatus (Bath) MmoS. Biochemistry 48: 2207-2215, 2009.

375. Umezawa Y, Shimada T, Kori A, Yamada K, and Ishihama A. The uncharacterized transcription factor YdhM is the regulator of the nemA gene, encoding $\mathrm{N}$-ethylmaleimide reductase. J Bacteriol 190: 5890-5897, 2008.

376. van Beilen JW and Hellingwerf KJ. All three endogenous quinone species of Escherichia coli are involved in controlling the activity of the aerobic/anaerobic response regulator ArcA. Front Microbiol 7: 1339, 2016.

377. VanderWal AR, Makthal N, Pinochet-Barros A, Helmann JD, Olsen RJ, and Kumaraswami M. Iron efflux by PmtA is critical for oxidative stress resistance and contributes significantly to Group A Streptococcus virulence. Infect Immun 85: e0091-17, 2017.

378. Vass IZ, Kós PB, Knoppová J, Komenda J, and Vass I. The cry-DASH cryptochrome encoded by the sll1629 gene in the cyanobacterium Synechocystis PCC 6803 is required for photosystem II repair. J Photochem Photobiol B 130: 318-326, 2014.

379. Vázquez-Torres A. Redox active thiol sensors of oxidative and nitrosative stress. Antioxid Redox Signal 17: 12011214, 2012.

380. Velasco L, Mesa S, Delgado MJ, and Bedmar EJ. Characterization of the nirK gene encoding the respiratory, $\mathrm{Cu}-$ containing nitrite reductase of Bradyrhizobium japonicum. Biochim Biophys Acta 1521: 130-134, 2001.

381. Velasco L, Mesa S, Xu CA, Delgado MJ, and Bedmar EJ. Molecular characterization of nosRZDFYLX genes coding for denitrifying nitrous oxide reductase of Bradyrhizobium japonicum. Antonie Van Leeuwenhoek 85: 229-235, 2004. 
382. Verhamme DT, Murray EJ, and Stanley-Wall NR. DegU and Spo0A jointly control transcription of two loci required for complex colony development by Bacillus subtilis. J Bacteriol 191: 100-108, 2009.

383. Vitale S, Fauquant C, Lascoux D, Schauer K, Saint-Pierre C, and Michaud-Soret I. A ZnS(4) structural zinc site in the Helicobacter pylori ferric uptake regulator. Biochemistry 48: 5582-5591, 2009.

384. Volbeda A, Darnault C, Renoux O, Nicolet Y, and Fontecilla-Camps JC. The crystal structure of the global anaerobic transcriptional regulator FNR explains its extremely fine-tuned monomer-dimer equilibrium. Sci $A d v$ 1: e1501086, 2015.

385. Volbeda A, Dodd EL, Darnault C, Crack JC, Renoux O, Hutchings MI, Le Brun NE, and Fontecilla-Camps JC. Crystal structures of the NO sensor NsrR reveal how its iron-sulfur cluster modulates DNA binding. Nat Commun 8: 15052, 2017.

386. von Zadow A, Ignatz E, Pokorny R, Essen LO, and Klug G. Rhodobacter sphaeroides CryB is a bacterial cryptochrome with (6-4) photolyase activity. FEBS J 283: 4291-4309, 2016.

387. Wan F, Shi M, and Gao H. Loss of OxyR reduces efficacy of oxygen respiration in Shewanella oneidensis. Sci Rep 7: 42609, 2017.

388. Wang E, Bauer MC, Rogstam A, Linse S, Logan DT, and von Wachenfeldt C. Structure and functional properties of the Bacillus subtilis transcriptional repressor Rex. Mol Microbiol 69: 466-478, 2008.

389. Wang L, Li M, Dong D, Bach TH, Sturdevant DE, Vuong C, Otto M, and Gao Q. SarZ is a key regulator of biofilm formation and virulence in Staphylococcus epidermidis. $J$ Infect Dis 197: 1254-1262, 2008.

390. Watanabe S, Kita A, Kobayashi K, and Miki K. Crystal structure of the [2Fe-2S] oxidative-stress sensor SoxR bound to DNA. Proc Natl Acad Sci U S A 105: 41214126, 2008.

391. Wei Q, Minh PN, Dötsch A, Hildebrand F, Panmanee W, Elfarash A, Schulz S, Plaisance S, Charlier D, Hassett D, Häussler S, and Cornelis P. Global regulation of gene expression by OxyR in an important human opportunistic pathogen. Nucleic Acids Res 40: 4320-4333, 2012.

392. Wing HJ, Green J, Guest JR, and Busby SJ. Role of activating region 1 of Escherichia coli FNR protein in transcription activation at class II promoters. J Biol Chem 275: 29061-29065, 2000.

393. Winkler A, Heintz U, Lindner R, Reinstein J, Shoeman RL, and Schlichting I. A ternary AppA-PpsR-DNA complex mediates light regulation of photosynthesis-related gene expression. Nat Struct Mol Biol 20: 859-867, 2013.

394. Winterbourn CC. Toxicity of iron and hydrogen peroxide: the Fenton reaction. Toxicol Lett 82-83: 969-974, 1995.

395. Wippel K and Long SR. Contributions of Sinorhizobium meliloti transcriptional regulator DksA to bacterial growth and efficient symbiosis with Medicago sativa. J Bacteriol 198: 1374-1383, 2016.

396. Wu G, Cruz-Ramos H, Hill S, Green J, Sawers G, and Poole RK. Regulation of cytochrome bd expression in the obligate aerobe Azotobacter vinelandii by CydR (Fnr). Sensitivity to oxygen, reactive oxygen species, and nitric oxide. J Biol Chem 275: 4679-4686, 2000.

397. Wu J and Bauer CE. RegB/RegA, a global redoxresponding two-component system. Adv Exp Med Biol 631: 131-148, 2008.
398. Wu J and Bauer CE. RegB kinase activity is controlled in part by monitoring the ratio of oxidized to reduced ubiquinones in the ubiquinone pool. mBio 1: e00272-10, 2010.

399. Wu J, Cheng Z, Reddie K, Carroll K, Hammad LA, Karty $\mathrm{JA}$, and Bauer CE. RegB kinase activity is repressed by oxidative formation of cysteine sulfenic acid. J Biol Chem 288: 4755-4762, 2013.

400. Yamawaki T, Ishikawa H, Mizuno M, Nakamura H, Shiro Y, and Mizutani Y. Regulatory implications of structural changes in Tyr201 of the oxygen sensor protein FixL. Biochemistry 55: 4027-4035, 2016.

401. Yano S, Ishikawa H, Mizuno M, Nakamura H, Shiro Y, and Mizutani Y. Ultraviolet resonance Raman observations of the structural dynamics of rhizobial oxygen sensor FixL on ligand recognition. J Phys Chem B 117: 1578615791, 2013.

402. Yeo WS, Lee JH, Lee KC, and Roe JH. IscR acts as an activator in response to oxidative stress for the suf operon encoding Fe-S assembly proteins. Mol Microbiol 61: 206218, 2006.

403. Yeom J, Lee Y, and Park W. ATP-dependent RecG helicase is required for the transcriptional regulator OxyR function in Pseudomonas species. J Biol Chem 287: 24492-24504, 2012.

404. Yin L, Dragnea V, and Bauer CE. PpsR, a regulator of heme and bacteriochlorophyll biosynthesis, is a hemesensing protein. J Biol Chem 287: 13850-13858, 2012.

405. Youn H, Kerby RL, Conrad M, and Roberts GP. Functionally critical elements of CooA-related CO sensors. $J$ Bacteriol 186: 1320-1329, 2004.

406. Youn H, Kerby RL, Thorsteinsson MV, Conrad M, Staples CR, Serate J, Beack J, and Roberts GP. The heme pocket afforded by Gly117 is crucial for proper heme ligation and activity of CooA. J Biol Chem 276: $41603-$ 41610, 2001.

407. Yukl ET, Elbaz MA, Nakano MM, and Moënne-Loccoz P. Transcription factor NsrR from Bacillus subtilis senses nitric oxide with a 4Fe-4S cluster. Biochemistry 47: 13084-13092, 2008.

408. Yukl ET, Ioanoviciu A, de Montellano PR, and MoënneLoccoz P. Interdomain interactions within the twocomponent heme-based sensor DevS from Mycobacterium tuberculosis. Biochemistry 46: 9728-9736, 2007.

409. Zhang L and Guarente L. Heme binds to a short sequence that serves a regulatory function in diverse proteins. EMBO J 14: 313-320, 1995.

410. Zhao C, Zhao Q, Li Y, and Zhang Y. Engineering redox homeostasis to develop efficient alcohol-producing microbial cell factories. Microb Cell Fact 16: 115, 2017.

411. Zheng F, Long Q, and Xie J. The function and regulatory network of WhiB and WhiB-like protein from comparative genomics and systems biology perspectives. Cell Biochem Biophys 63: 103-108, 2012.

412. Zheng $M$ and Storz G. Redox sensing by prokaryotic transcription factors. Biochem Pharmacol 59: 1-6, 2000.

413. Zheng M, Wang X, Doan B, Lewis KA, Schneider TD, and Storz G. Computation-directed identification of OxyR DNA binding sites in Escherichia coli. J Bacteriol 183: 4571-4579, 2001.

414. Zheng Y, Ko TP, Sun H, Huang CH, Pei J, Qiu R, Wang AH, Wiegel J, Shao W, and Guo RT. Distinct structural features of Rex-family repressors to sense redox levels in anaerobes and aerobes. J Struct Biol 188: 195-204, 2014. 
415. Zoltowski BD, Motta-Mena LB, and Gardner KH. Blue light-induced dimerization of a bacterial LOV-HTH DNA-binding protein. Biochemistry 52: 6653-6661, 2013.

Address correspondence to:

Prof. María F. Fillat

Departamento de Bioquímica y Biología

Molecular y Celular

Universidad de Zaragoza

50009 Zaragoza

Spain

E-mail: fillat@unizar.es

Date of first submission to ARS Central, November 14, 2017; date of final revised submission, July 27, 2018; date of acceptance, August 1, 2018.

\section{Abbreviations Used}

$\mathrm{BLUF}=$ blue light sensors using FAD

DASH $=$ Drosophila-Arabidopsis-Synechocystis-Homo

DTT $=$ dithiotreitol

$\mathrm{FAD}=$ flavin adenine dinucleotide

$\mathrm{FMN}=$ flavin mononucleotide

$\mathrm{FNR}=$ fumarate nitrate reductase regulator

Fur $=$ ferric uptake regulator
$\mathrm{GAF}=\mathrm{cGMP}$-specific phosphodiesterases, adenylyl cyclases, and FhlA

$\mathrm{HK}=$ histidine kinase

$\mathrm{HRM}=$ heme regulatory motif

$\mathrm{HTH}=$ helix-turn-helix

LOV = light-oxygen-voltage sensing

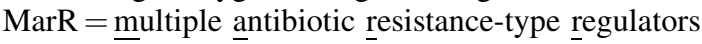

$\mathrm{NEM}=\overline{\mathrm{N}}$-ethylmaleimide

$\mathrm{NsrR}=$ nitric oxide sensitive repressor

OHPs $=$ organic hydroperoxides

$\mathrm{Ohr}=$ organic hydroperoxide reductase

PAS $=$ Per-Arnt-Sim

$\mathrm{PDB}=$ Protein Data Bank

ppGpp = guanosine tetraphosphate

pppGpp = guanosine pentaphosphate

$\mathrm{RcoM}=$ regulator of $\mathrm{CO}$ metabolism

$\mathrm{RCS}=$ reactive chlorine species

$\mathrm{RES}=$ reactive electrophile species

$\mathrm{RNAP}=\mathrm{RNA}$ polymerase

$\mathrm{RNS}=$ reactive nitrogen species

$\mathrm{ROS}=$ reactive oxygen species

$\mathrm{RR}=$ receiver domain

$\mathrm{RReg}=$ response regulator

SCHIC $=$ sensor containing heme instead of cobalamin

sMMO $=$ soluble methane monooxygenase

STAS $=$ sulfate transporter anti $-\sigma$ antagonist

TCA $=$ tricarboxylic acids

$\mathrm{UV}=$ ultraviolet

wHTH $=$ winged helix-turn-helix 